\title{
Recent Progress in Hydrogen Flammability Prediction for the Safe Energy Systems
}

\author{
Joongoo Jeon ${ }^{1}\left[\right.$ and Sung Joong Kim ${ }^{1,2, *} \mathbb{C}$ \\ 1 Department of Nuclear Engineering, Hanyang University, Seoul 04763, Korea; jgjeon@hanyang.ac.kr \\ 2 Institute of Nano Science \& Technology, Hanyang University, Seoul 04763, Korea \\ * Correspondence: sungjkim@hanyang.ac.kr
}

Received: 30 October 2020; Accepted: 24 November 2020; Published: 27 November 2020

check for updates

\begin{abstract}
Many countries consider hydrogen as a promising energy source to resolve the energy challenges over the global climate change. However, the potential of hydrogen explosions remains a technical issue to embrace hydrogen as an alternate solution since the Hindenburg disaster occurred in 1937. To ascertain safe hydrogen energy systems including production, storage, and transportation, securing the knowledge concerning hydrogen flammability is essential. In this paper, we addressed a comprehensive review of the studies related to predicting hydrogen flammability by dividing them into three types: experimental, numerical, and analytical. While the earlier experimental studies had focused only on measuring limit concentration, recent studies clarified the extinction mechanism of a hydrogen flame. In numerical studies, the continued advances in computer performance enabled even multi-dimensional stretched flame analysis following one-dimensional planar flame analysis. The different extinction mechanisms depending on the Lewis number of each fuel type could be observed by these advanced simulations. Finally, historical attempts to predict the limit concentration by analytical modeling of flammability characteristics were discussed. Developing an accurate model to predict the flammability limit of various hydrogen mixtures is our remaining issue.
\end{abstract}

Keywords: hydrogen energy; hydrogen safety; flammability; flame extinction; heat loss; Lewis number; flame stretch; chemical kinetics

\section{Introduction}

The European Union (EU) is committed to constructing a decarbonized energy system. Many experts predict that the conventional energy generation, distribution, and storage system in the EU will be radically transformed [1]. Fuel cells as an efficient conversion technology and hydrogen as a carbon-free fuel have a great potential for contributing to address the energy challenges facing Europe. For this reason, an ambitious hydrogen energy roadmap was developed by the Fuel Cells and Hydrogen Joint Undertaking (FCH JU) as shown in Figure 1. They expected the growth of hydrogen energy generation to approximately reach 2250 TWh in Europe by 2050. This amount is roughly a quarter of the EU's total energy demand [1]. South Korea also considers hydrogen as a promising energy source for transportation and the research related to hydrogen-fuel infrastructure are being vigorously explored. The South Korean government developed a hydrogen energy roadmap of supplying 630,000 fuel-cell electric vehicles (FCEVs) and installing 520 hydrogen stations by 2030 [2]. 


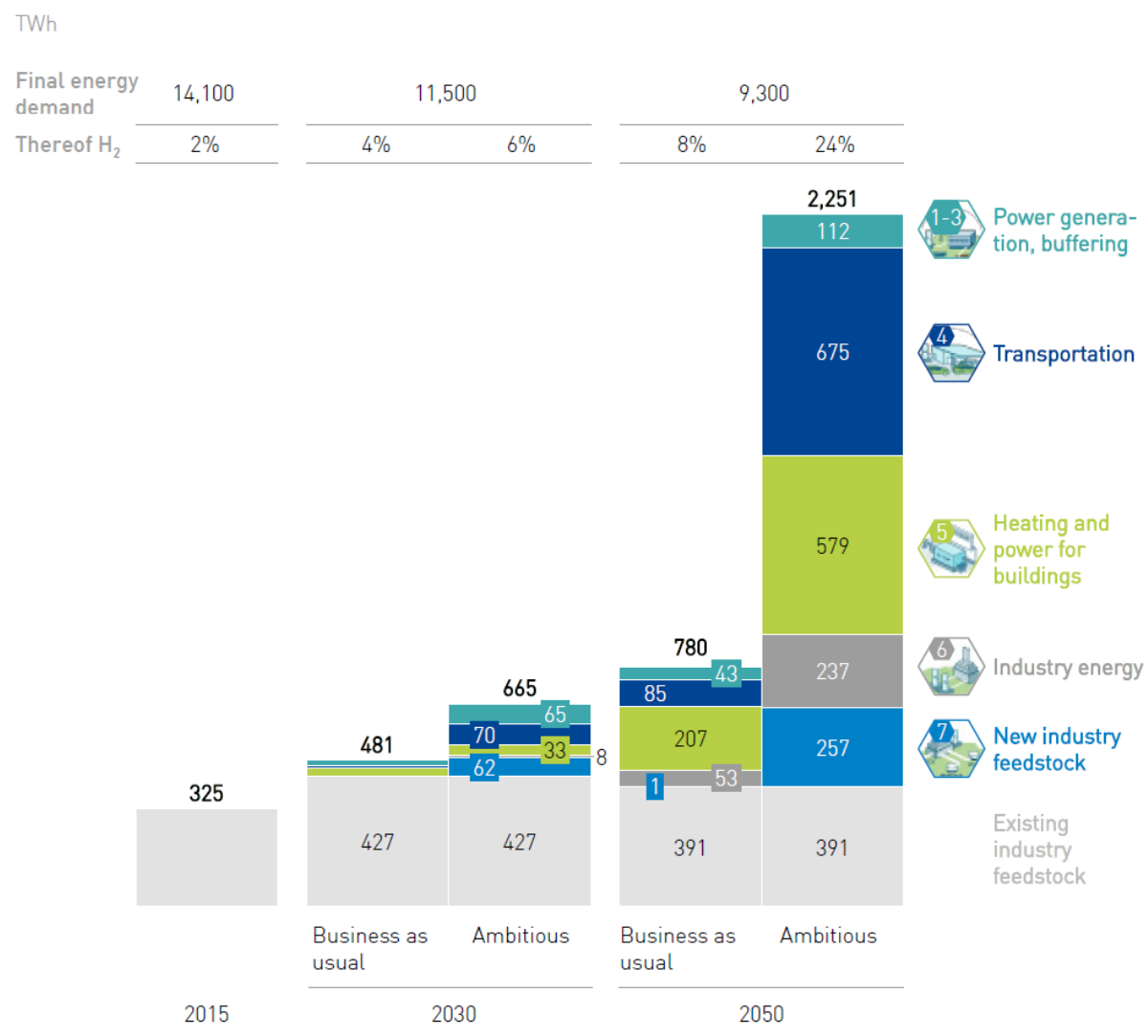

Figure 1. Expectations for hydrogen energy deployment in the EU by Fuel Cells and Hydrogen Joint Undertaking (FCH JU) [1].

However, since the Hindenburg disaster occurred in 1937, the potential threat of hydrogen explosions still shadowing the great potential of utilizing hydrogen energy, and hence the importance of hydrogen safety research has been most pronounced [3]. As far as the drawback of hydrogen, in the nuclear industry, hydrogen combustion is one of the remaining issues threatening the safety of a nuclear power plant (NPP). A significant amount of hydrogen gas can be emitted through an exothermic reaction of zircaloy and high-temperature steam during a severe accident. If partial hydrogen gas is leaked into the containment atmosphere, combustible mixtures can be formed. If the local hydrogen concentration exceeds the flammability limit, flame acceleration (FA) and detonation can occur depending on the mixture and geometric conditions, and their potential risk should be evaluated based on rigorous regulatory standards $[4,5]$. As compared to other fuels, hydrogen has a wide range of flammability $(4-75 \mathrm{vol} \%)$ which means the accidental leakage has a high probability to cause fire [6,7]. Therefore securing robust knowledge concerning hydrogen flammability is essential to ascertain the safe use of hydrogen energy including production, storage, and transportation as well as nuclear plant [8].

The flammability limit is the fuel concentration which can generate minimum combustion heat to continuous flame propagation. If unburned gas flowing into the reaction zone is sufficiently heated by the generated combustion heat, a continuous chemical reaction is possible. However, it is impractical to entirely transfer generated combustion heat to the unburned gas. As the soar of reaction rate with the temperature, the reaction mainly proceeds in a narrow reaction zone and the rapid heat loss rate from the reaction zone to ambient is inevitable in general [9]. There are three heat loss mechanisms in flame propagation; convection, conduction, and radiation. The peak temperature at the end of the reaction zone can be determined by considering the heat loss mechanisms as shown in Equation (1), which are based on a simple one-dimensional planar flame but are very useful for understanding the basic role of heat loss mechanisms. First, the convective heat loss $\left(q_{\text {conv }}\right)$ can be calculated as the heat transfer rate 
per unit flame area (Equation (2)). The convection transfers the generated combustion heat to the tube wall. The second heat loss mechanism is the conduction (indirect radiation) of heat $\left(q_{r a d, 1}\right)$ into the burned gas as shown in Equation (3). The negative temperature gradient for conduction is ultimately caused by radiation at the reaction end zone. The unit area is based on the flame front. Finally, the radiative heat loss rate from the reaction zone itself (direct radiation) is calculated by integration (Equation (4)). These one-dimensional heat loss calculations for each mechanism are described in more detail in Refs. [10,11]

$$
\begin{gathered}
\rho_{u} S_{u}\left[c_{p} T_{u}+H^{a}\right]-\rho_{u} S_{u} c_{p} T_{f}-q_{\text {loss }}=0 \\
q_{c o n v}=\frac{h\left(T_{f}-T_{u}\right) \pi D \delta}{\pi D^{2} / 4} \\
q_{r a d, 1}\left(q_{\text {cond }}\right)=-k_{f}\left(\frac{d T}{d x}\right)_{x=x_{f}}=k_{f} \frac{R}{\rho_{u} c_{p} S_{u}} \\
q_{r a d, 2}=\int_{0}^{\delta} R d x
\end{gathered}
$$

When the generated heat cannot cover the sum of the heat to be transferred to unburned gas and the heat to be lost, the reaction zone can be gradually decreased, and ultimately flame extinction can occur. This simple principle of flame extinction becomes more complicated for stretched flames although the hydrodynamic deflagration instabilities can be stabilized by large wavelengths in upward propagating flame with buoyancy force [12]. In stretched flame, the Lewis number effect can dramatically increase the local burning intensity with the stretch rate compared to the theoretical planar flame. On the other hand, the extinction can be caused by a further high stretch rate where the convective residence time is too short to generate a flame (stretch extinction limit) [13].

The objective of this study is to review the historical attempts to predict the flammability limit by understanding these complex flame extinction mechanisms as shown in Figure 2. Existing studies were reviewed by focusing on the lower flammability limit (LFL) in the upward propagating flame. The practical considerations of fire safety dictated that the flammability limits should be determined in the upward flame experiments because limits are wider [14]. Early studies focused on the investigation of the limit hydrogen concentration because the limit concentration is significantly varied depending on the mixture conditions such as temperature, diluent type, and diluent concentration. These experimental studies were introduced in Section 2. The stationary flame experiments to understand the extinction mechanism were also described. In Section 3, numerical methods to predict the flammability limit were introduced. The continued advances in computer performance enabled even multi-dimensional stretched flame analysis following one-dimensional planar flame analysis. The calculation results of hydrocarbon fuels were discussed together to effectively explain the progress of numerical studies. In Section 4, the analytical studies for modeling the flammability limit was introduced. Although there were significant efforts to measure the flammability limit by extensive experimental studies and elaborated numerical simulations, it is still difficult to accurately predict the flammability limit of various hydrogen mixtures. The representative analytical modeling, including adiabatic flame temperature theory and stretch theory considering flow characteristics of upward propagating flame, was discussed in a chronological order. 


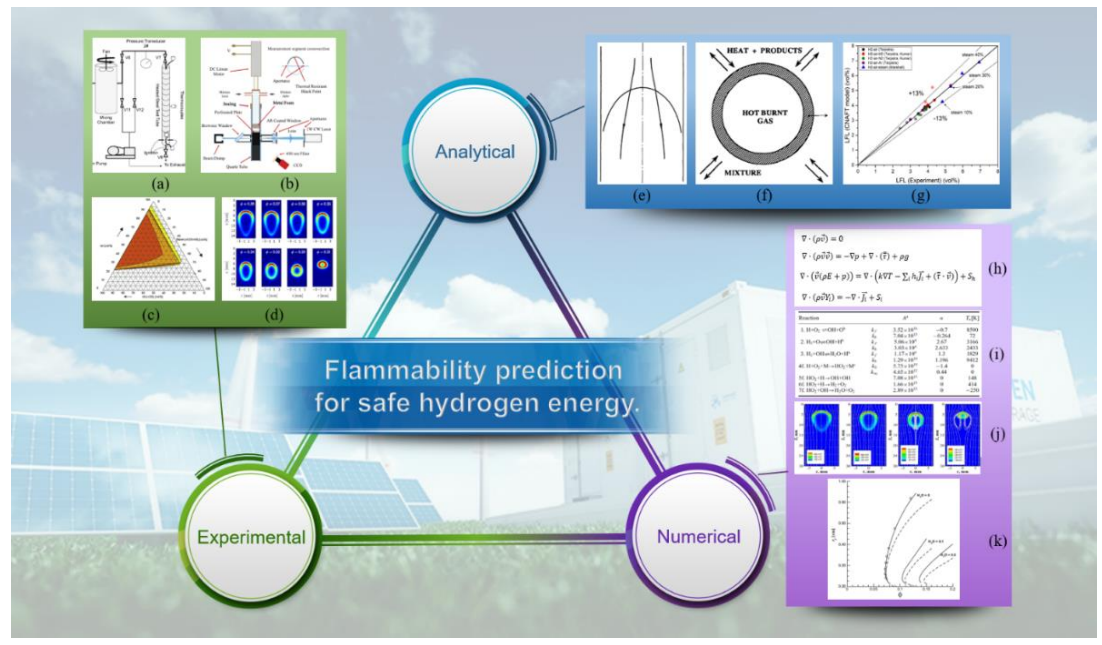

Figure 2. Analytical, numerical and experimental studies for prediction of hydrogen flammability ((a) standard tube for measuring the flammability limit [15], (b) schematic of experimental setup for stabilized flame observation [16], (c) Shapiro diagram for flammability [17], (d) chemiluminescence images of flame [18], (e) configuration of straining flow [19], (f) configuration of flame ball concept [20], (g) accuracy of the calculated non-adiabatic flame temperature (CNAFT) model [11], (h) governing equations for numerical flame analysis, (i) reduced chemical kinetics [21], (j) flame structures by numerical simulation [22], (k) identified turning point in flame ball analysis [23]).

\section{Experimental Studies}

\subsection{Flame Propagation Experiments to Measure the Flammability Limit}

Many flame propagation experiments have been vigorously conducted to understand the flammability characteristics of hydrogen as well as to measure the limit concentration. As a detailed review of studies of hydrogen flammability characteristics are well described in Ref. [12], our focus here is on the introduction of the experiments to measure the limit. Measurement of the flammability limit of combustible gases has been carried out since the 19th century. Coward and Jones summarized the limits observed experimentally for hydrogen gas at normal temperature and pressure until the 1950s, as shown in Table 1 [14]. The measurement results are in good agreement with the currently known LFL concentration (4.1 vol\%) at normal conditions. In detail, the observed LFLs in the $2.5 \mathrm{~cm}$ diameter tube was slightly higher than the results with a larger diameter tube. Although it was known that the convection effect generating heat loss to the wall decreases as the diameter increases, the changes in LFL by the convection was negligible at above $2 \mathrm{~cm}$ diameter [24].

Table 1. Measured flammability limits of hydrogen in air at normal temperature and pressure. Reproduced from Ref. [14], US Government Printing Office: 1952.

\begin{tabular}{cccccc}
\hline \multirow{2}{*}{ Authors } & \multicolumn{2}{c}{ Dimension of Tube (cm) } & \multicolumn{2}{c}{ Observed Limit (vol\%) } & \multirow{2}{*}{ Ref. } \\
\cline { 2 - 5 } & Diameter & Length & LFL & UFL & \\
\hline White & 7.5 & 150 & 4.2 & 75.0 & {$[25]$} \\
Egerton et al. & 5.3 & 150 & 4.2 & 74.6 & {$[26]$} \\
Egerton et al. & 5.3 & 150 & 4.1 & 74.3 & {$[26]$} \\
Egerton et al. & 5.3 & 150 & 4.2 & 74.8 & {$[26]$} \\
White & 5.0 & 150 & 4.2 & 74.5 & {$[25]$} \\
Jones & 5.0 & 180 & 4.0 & 72.0 & {$[27]$} \\
Burgoyne et al. & 4.8 & 150 & 4.0 & 73.8 & {$[28]$} \\
Clusius et al. & 4.5 & 80 & 4.1 & - & {$[29]$} \\
Payman & 2.5 & 150 & 4.2 & - & {$[30]$} \\
White & 2.5 & 150 & 4.3 & 73.0 & {$[25]$} \\
\hline
\end{tabular}


Coward and Jones discussed several experimental parameters as well as the tube diameter which can affect the measurement results. First, the suitable size and intensity of the ignition source are important to measure the reliable limit concentration because the capability of the mixture to propagate flame not the capacity of the energy source is our concern. If the limit concentration was obtained with the excessive ignition energy, it should be considered as the ignitibility limit. The second parameter is the tube length. The traditional experiments recognized the flammability of the mixture when flame propagated to the end of the tube by ignition. Coward and Jones discussed that, provided it is long enough (about $1 \mathrm{~m}$ ), the tube length has no effect on the observed limit [14]. It was identified that the slight pressure variation accompanied in the measurement process cannot significantly affect the limits of flammability by many experimental results. In conclusion, the standard of Bureau of Mines is known as an open tube with a diameter of $5 \mathrm{~cm}$ and a length of $1.5 \mathrm{~m}$. The more detailed descriptions for each parameter can be found in Ref. [14]. Apart from the Bureau of Mines standard, there are several established flammability experimental standards in many countries. Van den Schoor summarized major standard methods for measuring gas flammability as shown in Table 2. The detailed descriptions for these methods can be found in Ref. [31].

Table 2. Comparison between standardized methods to determine the flammability limit. Reproduced from Ref. [31], KU Leuven: 2007.

\begin{tabular}{cccc}
\hline Method & Bureau of Mines (Coward and Jones) & DIN 51 649 & EN 1839 Tube \\
\hline $\begin{array}{c}\text { Tube } \\
\text { geometry }\end{array}$ & $\begin{array}{c}\text { Open tube } \\
\mathrm{D}=5 \mathrm{~cm}, \mathrm{~L}=1.5 \mathrm{~m}\end{array}$ & $\begin{array}{c}\text { Open tube } \\
\mathrm{D}=6 \mathrm{~cm}, \mathrm{~L}=0.3 \mathrm{~m}\end{array}$ & $\begin{array}{c}\text { Open tube } \\
\mathrm{D}=8 \mathrm{~cm}, \mathrm{~L}=0.3 \mathrm{~m}\end{array}$ \\
\hline $\begin{array}{c}\text { Ignition } \\
\text { source }\end{array}$ & spark/flame bottom end & $\begin{array}{c}\text { spark bottom end } \\
\mathrm{E}=5 \mathrm{~J}, \mathrm{t}=0.5 \mathrm{~s}\end{array}$ & $\begin{array}{c}\text { spark bottom end } \\
\mathrm{E}=2 \mathrm{~J}, \mathrm{t}=0.2 \mathrm{~s}\end{array}$ \\
\hline Flammability criterion & visual flame propagation over $1.5 \mathrm{~m}$ & visual flame detachment & $\begin{array}{c}\text { visual flame propagation } \\
\text { over 0.1 m }\end{array}$ \\
\hline Flammability limit definition & halfway between the flammable and \\
non-flammable point & at non-flammable point & at non-flammable point \\
\hline
\end{tabular}

Because the flammability limit of hydrogen gas depends on the diluent type as well as other variables, experimental studies have been continuously conducted since the 1950s as summarized in Table 3. Each study has a distinct purpose such as measuring the limit at elevated temperature and pressure or binary fuel condition. The results of these experiments were discussed in the following sections.

Table 3. Summary of experimental flammability limit studies since the 1950s.

\begin{tabular}{|c|c|c|c|c|}
\hline Year & Authors & Mixture & Tube Geometry & Ref. \\
\hline 1957 & Scott et al. & $\begin{array}{c}\mathrm{H}_{2}-\mathrm{NO}-\mathrm{N}_{2} \mathrm{O} \\
\mathrm{H}_{2}-\mathrm{N}_{2} \mathrm{O} \text {-air } \\
\mathrm{H}_{2}-\mathrm{NO} \text {-air }\end{array}$ & Bureau of Mines & [32] \\
\hline 1984 & Shebeko et al. & $\begin{array}{c}\mathrm{H}_{2}-\mathrm{O}_{2}-\mathrm{He} \\
\mathrm{H}_{2}-\mathrm{O}_{2}-\mathrm{CO}_{2} \\
\mathrm{H}_{2}-\mathrm{O}_{2}-\mathrm{N}_{2} \\
\mathrm{H}_{2}-\mathrm{O}_{2}-\mathrm{Ar}\end{array}$ & - & [33] \\
\hline 1985 & Kumar & $\begin{array}{c}\mathrm{H}_{2}-\mathrm{O}_{2}-\mathrm{N}_{2} \\
\mathrm{H}_{2}-\mathrm{O}_{2}-\mathrm{CO}_{2} \\
\mathrm{H}_{2}-\mathrm{O}_{2}-\mathrm{H}_{2} \mathrm{O} \\
\mathrm{H}_{2}-\mathrm{Air}-\mathrm{H}_{2} \mathrm{O} \\
\mathrm{H}_{2}-\mathrm{O}_{2}-\mathrm{Ar} \\
\mathrm{H}_{2}-\mathrm{O}_{2}-\mathrm{He}\end{array}$ & Bureau of Mines & [34] \\
\hline
\end{tabular}


Table 3. Cont.

\begin{tabular}{|c|c|c|c|c|}
\hline Year & Authors & Mixture & Tube Geometry & Ref. \\
\hline 1986 & Marshall & $\mathrm{H}_{2}$-air- $\mathrm{H}_{2} \mathrm{O}$ & FITS vessel & [35] \\
\hline 1988 & Hustad et al. (b) & $\mathrm{H}_{2}$-air & $\mathrm{D}=10 \mathrm{~cm}, \mathrm{~L}=3 \mathrm{~m}$ & {$[36]$} \\
\hline 1995 & Shebeko ${ }^{\text {(a) }}$ & $\begin{array}{c}\mathrm{H}_{2}-\mathrm{O}_{2}-\mathrm{He} \\
\mathrm{H}_{2}-\mathrm{O}_{2}-\mathrm{CO}_{2} \\
\mathrm{H}_{2}-\mathrm{O}_{2}-\mathrm{N}_{2} \\
\mathrm{H}_{2}-\mathrm{O}_{2}-\mathrm{Ar} \\
\mathrm{H}_{2}-\mathrm{O}_{2}-\mathrm{He}-\mathrm{H}_{2} \mathrm{O} \\
\mathrm{H}_{2}-\mathrm{O}_{2}-\mathrm{He}-\mathrm{CO}_{2} \\
\mathrm{H}_{2}-\mathrm{O}_{2}-\mathrm{N}_{2}-\mathrm{CO}_{2}\end{array}$ & $\mathrm{D}=30 \mathrm{~cm}, \mathrm{~L}=80 \mathrm{~cm}$ & [37] \\
\hline 1998 & Ale $^{(\mathrm{c})}$ & $\mathrm{H}_{2}$-air & Bureau of Mines & [38] \\
\hline 2001 & Wierzba et al. & $\mathrm{H}_{2}$-CO-air & Bureau of Mines & [7] \\
\hline 2007 & Van den Schoor $^{(d)}$ & $\mathrm{H}_{2}-\mathrm{CH}_{4}$-air & DIN 51649 & [31] \\
\hline 2012 & Terpstra & $\begin{array}{c}\mathrm{H}_{2} \text {-air } \\
\mathrm{H}_{2} \text {-air- } \mathrm{N}_{2} \\
\mathrm{H}_{2} \text {-air-He } \\
\mathrm{H}_{2} \text {-air-Ar } \\
\mathrm{H}_{2} \text {-air-CO } \mathrm{CO}_{2}\end{array}$ & Bureau of Mines & [15] \\
\hline 2014 & Liu et al. (e) & $\mathrm{H}_{2}$-air & $\mathrm{D}=16 \mathrm{~cm}, \mathrm{~L}=0.34 \mathrm{~m}$ & [39] \\
\hline 2015 & Hernandez-Perez et al. (f) & $\mathrm{H}_{2}-\mathrm{CH}_{4}$-air & $\mathrm{D}=1.35 \mathrm{~cm}, \mathrm{~L}=3 \mathrm{~cm}$ & [18] \\
\hline 2018 & Zhou et al. (f) & $\begin{array}{c}\mathrm{H}_{2} \text {-air } \\
\mathrm{H}_{2}-\mathrm{CH}_{4} \text {-air }\end{array}$ & $\mathrm{D}=1.35 \mathrm{~cm}, \mathrm{~L}=10 \mathrm{~cm}$ & [22] \\
\hline 2020 & Xu et al. & $\begin{array}{c}\mathrm{H}_{2}-\mathrm{O}_{2}-\mathrm{N}_{2} \\
\mathrm{H} 2-\mathrm{O}_{2}-\mathrm{CO}_{2}\end{array}$ & $\mathrm{D}=18 \mathrm{~cm}, \mathrm{~L}=20 \mathrm{~cm}$ & [40] \\
\hline
\end{tabular}

\subsection{Diluent Effects}

Early experiments mainly focused on measuring the limit concentration in various mixture types. As shown in Figure 3, the limits of $\mathrm{H}_{2}$-air- $\mathrm{N}_{2}$ were measured depending on the additional nitrogen concentration. The measurements were made in a $1.8 \mathrm{~m}$ length and $5 \mathrm{~cm}$ diameter tube with upward propagation. These results are useful for confirming the safety of the energy system when nitrogen was added or part of oxygen was removed in the system [27]. It was identified that the change in LFL with nitrogen concentration was negligible. This trend is acceptable because the air already contains large amounts of nitrogen. Recently, Jeon et al. confirmed that this negligible effect can be understood by analytical modeling of flammability limit considering diluent properties [11,41]. In other experiments, the limit with downward propagation for the same mixture series were measured. The obtained LFLs were 5 to 6 vol\% greater than the upward propagation tests. The flammability limits of $\mathrm{H}_{2}$-air- $\mathrm{CO}_{2}$ dependent on carbon dioxide concentrations are also presented in Figure 3. The increase in LFL in the downward propagation was confirmed to be about 5 to $6 \mathrm{vol} \%$ as well [27]. As discussed in Section 1, the practical considerations of fire safety dictated that the flammability limits should be determined in the upward flame experiments because limits are wider.

Because the density of helium gas is small enough to be close to hydrogen gas, the diluent effect of helium gas has been investigated especially for the airship environment. Satterly et al. concluded that hydrogen safety can be insured when the hydrogen ratio is less than $26 \%$ in hydrogen-helium mixed fuel by experiments with 6.3 diameters of thin rubber balloons [42]. However, Coward and Jones observed that the generation of the weak flame is possible as little as $8.7 \%$ of the hydrogen 
ratio [14]. These different results highlighted the importance of standardized experimental apparatus for determining the flammability limit.

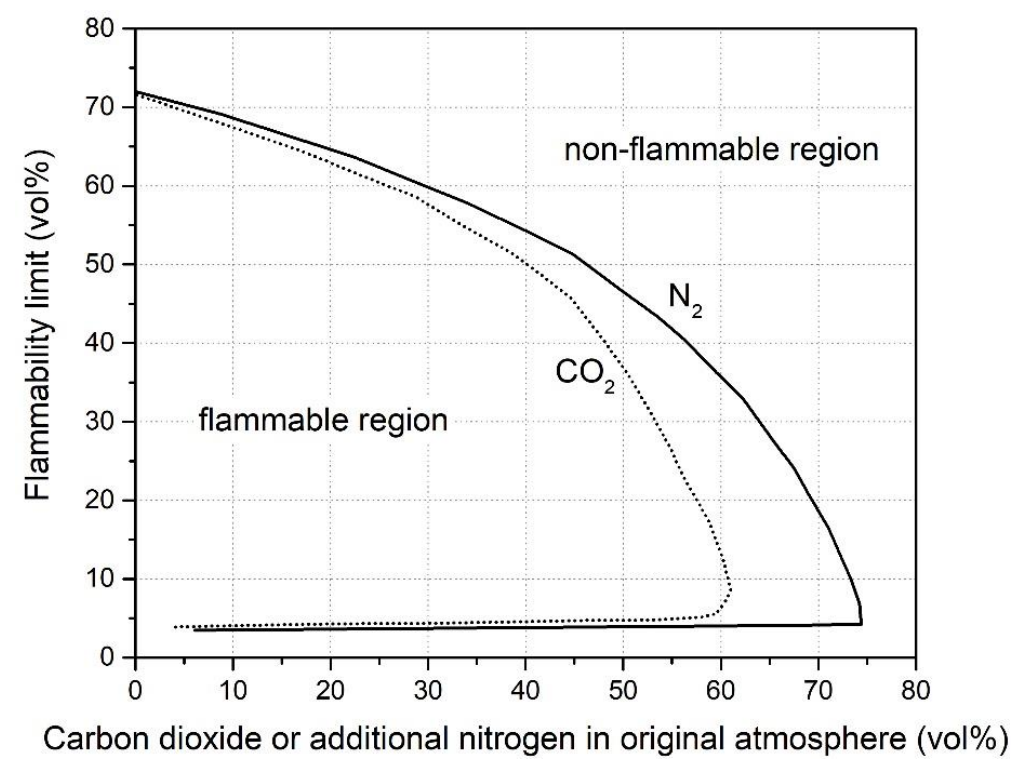

Figure 3. Measured flammability limit of hydrogen in air and nitrogen or carbon dioxide. Reproduced from Ref. [27], US Government Printing Office: 1929.

Scott et al. obtained flammability diagrams for the $\mathrm{H}_{2}-\mathrm{NO}-\mathrm{N}_{2} \mathrm{O}$ and $\mathrm{H}_{2}-\mathrm{N}_{2} \mathrm{O}$-air, $\mathrm{H}_{2}-\mathrm{NO}$-air as shown in Figure 4 [32]. The flammability limit of hydrogen in mixtures of nitric oxide and nitrous oxide is important in the industrial process involving these oxidants. They also measured the limits when a single oxidant was present with hydrogen gas. As shown in Figure 4, the upper flammability limit (UFL) curves obtained in binary oxidants show a discrepancy with the calculated curves by the Le Chatelier Law using single oxidant results [32]. In addition to this study, the limitation of the Le Chatelier Law has been noticed in UFL prediction rather than LFL.

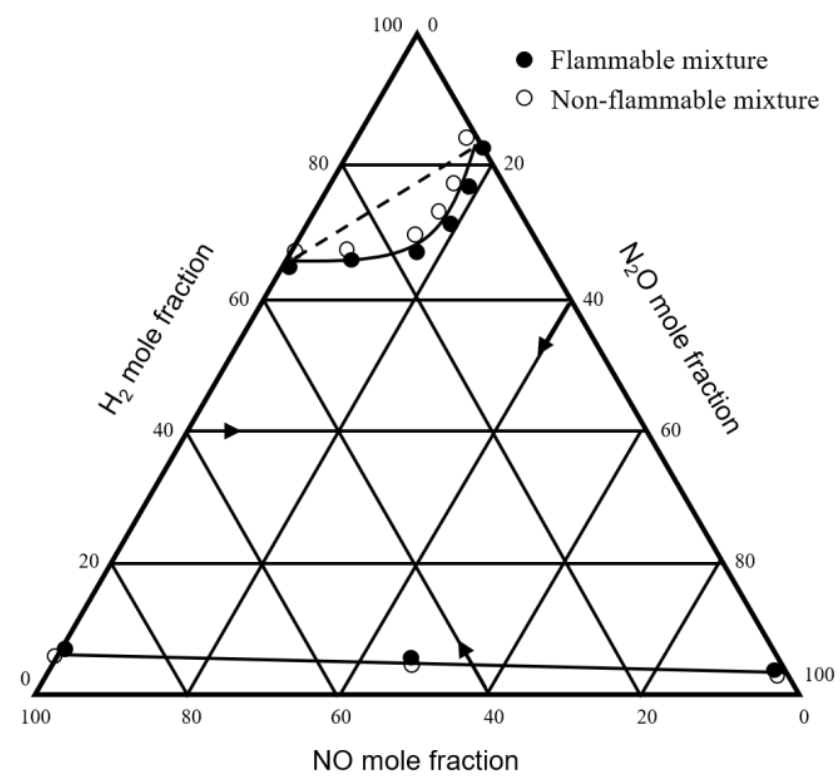

Figure 4. Measured flammability limit of $\mathrm{H}_{2}-\mathrm{NO}-\mathrm{N}_{2} \mathrm{O}$ at normal temperature and pressure. The dashed line represents the calculated upper flammability limit (UFL) by the Le Chatelier Law. Reproduced from Ref. [32], The Combustion Institute: 1957. 
After the Three Mile Island (TMI) Nuclear Power Plant Unit 2 accident in 1979, the research for flammability limits of hydrogen mixtures that might occur inside nuclear reactor containment during a loss-of-coolant accident has become ever important. The FITS experiment conducted by Sandia National Laboratories (SNL) was one of the representative experiments to resolve these issues. The flammability limits of $\mathrm{H}_{2}$-air- $\mathrm{H}_{2} \mathrm{O}$ were measured in a $5.6 \mathrm{~m}^{3}$ Fully Instrumented Test site (FITS) vessel. The initial temperature for all experiments was set to approximately $110^{\circ} \mathrm{C}$. In FITS experiments, the flammability limit was determined by detecting the pressure variation in the vessel; (1) if no appreciable pressure was detected (generally much less than $6 \mathrm{kPa}$, a mixture was classified as a "no-burn", (2) if the measured overpressure was less than $10 \%$ of the AICC pressure, a mixture was classified as a "marginal burn", (3) if the measured overpressure exceeded $10 \%$ of AICC pressure, a mixture was classified as a "burn". With this definition, many iterative experiments were performed and the diluent limit concentration of steam was derived in Equation (5) [35]. Although the hydrogen mixtures containing steam have a higher initial temperature, the measured LFL is higher than the $\mathrm{H}_{2}$-air mixture at normal temperature. The reason for this rise can be understood by increased thermal radiation rate by steam, which is classified as a radiating species [41,43]. Kumar et al. also measured the flammability limit $\mathrm{H}_{2}$-air- $\mathrm{H}_{2} \mathrm{O}$ by the standard of the Bureau of Mine [44]. The individual experimental results were gathered and displayed in charts, as widely known Shapiro diagram as shown in Figure 5. Bentaib et al. noted that the Shapiro diagram is a general method to determine whether the mixture is flammable in nuclear accident analysis [17].

$$
\% \text { Steam }=100-\% \mathrm{H}_{2}-37.3 \times 10^{-0.007 . \% \mathrm{H}_{2}}-518.0 \times 10^{-0.488 . \% \mathrm{H}_{2}}
$$

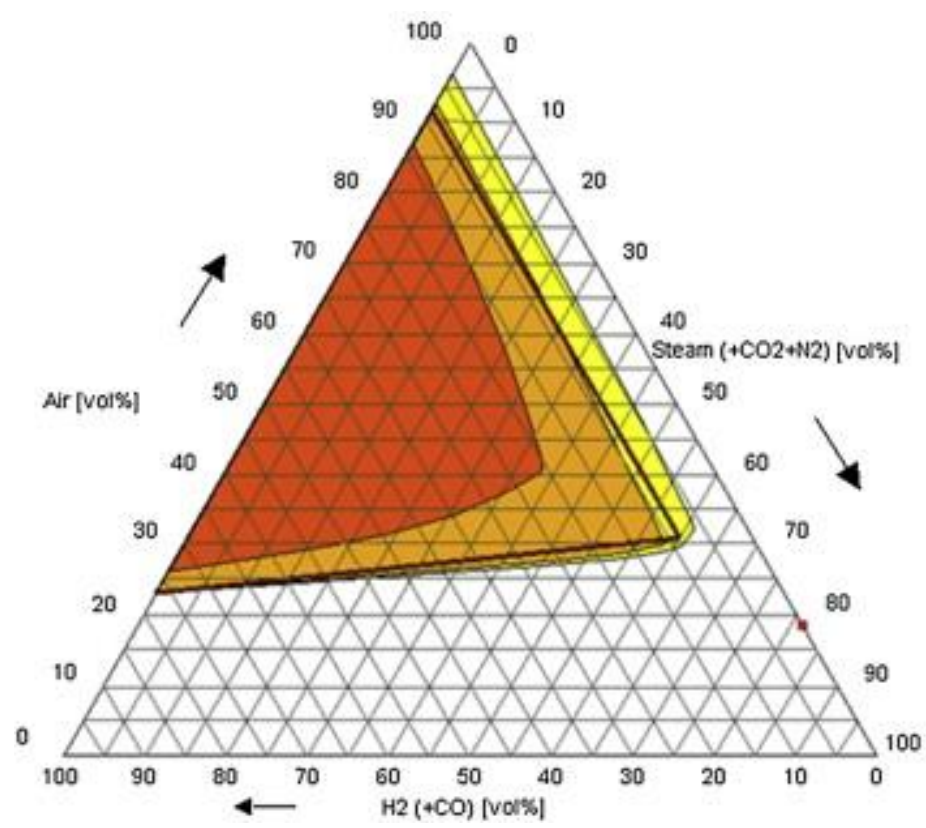

Figure 5. Shapiro diagram for hydrogen-air-steam mixtures at 1 bar and ambient. The diluent concentration is added to the steam concentration [17].

Many previous studies have evaluated the hydrogen risk of nuclear power plants using these experimental flammability limit results. It was noted that the MAAP code, a representative nuclear reactor accident analysis code developed by Fauske and Associates, still relies on FITS experimental results to date [45]. The MELCOR code, which is the severe accident simulation code developed by SNL [46], also evaluates the hydrogen risk of nuclear reactor containment by relying on experimental results. Recently, Choi et al. analyzed the efficacy of hydrogen mitigation measures of CANDU NPP under the loss of coolant accident (LOCA) using MELCOR code. The flammability of hydrogen was 
evaluated by using the Shapiro diagram [47]. From Kumar's experimental results, Byun et al. analyzed hydrogen risk in the nuclear reactor during a severe accident scenario by the GOTHIC code. Equations (6) and (7) show the derived LFL empirical correlation for upward and downward propagating in their analysis. In addition, there is a limiting steam concentration where no combustion occurs regardless of hydrogen concentration. The inerting limit is given by Equation (8) [48]. The computational analyses which evaluated the hydrogen risk by relying on the empirical flammability limit correlation are not limited to the nuclear reactor system codes. Martin-Valdepenas et al. predicted the hydrogen combustion behavior using a commercial computational fluid dynamics (CFD) code. The empirical correlation similar to Equations (6) and (7) was used to predict the flammability limit at each grid of the computational domain. If the mixture reached the flammability limit, the combustion would occur at the corresponding node in their simulation [49]. Jeon et al. analyzed the hydrogen behavior in the steam generator compartment in the pipe rupture scenario by CFD code. They also predicted the hydrogen flammability in the compartment using Kumar's experimental data [50].

$$
\begin{gathered}
L F L_{H_{2}}(\text { up })=0.037+0.2381 X_{\text {steam }}-5 \times 10^{-5}(T-373) \\
L F L_{H_{2}}(\text { down })=0.075+0.2381 X_{\text {steam }}-1.0135 \times 10^{-5}(T-373) \\
X_{\text {steam }}(\text { inert })=0.63+3 \times 10^{-4}(T-373)
\end{gathered}
$$

\subsection{Elevated Temperature and Pressure}

Since the hydrogen mixtures in elevated temperature and elevated pressure can exist under accident conditions, these extreme mixture conditions have been explored by many researchers. Shebeko et al. measured the limit of hydrogen mixtures at elevated temperatures (up to $250{ }^{\circ} \mathrm{C}$ ) and pressures (up to $40 \mathrm{bar}$ ) [37]. It was identified that the flammability range was widened for all measured mixtures as the initial temperature increased. This is because the higher the initial temperature, the less thermal energy is required to reach the threshold flame temperature for flame propagation. Hustad and Soju measured the LFL of $\mathrm{H}_{2}$-air mixtures at temperatures up to $450{ }^{\circ} \mathrm{C}$. They also observed that the LFL of each gas linearly decreased with temperature increase in the tested mixtures [36]. These results suggested that linear LFL prediction was possible under diluent-free conditions. Ale also measured the variation of LFL at elevated temperatures [38]. Unlike the temperature as an affecting variable, the pressure exhibits a more complicated dependence on the limit because the pressure has distinctive effects on reaction rate depending on each chemical reaction. Figure 6 shows the measured flammability of $\mathrm{H}_{2}-\mathrm{O}_{2}-\mathrm{N}_{2}$ mixtures at elevated pressure from 6 to 40 bar by Shebeko et al. The LFL at the same initial pressure was almost constant for nitrogen concentration but the LFL increased until the initial pressure increased to 30 bar. The measured LFLs at 30 and 40 bar were almost identical. In all the mixture studied by Shebeko et al. except $\mathrm{H}_{2}$-air-steam, the flammable region was slightly narrowed with increasing pressure until a certain pressure. Only in the $\mathrm{H}_{2}$-air-steam mixture, the noticeable pressure dependence on flammability limit was not observed until 40 bars [37].

Law explained the higher LFL at elevated pressure as the dominant effect of the three-body termination reaction. In other words, the significance of pressure is not on thermal effects but kinetic effects. As the pressure increases, the importance of the dominant three-body termination reaction over the dominant two-body branching reaction becomes pronounced, increasing the lean limit [43]. The complex effect of pressure increase on chemical reactions in hydrogen combustion was more detailed in Ref. [51]. Liu and Zhang investigated the influence of initial temperature and pressure on the flammability limit of $\mathrm{H}_{2}$-air mixtures. They confirmed that the decrement of LFL as the initial temperature increased from 20 to $90{ }^{\circ} \mathrm{C}$ was less than $1 \%$ in all pressure cases (1-4 bars) [39]. As shown in Equations (5)-(8), it is impractical to predict the flammability limit of numerous mixture conditions, which depends on many variables including temperature, pressure, and diluent type, by simple empirical correlation. Developing a robust model to predict the hydrogen flammability limits considering the multiple variables is a remaining task. 


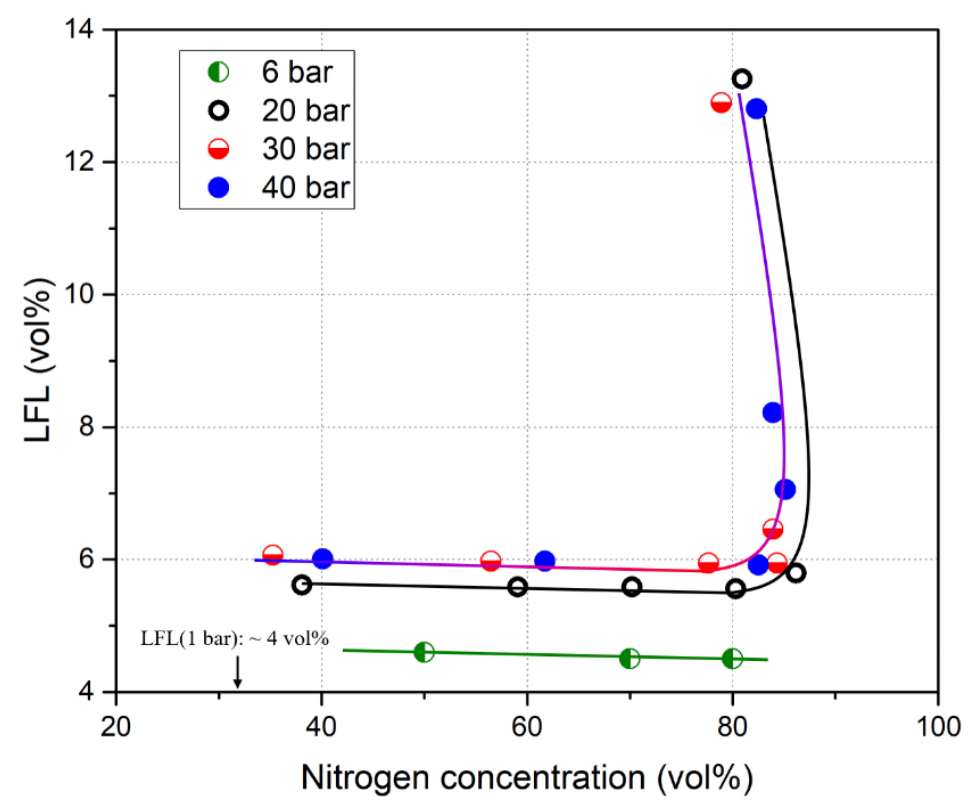

Figure 6. Flammability limits in $\mathrm{H}_{2}-\mathrm{O}_{2}-\mathrm{N}_{2}$ mixtures at temperature $20{ }^{\circ} \mathrm{C}$. Reproduced from [37], The Combustion Institute: 1995.

\subsection{Binary Fuels and Diluents}

In accident conditions, a possibility exists that a hydrogen mixture containing binary fuels or diluents coexists. Shebeko et al. investigated the dilution effect on the LFL of a mixed diluent such as $\mathrm{H}_{2}-\mathrm{O}_{2}-\mathrm{He}-\mathrm{H}_{2} \mathrm{O}$ and $\mathrm{H}_{2}$-air-He- $\mathrm{CO}_{2}$. Figure 7 shows the measured LFL of $\mathrm{H}_{2}-\mathrm{O}_{2}-\mathrm{He}-\mathrm{H}_{2} \mathrm{O}$ mixtures. The total diluent concentration was maintained at $75 \mathrm{vol} \%$, and only the ratio of steam and helium was changed. It should be noted that the LFL concentration was the highest when helium and steam had a certain ratio. In the traditional combustion risk method of the Shapiro diagram, the flammability limits were predicted through the sum of diluent concentration regardless of mixed type (Figure 5). The noticeable changes in LFL according to the diluent ratio (Figure 7) can significantly affect the hydrogen risk during accident scenarios. In other words, it is still necessary to develop an analytical model that can thoroughly reflect these individual diluent characteristics in mixed diluent conditions.

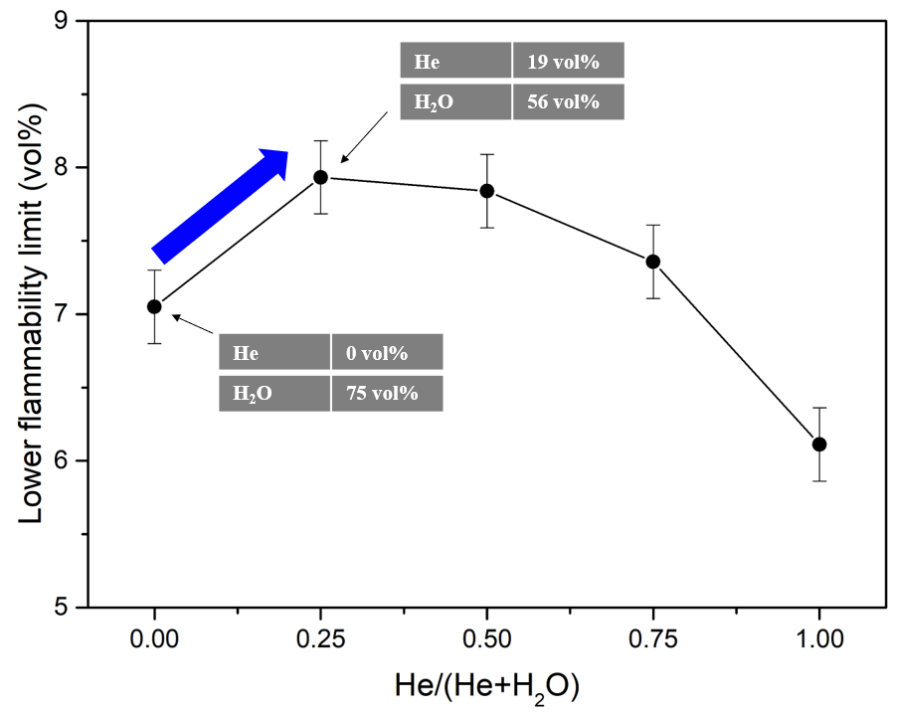

Figure 7. Dependence of hydrogen LFL on diluent composition $\left(P=6\right.$ bar, $T=250{ }^{\circ} \mathrm{C}$, composite diluent concentration $=75 \%$ ). Reproduced from Ref. [37], The Combustion Institute: 1995. 
In nuclear reactor accidents followed by severe core damage, the molten corium can be released outside the reactor vessel. If the molten corium-concrete interaction (MCCI) occurs at the reactor cavity, carbon monoxide will be generated with non-condensable gases [52]. Since carbon monoxide is also classified as a combustible gas, $\mathrm{H}_{2} / \mathrm{CO}$ binary fuel mixtures can exist inside the containment building. Safety concerns about binary fuel mixture are open issues in other industries as well. Recently, Baird et al. investigated 49 failure events leading to runway in battery industries. It was noted that most failure events emitted not only hydrogen but also carbon monoxide gases [53]. For this reason, many previous studies have investigated the flammability limits in binary fuel mixtures. Wierzba et al. measured the flammability limits of different $\mathrm{H}_{2}$-CO-air mixtures over a wide range of compositions and initial temperature up to $300{ }^{\circ} \mathrm{C}$ in a stainless-steel test tube apparatus similar to the standard of the Bureau of Mines. Experimental results showed that LFLs of $\mathrm{H}_{2}$-CO-air mixtures obeyed by Le Chatelier Law over the entire range of tested temperature as shown in Figure 8. However, UFLs deviated very significantly from the calculated values using this law [7].

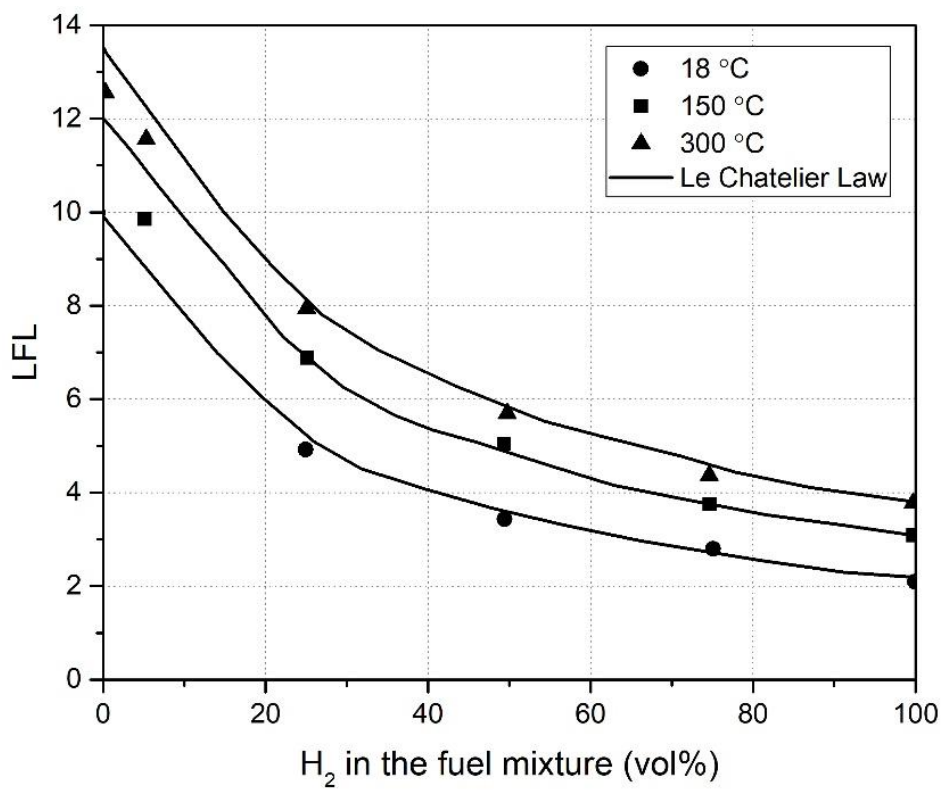

Figure 8. Lean flammability limits of $\mathrm{H}_{2}-\mathrm{CO}$ mixtures in the air at different temperatures. The solid line represents the calculated value by Le Chatelier Law using individual limit values of each fuel type. Reproduced from Ref. [7], International Association for Hydrogen Energy: 2001.

The effect of steam concentration on the flammability limit of $\mathrm{H}_{2} / \mathrm{CO}$ fuel was also experimentally investigated by Wierzba et al. They noted that the analytical model based on the constant adiabatic flame temperature concept discussed in Section 4.1 has less accuracy for the LFL prediction [7]. For this reason, Kim et al. developed a methodology for LFL evaluation of $\mathrm{H}_{2} / \mathrm{CO}$ binary fuel mixtures characterized by three factors as discussed in Section 4.2 [54]. As shown in Table 4, many other studies to obtain the flammability limit of $\mathrm{H}_{2} / \mathrm{CO}$ binary fuel mixtures have been conducted. Wang et al. and Grune et al. measured LFLs with the criterion of 3\% and 5\% pressure increase, respectively. The detailed descriptions for these studies can be found in Ref. [55,56]. 
Table 4. Summary of experimental flammability limit studies for binary fuel mixtures. Reproduced from Ref. [54], Korean Nuclear Society: 2020.

\begin{tabular}{ccc}
\hline Researcher & Mixture & Ref. \\
\hline \multirow{3}{*}{ Kilchyk } & $\mathrm{H}_{2}$-CO-air & \\
& $\mathrm{H}_{2}$-CO-air & \\
& $\mathrm{H}_{2}$-CO-air & {$[57]$} \\
& $\mathrm{H}_{2}-\mathrm{CO}-$ air- $\mathrm{H}_{2} \mathrm{O}$ & \\
& $\mathrm{H}_{2}-\mathrm{CO}-$ air- $\mathrm{H}_{2} \mathrm{O}$ & \\
\hline \multirow{2}{*}{ Wang et al. } & $\mathrm{H}_{2}-\mathrm{CO}-\mathrm{O}_{2}-\mathrm{N}_{2}$ & \\
& $\mathrm{H}_{2}-\mathrm{CO}-\mathrm{O}_{2}-\mathrm{N}_{2}$ & \\
\hline \multirow{2}{*}{ Grune et al. } & $\mathrm{H}_{2}-\mathrm{CO}-\mathrm{O}_{2}-\mathrm{N}_{2}-\mathrm{H}_{2} \mathrm{O}-\mathrm{CO}_{2}$ & \\
& $\mathrm{H}_{2}-\mathrm{CO}-\mathrm{O}_{2}-\mathrm{N}_{2}-\mathrm{H}_{2} \mathrm{O}-\mathrm{CO}_{2}$ & \\
\hline
\end{tabular}

Van den Schoor investigated the UFLs of $\mathrm{H}_{2}-\mathrm{CH}_{4}$-air. He observed that the UFL increased linearly with increasing initial temperature for initial pressures up to 6 bars. The slope of this linear function was not constant but increased with initial pressure [31]. Hernandez-Perez et al. also measured the flammability limit of $\mathrm{H}_{2}-\mathrm{CH}_{4}$-air mixtures in flame propagation experiments. However, they determined the limit by a stabilized flame experiment with a cylindrical burner, not an upward propagating flame tube. The flame can be stabilized in a cylindrical burner, which has a sapphire tube with a $30 \mathrm{~mm}$ height, $13.5 \mathrm{~mm}$ internal diameter, and $1 \mathrm{~mm}$ wall thickness, by the downward flow of premixed reactants [18]. The experimental setup was described in detail in Ref. [58]. It was seen that a nearly-spherical shape of the reacting front was developed as the LFL was approached [18]. Recently, Zhou et al. investigated the validity of the experiment technique, stabilized flame method with the downward flow by measuring the $\mathrm{LFL}$ of $\mathrm{H}_{2}$-air, $\mathrm{CH}_{4}$-air, and $\mathrm{H}_{2}-\mathrm{CH}_{4}$-air mixtures. As similar to results from Hernandez-Perez et al., a transition regime from the cell-like flame to the nearly ball-like flame was observed by decreasing fuel concentration in $\mathrm{H}_{2}$-air and $\mathrm{H}_{2}-\mathrm{CH}_{4}$-air mixtures. The LFL of the $\mathrm{H}_{2}$-air mixture was evaluated to be about $3.6 \mathrm{vol} \%(\varphi=0.09)$, which is quite similar to tube experiments (4.1 vol\%) [22]. The stabilized flame experiments seem to enable the reduction in flow uncertainty which is the main cause of experimental errors in tube experiments.

\subsection{Flame Ball and Counterflow Flame}

The previous sections introduced the flame propagation experiments to measure the flammability limit of hydrogen mixtures. Investigating the physical background which results in the existence of the flammability limit by experimental observation is as important as measuring the limit concentration. Although the tube experiments where the flame propagates through the tube was useful to determine the limit concentration, there were obvious limitations in observing propagating flames to investigate the detailed effect of each mechanism. For this reason, many previous studies have attempted to generate a stabilized flame through specific apparatuses and to analyze the structure of generated flames. In this paper, the representative stabilized flame method, flame ball and counterflow flame experiments were briefly reviewed.

50 years ago, Zeldovich suggested that stationary spherical flame balls can be investigated by solving mass, energy, and species conservation equations [59]. Figure 9 shows the configuration of the flame ball concept. The stabilized flame ball is fueled by diffusion flux (inward arrows) while maintaining a constant diameter. Conversely, the generated products and combustion heat diffused to ambient (outward arrows). The flame ball concept enabled us to thoroughly investigate the effects of thermal radiation on the flammability limit without being affected by buoyant convection. As discussed in Ref. [60], the zero-fluid velocity everywhere is required for mass conservation of stationary flame ball. The temperature and species mass fraction have a profile of the spherical from $c_{1}+c_{2} / r$, where $c_{1}$ and $c_{2}$ are constants. It was noted that corresponding solutions in planar $\left(c_{1}+c_{2} r\right)$ and cylindrical geometry $\left(c_{1}+c_{2} \ln (r)\right)$ cannot exist because the solutions are unbounded as $r \rightarrow \infty$ [60]. 


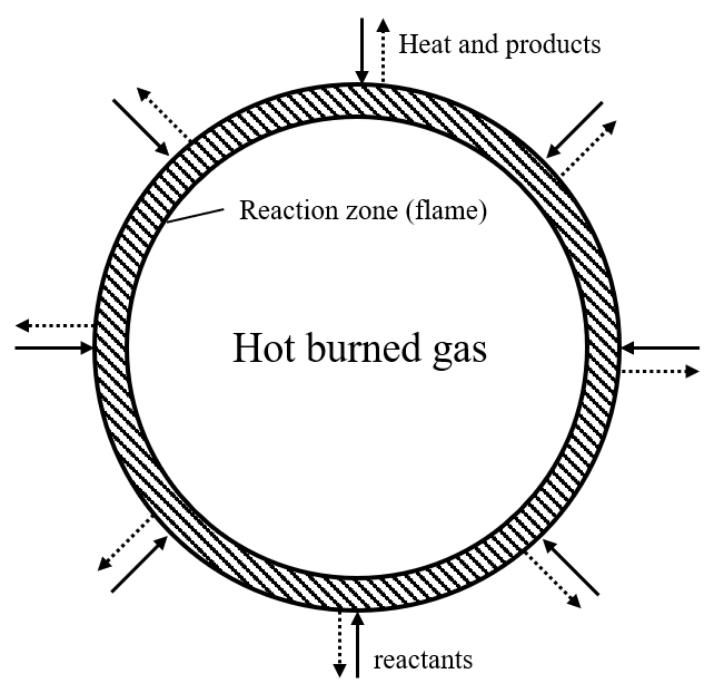

Figure 9. Flame ball configuration. The outward arrows represent the diffusion of heat and products; the inward arrows represent the diffusion of reactants.

Although the solution of the stationary flame ball was theoretically predicted, early studies doubted the existence of a physically observable flame ball. However, in the 1990s, apparently stable flame balls were observed in hydrogen mixtures (low- $L e$ ) at $\mu g$ experimental conditions [61]. The experimental apparatus consists of a constant volume cylindrical combustion vessel $25 \mathrm{~cm}$ in diameter and $25 \mathrm{~cm}$ in length. Microgravity was obtained during $2.2 \mathrm{~s}$ of free-fall in a drop tower. The detailed descriptions of the experimental apparatus and procedures can be found in Ref. [62]. The observed lean hydrogen flames are characterized by having a definite cellular structure. The unequal rates of diffusion of thermal energy and mass in sufficiently low-Le is known to lead to the spontaneous formation of cellular flame structure (diffusive-thermal instability). These theoretical predictions agree well with experimental investigations [63,64]. In particular, the role of Le on the spontaneous formation of cellular structures was verified [61]. At concentrations much greater than the flammability limit, expanding spherical fronts composed of many individual cells were observed. At limit condition, individual cells formed early moved far from the ignition source at increasing spacing. As the thermal and mass transfer between the cells is difficult to occur due to long-distance, they do not split evenly. Sequential photographs of flame balls and cellular flames can be seen in Ref. [61].

In flame ball experiments, the flammability limit can be defined as a concentration in which no more self-sustaining steady flames are generated [61]. However, it was difficult to precisely evaluate the limit due to the short available duration of $\mu g$ condition. A rough estimation of the LFL is $5 \% \mathrm{H}_{2}$ in the air with $0.4 \mathrm{CF}_{3} \mathrm{Br}$. $\mathrm{CF}_{3} \mathrm{Br}$ was added to the gas mixture for visualization of the flame structure. Since the analysis of stabilized flame ball corresponds to a low gravity environment, it is difficult to predict the exact LFL in general except possibly in a spacecraft environment. An essential difference between propagating flames and flame balls is that propagating flames are considerably affected by advection whereas flame balls have purely diffusive zones. Nevertheless, the flame ball experiments allowed methods of flame analysis using analytical or numerical analysis as well as an in-depth evaluation of the radiation effect on hydrogen flammability limit. The more detailed characteristics of the flame ball can be found in Ref. [12,60].

The counterflow experiment is also one of the representative methods of generating stationary premixed flame. As shown in Figure 10, two impinging cylindrical jets with uniform velocity and the same composition can generate the stabilized twin flames [65]. In Liu et al.'s experiment, symmetry premixed flames can be generated at a position where the axial velocity of the preheat zone is approximately equal to the laminar burning velocity. It means that the location of the symmetry flames can be controlled by changing fuel concentration, jet velocities, and the distance between the burners [65]. The more detailed experimental procedures were described in Ref. [65]. Because the 
control of experimental variables is favorable in the counterflow flame experiments, previous studies provided a detailed analysis of extinction conditions by this experimental method [66-69].

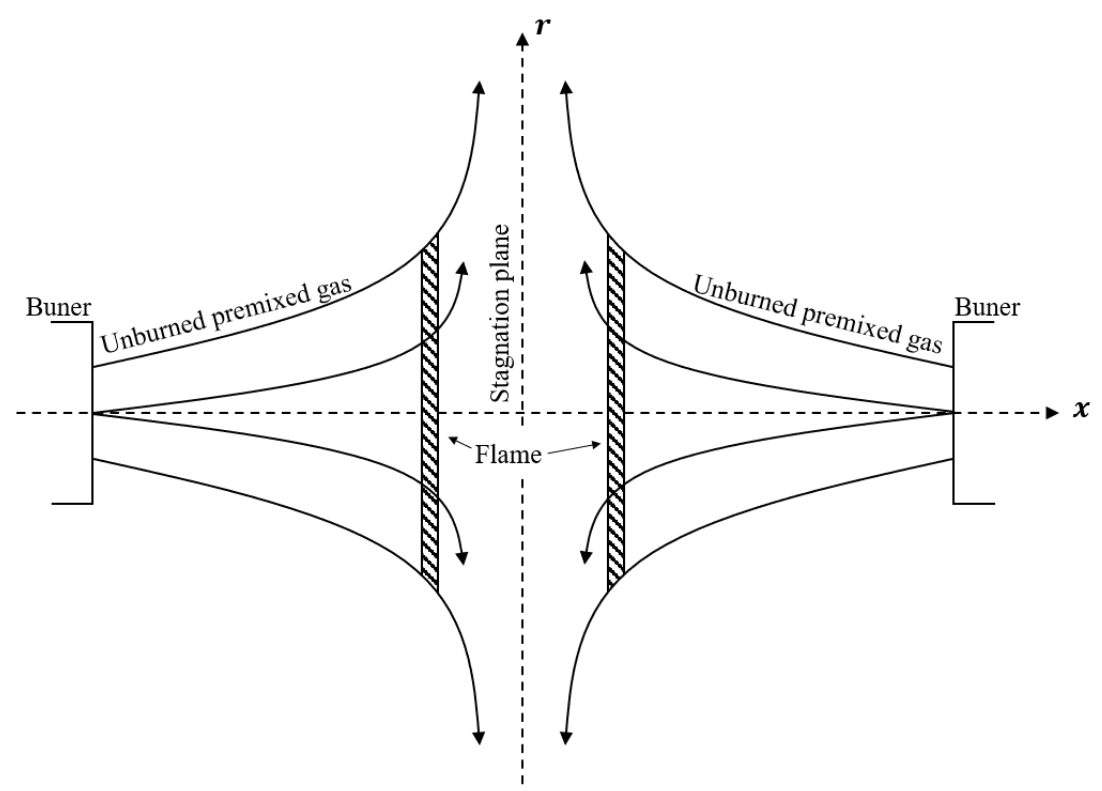

Figure 10. Schematic of counterflow premixed flame experiment.

As discussed above, the stationary flame ball analysis in the absence of buoyant convection showed that the radiation dominantly led to the flammability limit at a low stretch rate. However, counterflow flame studies have highlighted the importance of flame stretch rate to understand flame extinction [70]. Equation (9) shows a general definition of flame stretch rate, as a time derivative of flame surface area $A$, given by Karlovitz [71]. The stretch rate can be calculated as a combination of the flame surface curvature $\kappa$ and the hydrodynamic strain $K_{S}$ [72] (Equation (10)) $S_{L}$ is the laminar burning velocity and $\kappa$ is equal to the divergence of the unit normal vector of a flame iso-surface $\nabla \cdot n$.

$$
\begin{gathered}
K=\frac{1}{A} \frac{d A}{d t} \\
K=S_{L} \kappa+K_{S}
\end{gathered}
$$

As Giannakopoulos noted, a stationary flame ball having $\kappa=-2 / R, K_{S}=2 S_{L} / R$ experiences no stretch. In contrast, an outwardly propagating spherically-symmetric flame is stretched and the stretch rate $K=2 \dot{R} / R$. A stationary cylindrically flame (Section 3.1), which is being analyzed recently to elucidate the extinction mechanism under the conditions closest to the actual upward propagating flames, also experience the local flame stretch rate as shown in Equation (11) [13].

$$
K=\frac{d v_{t}}{d L}+\frac{v_{t} \cos \theta}{R}
$$

The counterflow experiment can provide a well-characterized stretch rate on the flame by burner inlet condition. Platt and Tien numerically investigated the counterflow flame at a low stretch rate and confirmed that the radiation extinction limit also existed [73]. On the other hand, other counterflow experiments revealed that methane flame extinction can occur only by increasing the stretch rate (stretch extinction limit) [74]. It means that the counterflow experiments enabled the investigation of the combined effect of radiation heat loss and stretch on flame extinction/flammability limit. It is of interest that flame extinction at a low stretch rate is caused by radiation but extinction at an elevated stretch rate is attributed to the effect of the stretch itself [75]. The elevated stretch rate can quench the flame due to stretch-induced incomplete combustion. In more detail, the flame pushed towards the 
stagnation plane by further increases of stretch rate has a reduced residence time and cannot complete chemical reaction.

Previous experimental works suggested that the flame extinction due to elevated stretch rate also can occur in upward propagating flames. Jarosinski et al. observed that the extinction of upward propagating methane flames began at the flame tip [76]. Shoshin et al. identified that the outflow rate of combustion products from the reaction zone was reduced at the flame tip. They concluded that the higher stretch rate caused a stagnation zone below the flame tip and hence extinction of lean limit methane flames occurred [77]. Because the preferential diffusion (Lewis number effect) characterized by the Lewis number can enhance the burning intensity with increased stretch rate, the extinction mechanism is dependent on mixture types. In hydrogen flames, the recirculation-based extinction mechanism was recently proposed by Jeon et al. Although the final extinction occurs at the flame tip having the highest stretch rate, the primary extinction at the trailing edge is important to understand the hydrogen flame extinction process [41].

\section{Numerical Studies}

The previous section showed that extensive experimental studies have been conducted to measure the flammability limit and clarify the physical background of the existence of the limit concentration. Although various hydrogen mixtures were tested by these experimental studies, numerical studies have been actively investigated near limit flames since the 1990s. To depict detailed flame structure by numerical simulation, not only fluid dynamics but also chemical kinetics should be solved simultaneously for each small grid. For this reason, early studies mainly focused on the experimental observation in Section 2 and the analytical modeling in Section 4. However, the continued advances in computer performance enabled even multi-dimensional stretched flame analysis following one-dimensional planar flame analysis. Furthermore, feasible chemical kinetic schemes have been developed considering the computing cost. A seven-step scheme with four irreversible reactions and three reversible reactions is shown to provide good predictions of lean hydrogen flame burning velocities [21]. Subsequently, Fernandez-Galisteo et al. derived an explicit expression of the one-step reaction for the non-Arrhenius rate from the seven-step detailed mechanism [78]. Recent numerical studies predicting the flammable range of several hydrogen carbons using chemical kinetics highlighted the importance of the reaction mechanism to simulate the lean flame [79]. The current numerical calculation can include detailed chemical kinetic schemes like the so-called San Diego mechanism for hydrogen oxidation (Table 5) [80].

There are several main motivations in conducting numerical studies. First, the numerical simulation can provide the microscopic flame analysis because it solves mass, momentum, energy, and species equations in each grid. Major mechanisms causing the flame extinction such as thermal radiation and flame stretch occur at a significantly thin flame front, making it quite difficult to observe with experiments. In the numerical simulation, it is feasible to quantitatively evaluate the effect of each mechanism on the flammability limit through the correction of the corresponding model. For example, Lakshimisha simulated steadily propagating $\mathrm{CH}_{4}$-air flames with and without the radiation model by one-dimensional planar flame. It was confirmed that the adiabatic flame can steadily propagate at a concentration lower than the limit concentration in the non-adiabatic flame [81]. Second, numerical studies are needed to verify the experimental observation. It is difficult to completely control the initial and boundary conditions in the experiment, hence comparisons of numerical and experimental observations are essential. For example, Ju et al. compared axial temperature profiles in counterflow flame between experiment and numerical results to mutually verify each result [70]. Undoubtedly, the reduced physical constraints to measure the flammability also encouraged the numerical studies for further various hydrogen mixtures. Recently, Bertolino et al. predicted the flammable range for various fuel types including methane, ethane, propane by numerical simulation [79]. Although uncertainty with some models like the gas diffusion model remained, the accuracy of predicting flammability limit increased as it becomes possible to depict even stretched propagating flame, not planar flame. 
There are many historical attempts to develop a computational scheme for observation of propagating limit flames. Since a detailed review of these schemes is beyond the scope of this paper, relevant progress was briefly described with the recent representative results in the following sections.

Table 5. 20 reversible elementary reactions in San Diego mechanism for hydrogen combustion. Reproduced from Ref. [12], Elsevier Ltd: 2013.

\begin{tabular}{|c|c|}
\hline Type & Reaction \\
\hline Shuffle reactions & $\begin{aligned} \mathrm{H}+\mathrm{O}_{2} & \leftrightarrow \mathrm{OH}+\mathrm{O} \\
\mathrm{H}_{2}+\mathrm{O} & \leftrightarrow \mathrm{OH}+\mathrm{H} \\
\mathrm{H}_{2}+\mathrm{OH} & \leftrightarrow \mathrm{H}_{2} \mathrm{O}+\mathrm{H} \\
\mathrm{H}_{2} \mathrm{O}+\mathrm{O} & \leftrightarrow \mathrm{OH}+\mathrm{OH}\end{aligned}$ \\
\hline Hydroperoxyl reactions & $\begin{array}{c}\mathrm{H}+\mathrm{O}_{2}+\mathrm{M} \leftrightarrow \mathrm{HO}_{2}+\mathrm{M} \\
\mathrm{HO}_{2}+\mathrm{H} \leftrightarrow \mathrm{OH}+\mathrm{OH} \\
\mathrm{HO}_{2}+\mathrm{H} \leftrightarrow \mathrm{H}_{2}+\mathrm{O}_{2} \\
\mathrm{HO}_{2}+\mathrm{H} \leftrightarrow \mathrm{H}_{2} \mathrm{O}+\mathrm{O} \\
\mathrm{HO}_{2}+\mathrm{O} \leftrightarrow \mathrm{OH}+\mathrm{O}_{2} \\
\mathrm{HO}_{2}+\mathrm{OH} \leftrightarrow \mathrm{H}_{2} \mathrm{O}+\mathrm{O}_{2}\end{array}$ \\
\hline Radical-radical recombination reactions & $\begin{array}{c}\mathrm{H}+\mathrm{OH}+\mathrm{M} \leftrightarrow \mathrm{H}_{2} \mathrm{O}+\mathrm{M} \\
\mathrm{H}+\mathrm{H}+\mathrm{M} \leftrightarrow \mathrm{H}_{2}+\mathrm{M} \\
\mathrm{O}+\mathrm{O}+\mathrm{M} \leftrightarrow \mathrm{O}_{2}+\mathrm{M} \\
\mathrm{H}+\mathrm{O}+\mathrm{M} \leftrightarrow \mathrm{OH}+\mathrm{M}\end{array}$ \\
\hline Hydrogen peroxide reactions & $\begin{array}{c}\mathrm{OH}+\mathrm{OH}+\mathrm{M} \leftrightarrow \mathrm{H}_{2} \mathrm{O}_{2}+\mathrm{M} \\
\mathrm{HO}_{2}+\mathrm{HO}_{2} \leftrightarrow \mathrm{H}_{2} \mathrm{O}_{2}+\mathrm{O}_{2} \\
\mathrm{H}_{2} \mathrm{O}_{2}+\mathrm{H} \leftrightarrow \mathrm{HO}_{2}+\mathrm{H}_{2} \\
\mathrm{H}_{2} \mathrm{O}_{2}+\mathrm{H} \leftrightarrow \mathrm{H}_{2} \mathrm{O}+\mathrm{OH} \\
\mathrm{H}_{2} \mathrm{O}_{2}+\mathrm{OH} \leftrightarrow \mathrm{H}_{2} \mathrm{O}+\mathrm{HO}_{2} \\
\mathrm{H}_{2} \mathrm{O}_{2}+\mathrm{O} \leftrightarrow \mathrm{HO}_{2}+\mathrm{OH}\end{array}$ \\
\hline
\end{tabular}

\subsection{Propagating Flame Simulations}

In the early days, the numerical simulation solving one-dimensional planar flame contributed to deepening the understanding of the flammability limit as shown in Table 6.

Table 6. Summary of numerical studies to investigate the flammability limit.

\begin{tabular}{|c|c|c|c|c|}
\hline Year & Researcher & Numerical Method & Mixture & Ref. \\
\hline 1990 & Lakshmisha et al. & 1D/planar/non-adiabatic/unsteady & $\mathrm{CH}_{4}$-air & [81] \\
\hline 1992 & Giovangigli et al. & 1D/planar/adiabatic/unsteady & $\begin{array}{c}\mathrm{H}_{2} \text {-air } \\
\mathrm{CH}_{4} \text {-air }\end{array}$ & [82] \\
\hline 1992 & Law et al. & 1D/planar/non-adiabatic/steady & $\begin{array}{l}\mathrm{H}_{2} \text {-air } \\
\mathrm{CH}_{4} \text {-air }\end{array}$ & [43] \\
\hline 1998 & Ju et al. & 1D/planar/non-adiabatic/steady & $\mathrm{CH}_{4}$-air & [83] \\
\hline 2008 & Van den Schoor et al. & $\begin{array}{l}\text { 1D/planar and spherical/non-adiabatic/steady } \\
\text { and unsteady }\end{array}$ & $\mathrm{CH}_{4}$-air & [84] \\
\hline 2008 & Shoshin et al. & 2D/stretched/non-adiabatic/unsteady & $\mathrm{CH}_{4}$-air & [85] \\
\hline 2009 & Fernandez-Galisteo et al. & 1D/planar/adiabatic/steady/7step & $\mathrm{H}_{2}$-air & [21] \\
\hline 2015 & Hernandez-Perez et al. & 2D/stretched/non-adiabatic/steady & $\mathrm{H}_{2}-\mathrm{CH}_{4}$-air & [18] \\
\hline 2018 & Zhou et al. & 2D/stretched/non-adiabatic/steady & $\mathrm{H}_{2}$ - $\mathrm{CH}_{4}$-air & [16] \\
\hline 2018 & Zhou et al. & 2D/stretched/non-adiabatic/steady & $\begin{array}{c}\mathrm{H}_{2} \text {-air } \\
\mathrm{CH}_{4} \text {-air } \\
\mathrm{H}_{2}-\mathrm{CH}_{4} \text {-air }\end{array}$ & [22] \\
\hline 2018 & Yakovenko et al. & 2D/stretched/non-adiabatic/unsteady & $\mathrm{H}_{2}$-air & [86] \\
\hline 2019 & Bertolino et al. & 1D/planar/non-adiabatic/steady & $\begin{array}{c}\mathrm{CH}_{4} \text {-air } \\
\mathrm{CH}_{3} \mathrm{OH} \text {-air } \\
\mathrm{C}_{2} \mathrm{H}_{6} \text {-air } \\
\mathrm{C}_{3} \mathrm{H}_{8} \text {-air, etc. }\end{array}$ & [79] \\
\hline 2019 & Jeon et al. & 2D/stretched/non-adiabatic/unsteady & $\mathrm{H}_{2}$-air & [87] \\
\hline
\end{tabular}


Lakshimisha et al.'s work is a representative numerical study that investigated the flammability limit through a planar flame analysis. Previous studies before their work, including studies by Gerstein and Stine [88], predicted flame behavior by using single step kinetics. As Lakshimisha et al. noticed that there were few numerical studies considering both detailed chemistry and heat loss mechanism, they simulated one-dimensional, planar, premixed, non-adiabatic $\mathrm{CH}_{4}$-air flames with detailed chemistry. The calculation of detailed chemistry was made with the kinetic schemes of Tsatsaronis et al. and Warnatz et al. $[89,90]$. They calculated differential equations where the heat loss term is added to the energy equation as shown in Equation (12). $h_{i}$ is the enthalpy at $i$-th species $\left(=h_{i}^{0}+\int c_{p, i} d T\right)$. $j_{i}$ is the diffusional mass flux at $i$-th species $\left(=\rho D_{i} \partial Y_{i} / \partial x+Y_{i} \sum \rho D_{j} \partial Y_{j} / \partial x\right) \cdot \dot{q}_{L}$ is the volumetric rate of heat loss from the gas to the ambiance as shown in Equation (13). They assumed that viscous effects and body force could be ignored and hence the momentum equation was not calculated. This approach is useful in near limit flames with negligible pressure change. Equations (14) and (15) show the corresponding boundary conditions at fresh unburned gas $(\psi \rightarrow+\infty)$ and burned gas far from the reaction zone $(\psi \rightarrow-\infty)$.

$$
\begin{gathered}
\frac{\partial H}{\partial t}=\frac{\partial}{\partial \psi}\left(\frac{\lambda \rho}{C_{p}} \frac{\partial H}{\partial \psi}\right)-\sum_{i=1}^{N_{s}} \frac{\partial}{\partial \psi}\left[h_{i}\left(J_{i}+\frac{\lambda \rho}{C_{p}} \frac{\partial Y_{i}}{\partial \psi}\right)\right]-\frac{\dot{q}_{L}}{\rho} \\
\dot{q}_{L}=4 \bar{a}_{p} \sigma\left(T^{4}-T_{u}^{4}\right) \\
\frac{\partial Y_{i}}{\partial \psi} \rightarrow 0, \frac{\partial T}{\partial \psi} \rightarrow 0 \text { at } \psi \rightarrow-\infty \\
Y_{i} \rightarrow Y_{i n}, T \rightarrow T_{u} \text { at } \psi \rightarrow+\infty
\end{gathered}
$$

Figure 11 shows the calculated flame temperature and flame speed in a steady state. It was noted that a steady propagation was observed for all lean mixture when heat loss term is not included. On the contrary, in heat loss conditions the steady propagation could not be observed below the certain methane concentration. They suggested that the predicted flammability limit with radiation showed good agreement with the zero-gravity experimental results. Since the buoyance force was not considered, the agreement between this calculation and zero-gravity experiments having a low stretch rate was deemed acceptable. In addition, a heat loss factor as the ratio of actual heat loss to the amount calculated by Equation (13) was defined. They investigated the effect of additional heat loss in the actual experimental process on the flammability limit. It was confirmed that the limit concentration increased with the heat loss factor [81].

The prediction of the flammability limit by using a one-dimensional planar flame was also actively carried out in hydrogen mixtures. Giovangigli et al. solved the governing equations for simulating a steady, one-dimensional, isobaric flame as shown in Equations (16)-(19). These governing equations included the mass burning rate, which is an eigenvalue of the problem. The turning point solution of the mass burning rate $\dot{m}$ could be obtained by using a standard pseudo-arclength continuation procedure. The solution methods combined a phase-space, Newton-like iteration, and global adaptive gridding as detailed in Refs. [82,91]. Turning points usually classify the stable solution from the unstable ones assuming that there is no Hopf bifurcation. A detailed chemical mechanism with 19 reactions and 9 species was used in their calculation. They suggested that the flammability for planar adiabatic flame was shown to be physically irrelevant points as the flame was thickened in finite-length computational domains. In the $\mathrm{H}_{2}$-air mixture at normal conditions, the LFL occurred at $\varphi=0.197$ $(7.6 \mathrm{vol} \%)$ and the UFL was at $\varphi=11.33(82.6 \mathrm{vol} \%)$. However, the artificial turning point was shown to be dependent on the computational domain length. It was identified that the flammable range was widened as the length increased [82]. It was confirmed that the planar flame analysis had difficulty in predicting the limit concentration in upward propagating hydrogen flames.

$$
\dot{m}=\rho v=\text { constant }
$$




$$
\begin{gathered}
\dot{m} \frac{d Y_{k}}{d x}=-\frac{d}{d x}\left(\rho Y_{k} V_{k}\right)+\dot{w}_{k} W_{k} \\
\dot{m} c_{p} \frac{d T}{d x}=\frac{d}{d x}\left(\lambda \frac{d T}{d x}\right)-\sum_{k=1}^{K} \rho Y_{k} V_{k} c_{p, k} \frac{d T}{d x}-\sum_{k=1}^{K} \dot{w}_{k} h_{k} W_{k} \\
\rho=\frac{p \bar{W}}{R T}
\end{gathered}
$$

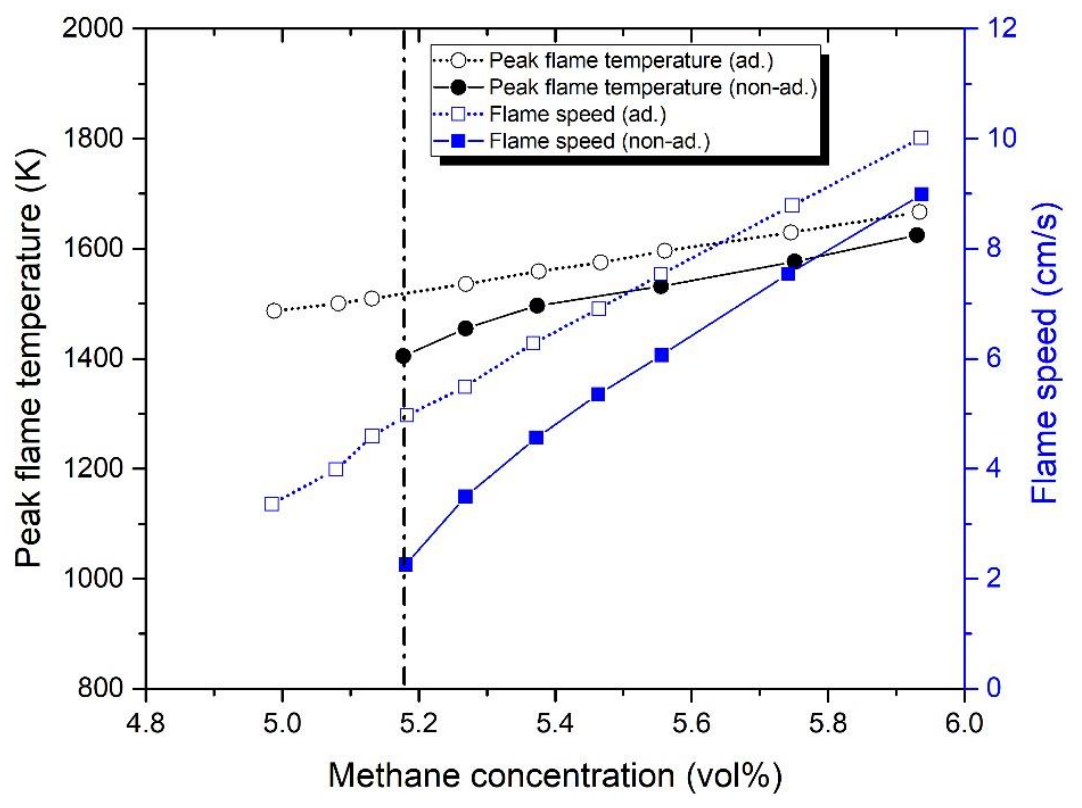

Figure 11. The calculated steady-state flame temperature and flame speed. Reproduced from Ref [81], The Combustion Institute: 1991.

Law et al. also evaluated the flammability limit of $\mathrm{CH}_{4}$-air at the turning point. As different to Giovangigli et al.'s work [82], the radiative heat loss from $\mathrm{H}_{2} \mathrm{O}, \mathrm{CO}_{2}, \mathrm{CO}$, and $\mathrm{CH}_{4}$ was included by assuming that the flames of interest were optically thin. Compared with the experimental results (5.4 $\mathrm{vol} \%)$, the predicted LFL (4.9 vol\%) with the non-adiabatic condition agreed better than the predicted value by Giovangigli et al. ( $3.2 \mathrm{vol} \%$ ) [43]. In addition, they introduced the kinetic criterion based on the response of the flammability exponent $\alpha$ to the concentration variations. The exponent was defined in Equation (20). $w_{b}$ is the maximum rate of the branching reaction and $w_{T}$ is the termination reaction rate at the location of the maximum branching reaction. They suggested that $\alpha=1$ could be identified as the incipient state where the termination reaction started to dominantly determine the overall reaction rate. They concluded that gas flammability limits could be conservatively predicted by the chain limits for the adiabatic flames if radiative heat loss was not massive. The detailed descriptions can be found in Ref. [43].

$$
\alpha(\varphi)=\partial\left(\ln w_{T}\right) / \partial\left(\ln w_{B}\right)
$$

Until recently, studies on predicting LFL of various combustible gases by using planar flame have been actively conducted [79]. Although one-dimensional planar flame analysis is very useful for investigating the effects of heat loss and chemical kinetics during flame propagation, it is difficult to depict the characteristics of upward propagating flame by buoyancy force. Shoshin et al. noted that the conduction (indirect radiation) mechanism from the flame to burned gas was significantly affected by the flow pattern near the flame [77]. In addition, the stretch effect should be considered for predicting the flammability of mixtures having non-unity $L e$. The observed methane flame extinction at the flame tip in methane flames can be understood by the stretch extinction limit [13]. On the other hand, the stretched flame tip in hydrogen mixtures $(L e \ll 1)$ leads to an increase of burning intensity 
due to the preferential diffusion effect [16]. For this reason, many studies simulated multi-dimensional stretched flames to understand the flammability limit under conditions favorable for matching the actual flames.

Zhou et al. observed the lean limit flames stabilized inside a $13.5 \mathrm{~mm}$ tube in a downward flow for premixed $\mathrm{H}_{2}$-air, $\mathrm{CH}_{4}$-air, and $\mathrm{H}_{2}-\mathrm{CH}_{4}$-air mixtures [16]. The flames under both laminar and axisymmetric conditions were numerically depicted by conservation equations for mass, momentum, and species in a cylindrical coordinate as shown in Equations (21)-(25) [18]. Unlike the above planar flame simulation, the momentum equation was solved with other conservation equations without calculating the eigenvalue of the flame speed (Equations (22) and (23)). A Newtonian flow was assumed and the mixture was treated as an ideal gas. They computed thermodynamic data and species net production/reduction rate by the CANTERA library [16]. They described that the stabilized flame burns in almost the same conditions as the one propagating upward in the tube and it allowed more detailed observations.

$$
\begin{gathered}
\frac{\partial \rho}{\partial t}+\frac{\partial\left(\rho u_{r}\right)}{\partial r}+\frac{\partial\left(\rho u_{z}\right)}{\partial z}=-\frac{\rho u_{r}}{r} \\
\frac{\partial\left(\rho u_{r}\right)}{\partial t}+\frac{\partial\left(\rho u_{r}^{2}+p\right)}{\partial r}+\frac{\partial\left(\rho u_{r} u_{z}\right)}{\partial z}=\frac{\partial \tau_{r r}}{\partial r}+\frac{\partial \tau_{r z}}{\partial z}+\frac{\tau_{r r}-\tau_{\theta \theta}-\rho u_{r}^{2}}{r} \\
\frac{\partial\left(\rho u_{z}\right)}{\partial t}+\frac{\partial\left(\rho u_{z} u_{r}\right)}{\partial r}+\frac{\partial\left(\rho u_{z}^{2}+p\right)}{\partial z}=\frac{\partial \tau_{r z}}{\partial r}+\frac{\partial \tau_{z z}}{\partial z}+\frac{\tau_{r z}-\rho u_{z} u_{r}}{r}+\rho g_{z} \\
\frac{\partial(\rho E)}{\partial t}+\frac{\partial\left[\rho u_{r}(E+p / \rho)\right]}{\partial r}+\frac{\partial\left[\rho u_{z}(E+p / \rho)\right]}{\partial z} \\
=\frac{\partial\left(u_{r} \tau_{r r}+u_{z} \tau_{r z}-q_{r}\right)}{\partial r}+\frac{\partial\left(u_{r} \tau_{r z}+u_{z} \tau_{z z}-q_{z}\right)}{\partial z}-\frac{\rho u_{r}(E+p / \rho)}{r}+\frac{u_{r} \tau_{r r}+u_{z} \tau_{r z}-q_{r}}{r}+\rho u_{z} g_{z} \\
\frac{\partial\left(\rho Y_{\alpha}\right)}{\partial t}+\frac{\partial\left[\rho Y_{\alpha}\left(u_{r}+V_{\alpha, x}\right)\right]}{\partial r}+\frac{\partial\left[\rho Y_{\alpha}\left(u_{z}+V_{\alpha, z}\right]\right.}{\partial z}=-\frac{\rho Y_{\alpha}\left(u_{r}+V_{\alpha, r}\right)}{r}+\dot{\omega}_{\alpha}
\end{gathered}
$$

Figure 12 shows the simulated distribution of chemical heat release rates and streamlines as the

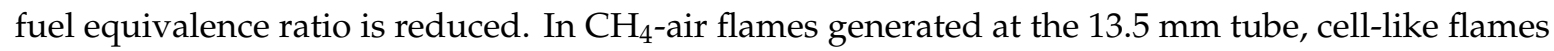
were maintained until flame extinction occurred. By decreasing the equivalence ratio, the flame became narrower and the flame trailing edge became brighter. Due to the weakness of preferential diffusion in $\mathrm{CH}_{4}$-air flames ( $\mathrm{Le} \sim 1$ ), the extinction occurred at the flame tip. On the contrary, a transition regime from the cell-like flame to the nearly ball-like flame was observed by decreasing fuel concentration in $\mathrm{H}_{2}$-air [22]. The trailing edge became shorter and eventually merged with the flame tip (flame extinction). It means that the primary extinction occurred at the trailing edge because the burning intensity at the flame tip could be effectively enhanced by strong preferential diffusion in $\mathrm{H}_{2}$-air flames $(L e \ll 1)$. Previous studies suggested that the enhancement of the local burning intensity at the flame tip compensated the cooling effect of the counterflowing combustion products [16,92]. We agree with this conclusion and believe that this distinct extinction process could be the main reason why a different approach was needed to analytically predict the flammability limit of methane and hydrogen. In other words, the heat loss effect on the trailing edge becomes crucial in the determination of hydrogen limit concentration. If the flame skirt length is shortened enough by the primary extinction, the enhanced recirculation flow is generated. Vigorous studies on flow characteristics near the hydrogen flames should be conducted to elucidate the extinction mechanism in future studies.

Figure 13 shows the experimental chemiluminescence distributions by Zhou et al. for comparison with the numerical results. It was confirmed that the experimental results were well comparable with the prediction of the flame structure by numerical simulation. The transition of cell-like flame to the ball-like flame was observed only in $\mathrm{H}_{2}$-air and $\mathrm{H}_{2}-\mathrm{CH}_{4}$-air flames as in the numerical prediction [22].

The accuracy of these numerical analysis needs to be verified quantitatively. Table 7 shows the predicted LFLs according to the computational analysis method. In $\mathrm{CH}_{4}$-air flame, the flammability limit was reasonably predicted even by $1 \mathrm{D}$ flat flame as well as $2 \mathrm{D}$ stretched flame [22]. It was consistent with the previous studies which well predicted the LFL of methane by 1D planar flame 
analysis. In hydrogen flame, it is interesting that the obtained limit concentration was much closer to the experimental results in stretched flame than flat flame. This is because preferential diffusion effects greatly increased the local burning intensity at the flame tip in the small Lewis number mixture. Because the $\mathrm{H}_{2}-\mathrm{CH}_{4}$-air mixture contained hydrogen gas, it showed a similar trend of prediction.

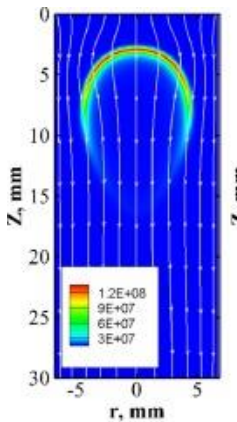

(a) $\phi=0.49$

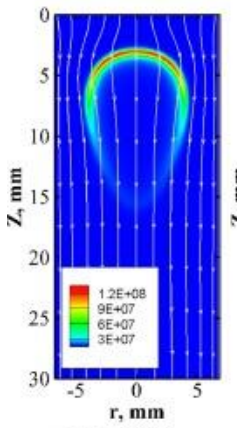

(e) $\phi=0.40$

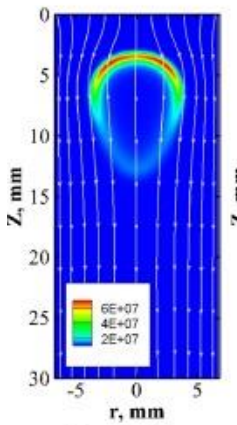

(i) $\phi=0.17$

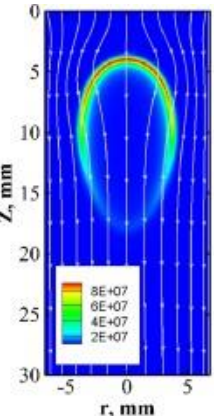

(b) $\phi=0.47$

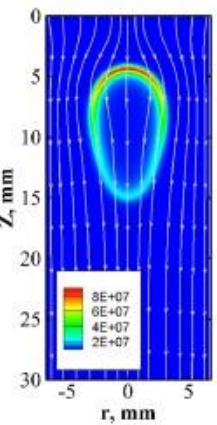

(f) $\phi=0.35$

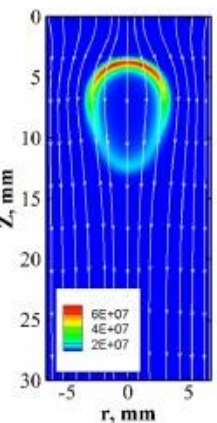

(j) $\phi=0.15$

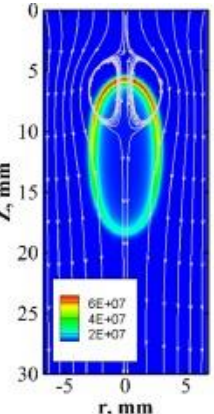

(c) $\phi=0.45$

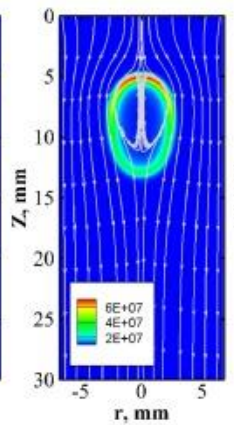

(g) $\phi=0.33$

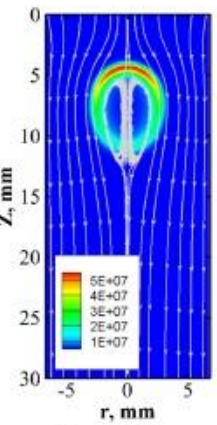

(k) $\phi=0.13$

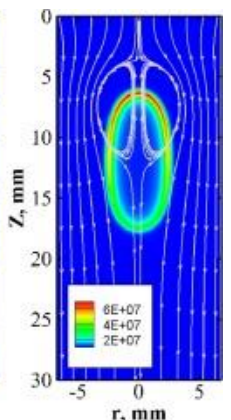

(d) $\phi=0.445$

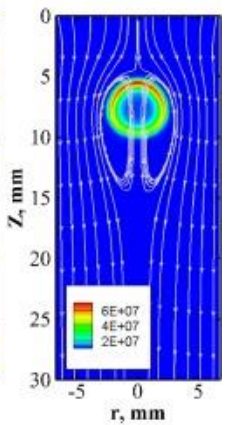

(h) $\phi=0.315$

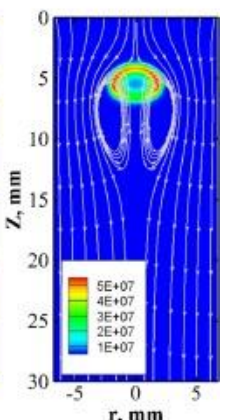

(1) $\phi=0.11$

Figure 12. Distribution of chemical heat release rate $\left(\mathrm{W} / \mathrm{m}^{3}\right)$ and flow streamlines for the flames studied in the simulations with a mixture-averaged transport model and skeletal mechanism at different fuel compositions (a-d): $\mathrm{CH}_{4}$-air, (e-h): $\mathrm{CH}_{4}-\mathrm{H}_{2}$, (i-1): $\mathrm{H}_{2}$ [22].

As a result, it was confirmed that the flammability limit was predicted more accurately by elaborated multi-dimensional numerical analysis. However, this accuracy needs to be verified for mixtures containing various diluents as well as a pure fuel mixture. Our recent simulations identified that the error became larger when the light diluent gas, having high mass diffusivity closer to hydrogen, was included in the mixture. This discrepancy may be caused by transport models as well as the uncertainties of the chemical kinetics and radiation calculation as remarked in other studies [22]. Especially, Dong et al. noted that notable discrepancies occurred between experiments and simulation by using kinetic mechanisms. The sensitivity of diffusion coefficients to the extinction response was found to be significant [93]. This uncertainty problem for each model could be a remaining issue to resolve. 

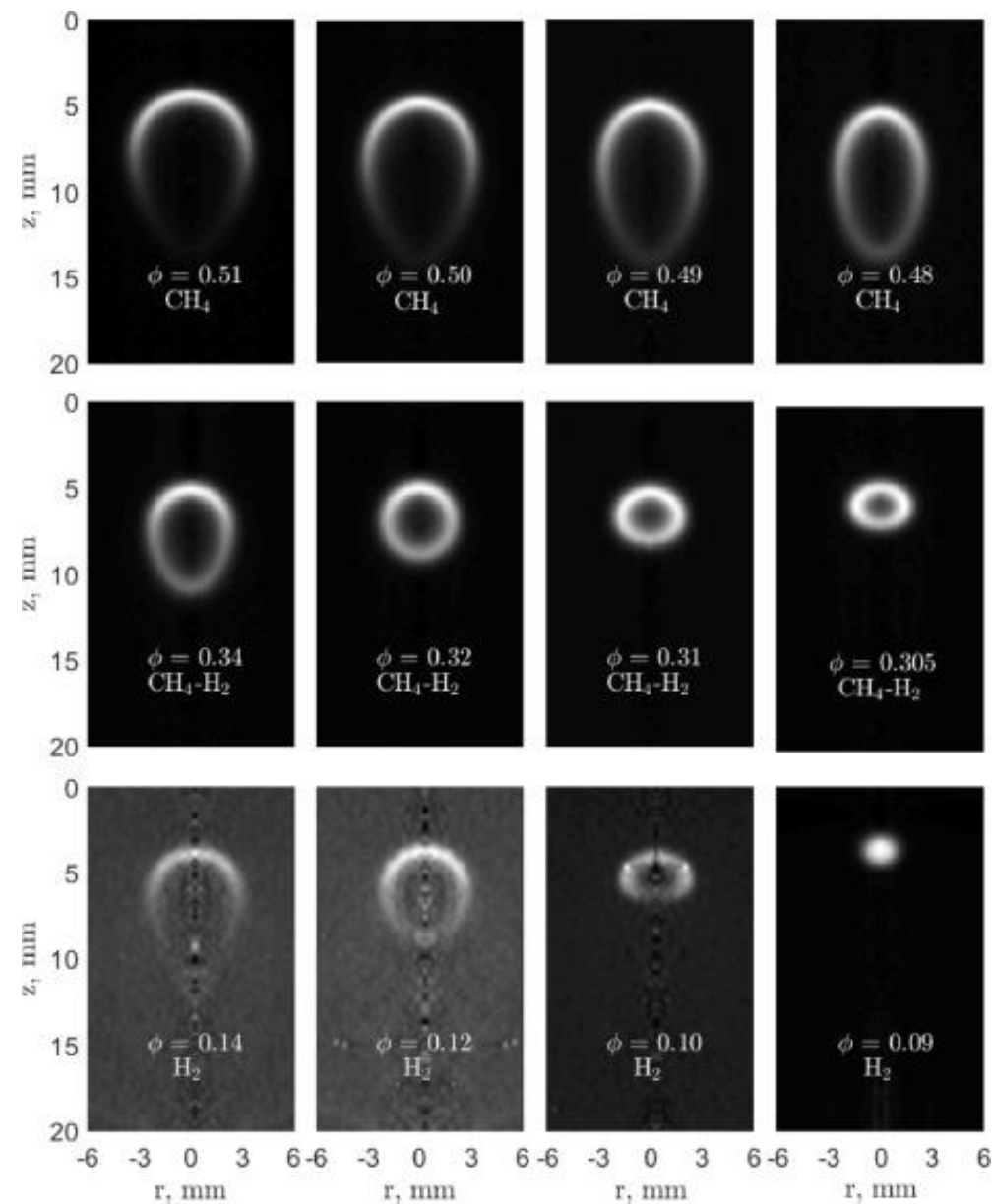

Figure 13. The Abel-inverted $\mathrm{CH}^{*}$ chemiluminescence contours for $\mathrm{CH}_{4}$-air and $40 \% \mathrm{H}_{2}+60 \% \mathrm{CH}_{4}$-air flames and $\mathrm{OH}^{*}$ chemiluminescence contours for $\mathrm{H}_{2}$-air flames with decreasing equivalence ratio [22].

Table 7. Prediction of lower flammability limit (LFL) (equivalent ratio) for different types of flame with different fuel compositions. The numerical simulation considered thermal radiation Reproduced in Ref. [22], The Combustion Institute: 2017.

\begin{tabular}{ccccc}
\hline Fuel & Exp. & Num. (2D) & 1D Flat Flame & 1D Flame Ball \\
\hline $\mathrm{CH}_{4}$ & 0.480 & 0.445 & 0.497 & - \\
$40 \% \mathrm{H}_{2}+60 \% \mathrm{CH}_{4}$ & 0.350 & 0.315 & 0.446 & 0.270 \\
$\mathrm{H}_{2}$ & 0.090 & 0.110 & 0.295 & 0.073 \\
\hline
\end{tabular}

\subsection{Stationary Flame Ball}

As discussed in Section 2, many experimental studies observed flame structure using specific apparatuses other than the standard tube. Although the generated stationary flame with these apparatuses cannot fully be depicted upward propagating flame, the separate effect analysis for each mechanism is more feasible. Due to this advantage, these stationary flames also have been investigated by numerical simulations. First, the stationary flame ball can be simulated by the integration of the convection-free energy and species conservation equations as described in Ref. [20,94,95]. This calculation includes detailed descriptions for transport, chemistry, and radiation.

Recently, Fernandez-Tarrzao et al. calculated the peak flame temperature of the generated flame ball dependent on fuel equivalence ratio as shown in Figure 14. They also compare the results depending on the presence of a detailed chemistry model as well as a detailed radiation model. The selected detailed chemistry was the San Diego mechanism (Table 5) [80]. The statistical narrow 
band (SNB) model includes both emission and absorption of thermal radiation with the discrete ordinate (DO) method. On the contrary, the optically thin approximation only calculated the emission of radiation. Because of the significant small flame thickness at the lean limit flame, the assumption of optically thin conditions was justified by referring to Hottel's charts [96]. Similar to the analytical study of Spading [97], all methods show both unstable and stable brunch. If unsteady effects in defining the limit concentration for flame-ball existence were neglected, the turning point can be evaluated as the flammability limit. Based on the results with the SNB radiation model and 21-step chemical scheme, the turning point of the flame ball was $0.0735(3 \mathrm{vol} \%)$ in the absence of steam. The predicted concentrations in the presence of steam were also lower than the experimental results for upward flame because the analysis of stationary flame ball corresponds to a zero-gravity environment.

\subsection{Counterflow Flame}

The computational analysis to investigate the gas flammability was also actively conducted for counterflow flame. Ju et al. investigated the extinction/flammability limit of stretched premixed $\mathrm{CH}_{4}$-air mixture by numerical simulation of the counterflow flame. In their work, the governing equation was based on the stagnation point flow approximation [98,99]. It solved the axisymmetric premixed flame and the one half of the domain was simulated due to the symmetry of the twin flame. As discussed in Section 2.5, the $\mathrm{CH}_{4}$-air mixture has a Lewis number less than but close to unity. Thus, a moderate stretch will strengthen the flame by preferential diffusion effect but a large stretch can quench it by incomplete combustion. For this reason, a moderate stretch rate enhances the combustion and makes the flame stable at a lower concentration compared to the measured limit by tube experiments [70]. The generating stable flame below the flammability limit was also observed by experimental counterflow studies. It was identified that the flame extinction occurred at $5.0 \mathrm{vol} \%$ of methane concentration which was slightly smaller than the measured limit concentration in tube experiments [65].

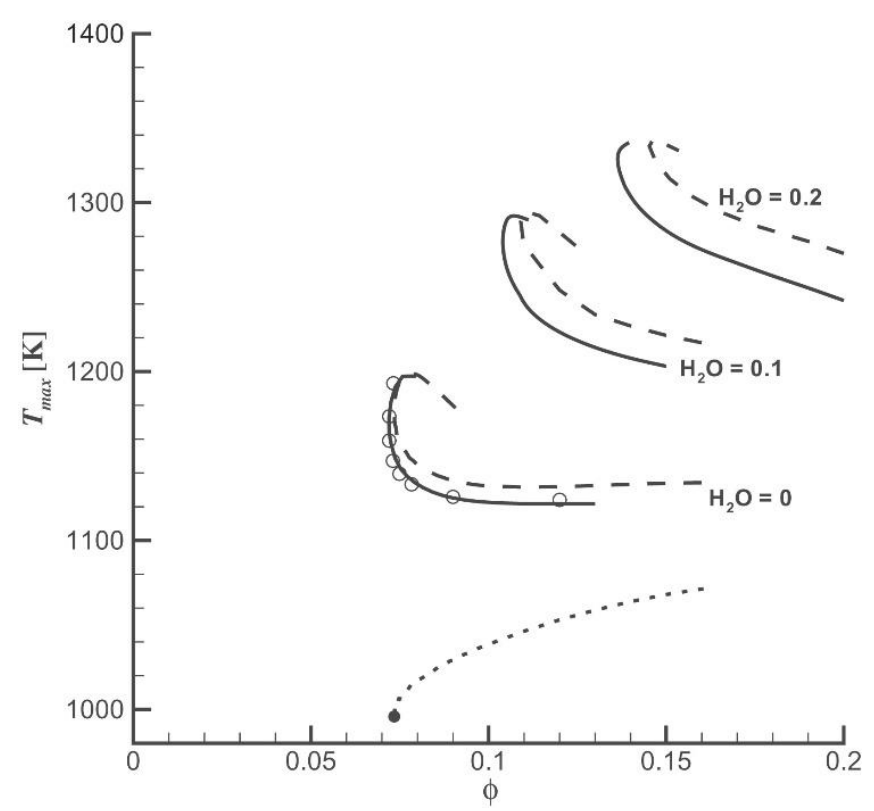

Figure 14. The variation with the equivalence ratio of the peak flame temperature as obtained from numerical integrations with the statistical narrow band (SNB) radiation model and 21-step chemical scheme (solid curve), with the SNB radiation model and the one-step reduced mechanism (circles), and with the optically thin approximation and the one-step reduced mechanism (dashed curve) [23].

However, it seems difficult to understand the extinction process of propagating flame by the existence of stretch extinction limit in lean hydrogen flames. The lean hydrogen mixture has a Lewis 
number much smaller than unity. The increased burning intensity in stretched flame was much greater than a methane flame due to the increased unequal rates of diffusion of thermal energy and mass (preferential diffusion effect). For this reason, it seems hard to observe the immediate flame quenching by the elevated stretch rate in lean hydrogen flame generally. These different characteristics of hydrogen flames compared to methane flames are remarkable in studies by Lee et al. [92]. They investigated the effects of stretch and preferential diffusion on the structure and extinction of $\mathrm{H}_{2}$-air premixed flames by numerical simulation. Figure 15 shows the effect of stretch on various losses for lean $\mathrm{H}_{2}$-air flame $\varphi=0.3$. The total loss ratio was defined as the ratio of $T_{a d}-T(y=0)$ to $T_{a d}-T_{\infty}$. The total gain initially increases through preferential diffusion. Although the total gain then slowly decreased by an increase in reaction incompleteness, it was still positive until the stretch rate approached to 3000/s [92]. The different extinction process of methane and hydrogen flame discussed in Section 3.1 would be related to the different trends in the total loss ratio as the stretch rate increases. It should be noted that, in lean $\mathrm{CH}_{4}$-air mixture, the stretch extinction limit was predicted to occur at a stretch rate of around 100/s [70].

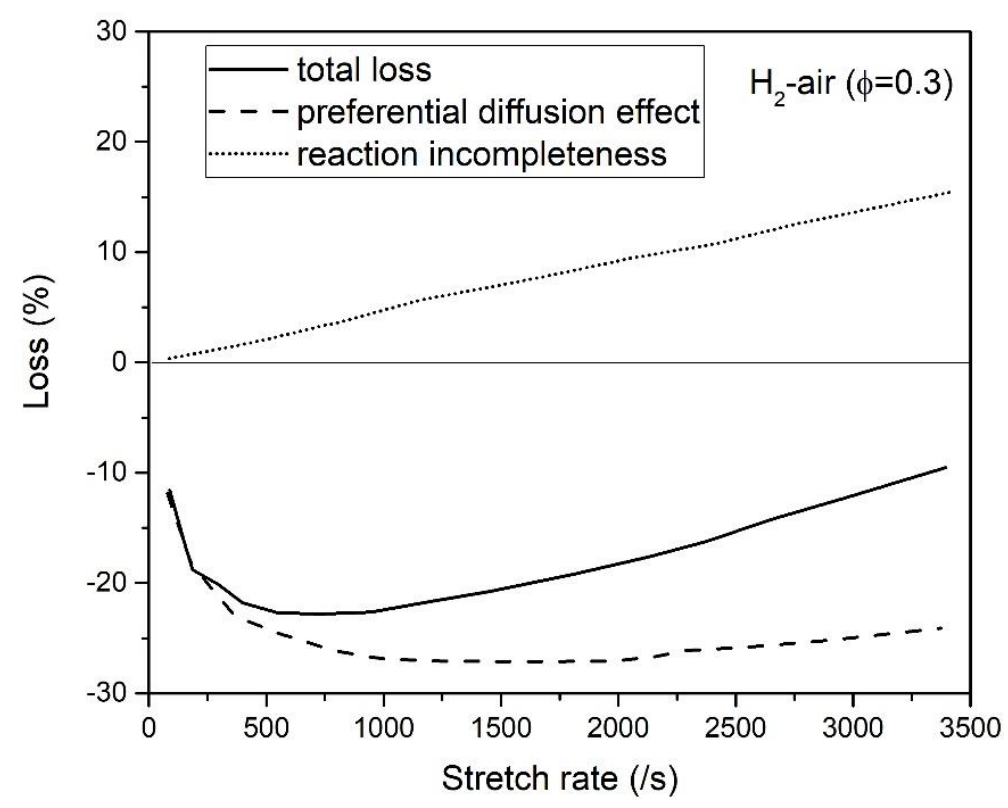

Figure 15. Variation of loss contributions as a function of stretch for lean hydrogen flame. Reproduced in Ref. [92], The Combustion Institute: 1998.

\section{Analytical Studies}

As discussed in Sections 2 and 3, there were significant efforts to investigate the flammability characteristics of hydrogen gas as well as to measure the flammability limit in various configurations. In experimental studies, vigorous experiments made it possible to develop the Shapiro diagram which was a practical tool for a safe energy system $[17,35]$. Flame ball and counterflow experiments provided a successful understanding of energy balance and stretch effect in lean limit flames [23,70]. In numerically, studies on reducing chemical kinetics made it possible to simulate the multi-dimensional flame propagation [16,78]. However, it is still difficult to accurately predict the flammability limit of hydrogen gases by recent numerical simulations. Recent studies identified that significant discrepancies between the numerical and experimental results can exist depending on the diluent type. This discrepancy may be caused by the uncertainties of the binary diffusion coefficients and radiation calculation as well as the reduced chemical kinetics. It is also impossible to measure the flammability limit of all hydrogen mixtures since there are numerous conditions including temperature, diluent type, diluent concentration. Furthermore, special attention was paid to the specific extinction condition in each devised apparatus, which can lose the generality of the measurement. For this reason, the analytical 
studies to find a method having a universal application for predicting hydrogen flammability have been actively conducted. In this section, these analytical studies were discussed.

\subsection{Systemic Combustion Analysis}

Many analytical studies have been conducted for simplifying the combustion process on a systematic scale to develop a useful LFL prediction method. They focused on getting insight from the ideal homogeneous flame where the heat transfer between the burned gas and unburned gas was neglected. Although these systematic analyses are difficult to consider the observed flame nature and detailed chemical kinetics, it allows effective estimation of LFL for extensive mixtures. The representative systematic analysis is the concept of calculated adiabatic flame temperature (CAFT) proposed by Egerton and Zabetakis [100,101]. They suggested that the adiabatic flame temperature at the flammability limit can be considered as approximately constant. The adiabatic flame temperature can be calculated by systematic energy balance as shown in Equation (26). In adiabatic processes, the heat produced during the exothermic chemical reaction is transferred only to the products, and the temperature of the products increases, where $\Delta H_{f, i}^{0}$ is the formation of enthalpy and $T_{r e f}$ is the reference temperature, $298 \mathrm{~K} . \bar{c}_{p, i}$ is the average specific heat. Macek confirmed that the adiabatic flame temperatures for lean limit mixtures in air clusters near 1500 or $1600 \mathrm{~K}$ for many hydrocarbon type fuels as shown in Table 8 [102]. The lean limit condition was based on the upward flame propagation at normal temperature and pressure. According to Arrhenius theory, the peak flame temperature occurring at the flame front determines the combustion heat rate. If the heat generated by combustion cannot overcome the heat loss, the flame does not propagate continuously, and consequently, flame extinction occurs. The threshold peak temperature is the temperature at which the minimum amount of combustion heat is generated for propagation. The previous studies remarked that peak temperature was proportional to the CAFT, and therefore the LFL concentration reaching the threshold peak temperature can be predicted by calculating the adiabatic temperature [103-105].

$$
\sum_{\text {reactants }} n_{i}\left[\Delta H_{f, i}^{0}+\bar{c}_{p, i}\left(T_{i}-T_{r e f}\right)\right]-\sum_{\text {products }} n_{i}\left[\Delta H_{f, i}^{0}+\bar{c}_{p, i}\left(T_{C A F T}-T_{r e f}\right)\right]=0
$$

Table 8. The calculated adiabatic flame temperature at flammability limit for hydrocarbon type fuels. Reproduced from Ref. [102], Gordon and Breach Science Publishers, Inc.: 1979.

\begin{tabular}{ccc}
\hline Fuel & LFL & $\mathbf{T}_{\text {ad }}(\mathbf{L F L})$ \\
\hline $\mathrm{CH}_{4}$ & 5.0 & 1480 \\
$\mathrm{C}_{2} \mathrm{H}_{6}$ & 3.0 & 1530 \\
$\mathrm{C}_{3} \mathrm{H}_{8}$ & 2.1 & 1540 \\
$n-\mathrm{C}_{4} \mathrm{H}_{10}$ & 1.8 & 1640 \\
$n-\mathrm{C}_{5} \mathrm{H}_{12}$ & 1.4 & 1590 \\
$n-\mathrm{C}_{6} \mathrm{H}_{14}$ & 1.2 & 1610 \\
$n-\mathrm{C}_{7} \mathrm{H}_{16}$ & 1.0 & 1620 \\
$n-\mathrm{C}_{8} \mathrm{H}_{18}$ & 0.9 & 1650 \\
\hline
\end{tabular}

Mashuga and Crowl proposed a method to predict the flammable zone considering diluent concentration using the CAFT. They confirmed that the flammable zone determined by the CAFT criterion $1200 \mathrm{~K}$ compared well over the experimental results for pure methane and ethylene although the reliability of the method was not maintained for a 50/50 mixture of methane and ethylene. They also suggested that the one possible reason with reasonable accuracy of the CAFT approach was linked to the reaction mechanisms of carbon monoxide. In hydrocarbon type fuels, $\mathrm{CO}$ is the primary product formed in substantial amounts. Conversion of $\mathrm{CO}$ to $\mathrm{CO}_{2}$ comes only after all the fuel and fragments are converted. It means that a reaction in Equation (27) did not begin appreciably until above $1100 \mathrm{~K}$ and is self-sustaining around $1400 \mathrm{~K}$. Since this highly exothermic reaction controls a sizable amount 
of the flam energy, its limiting temperature will control the overall flammable characteristics [106]. Razus et al. also investigated the utilization of CAFT to predict the flammability limit of methane. As different to Mashuga and Crowl, they focused on the LFL concentration depending on the diluent concentration. It was identified that the CAFT at LFL was maintained relatively constant until the nitrogen concentration was $40 \%$ and then the temperature increases as the concentration further increases. Given that the increase was at around $10 \%$, the LFL prediction through the CAFT approach was still valid. They also described a new method to estimate the limiting oxygen concentration (LOC) of fuel-air-inert premixed systems using the CAFT approach [107].

$$
\mathrm{CO}+\mathrm{OH} \rightarrow \mathrm{CO}_{2}+\mathrm{H}
$$

The adiabatic flame temperature approach to predict the LFL of hydrocarbon type fuel was further extended by Vidal et al. They calculated the adiabatic flame temperature using a computer code for equilibrium products of hydrocarbon-air combustion. The average adiabatic flame temperature at the flammability limit was obtained for each family group of chemicals. The paraffinic group including methane and propane has an average adiabatic temperature of $1590 \mathrm{~K}$ and the unsaturated group including ethylene has an average adiabatic temperature of $1600 \mathrm{~K}$. These average values are considered to be nearly identical with the temperature concluded by Shebeko et al. [37]. Figure 16 shows the adiabatic temperatures at the flammability limit for each paraffinic fuel type. The mixtures in the first category from methane to $n$-Hexadecane have fairly comparable adiabatic temperature regardless of fuel types. However, unlike hydrocarbon fuel, it has also been common knowledge that the adiabatic flame temperature of lean limit hydrogen mixtures at normal temperature is about $600 \mathrm{~K}$. The reliability of the adiabatic temperature approach to hydrogen mixture was discussed after the further descriptions for progress in hydrocarbon fuel types.

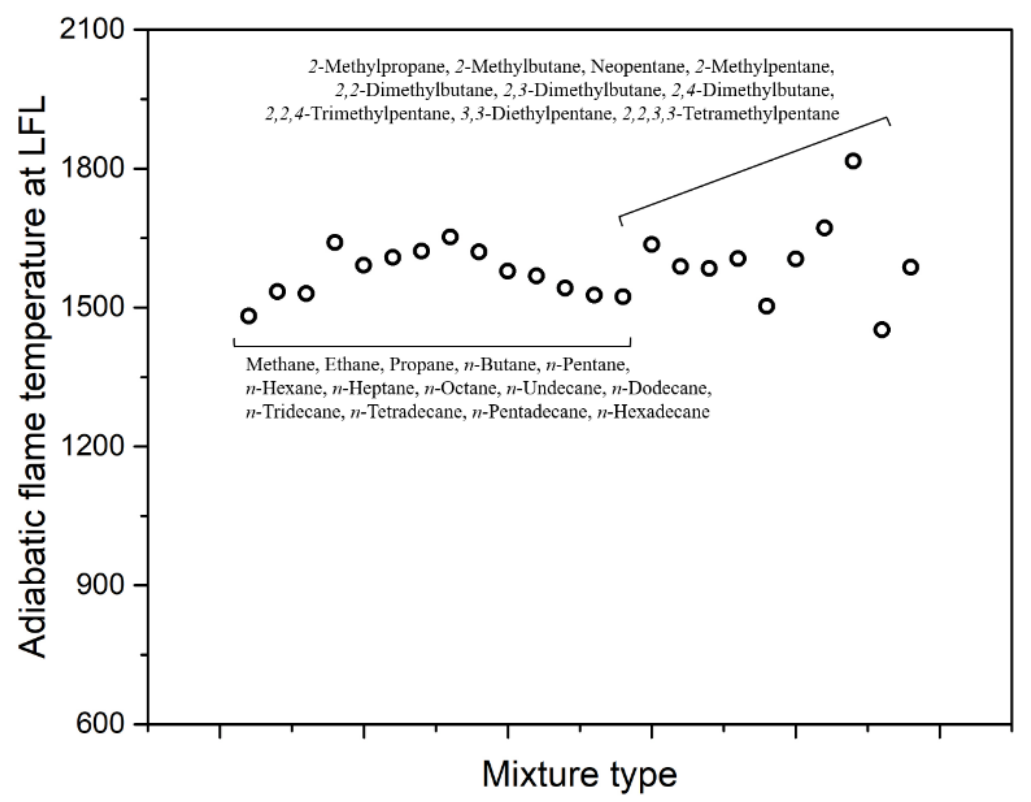

Figure 16. Calculated adiabatic flame temperature for paraffinic hydrocarbons by Vidal et al.'s data.

To prevent fire and explosion hazards, it is important to predict LFL for elevated temperature and pressure. The adiabatic flame temperature was calculated for lean fuel mixtures (T: 300-1200 K, P: 1-100 bar) by Wan et al. [108]. Almost constant values were identified at various temperatures when the pressure kept constant, which agreed well with the previous studies [101,109]. They also compared the average values of the adiabatic flame temperature for the same temperature range (300-1200 K) according to the initial pressure from 1 bar to 100 bar. The relative discrepancy of the 
adiabatic temperature between 1 bar and 100 bar did not exceed $10 \%$ for methane, ethylene, and propane fuel types.

Van den Schoor et al. calculated the adiabatic flame temperature at the experimentally determined UFL for methane-air mixtures. As shown in Table 9, the mixtures show nearly constant values for a given initial pressure, independent of initial temperature. In other words, the UFL of the mixture having elevated temperature and pressure can be obtained by the determined value of CAFT by averaging the experimental results. In their detailed analysis, the averaged CAFT for limiting mixture slightly decreases as the initial pressure increases. For this reason, the UFL prediction leads to underestimation at elevated pressure if the reference CAFT value was determined based on the ambient pressure [84].

Shu et al. similarly predicted the UFL for the hydrocarbon by using the CAFT concept, but they considered the incomplete combustion process for the fuel-rich mixture. In lean limit conditions, chemical kinetics is not important due to the sufficient oxygen to oxidize the hydrocarbon to be $\mathrm{CO}_{2}$. On the contrary, kinetics become important in rich limit conditions having lean oxygen. They assumed oxygen is consumed with three steps. First, the hydrocarbon is oxidized to $\mathrm{CO}$ and hydrogen. Second, oxidizing hydrogen to steam depending on the remaining oxygen content. Third, if there is still oxygen left, the $\mathrm{CO}$ is oxidized to $\mathrm{CO}_{2}$. This three-step hypothesis was first proposed by Lewis et al. [110]. and Bartok and Sarofim [111]. In their opinion, the remaining oxygen in the fuel-rich mixtures is consumed on such sequential steps. They suggested that the reduced accuracy for UFL than LFL was caused by these chemical effects. In their computation of CAFT, the content of each gas species after the combustion (product) was calculated through this hypothesis. They noted that the average relative difference between the calculated results and experimental results were less than $8.8 \%$. The chemical equilibrium code can also be used to determine the composition of each product, such as studies by Vidal et al. and Melhem [112,113]. Wu et al. introduced the variable calculated adiabatic flame temperature (VAFT) concept to reduce the errors which are still greater in UFL than LFL. They observed a linear relationship between the dilution ratio and the CAFT value. In other words, the UFL concentration can be estimated by determining the threshold CAFT value as a linear function for the diluent ration instead of a constant value. Although this method can provide useful tools for estimating the flammability limit in diluent conditions, sufficient experimental results for each diluent are essentially required.

Table 9. The calculated adiabatic flame temperature (CAFT) at the experimentally determined UFL of methane-air mixtures at different initial pressure and temperatures. Reproduced from Ref. [84], Elsevier B.V.: 2008.

\begin{tabular}{cccc}
\hline Pressure (bar) & 298 K & 373 K & 473 K \\
\hline 1 & 1692 & 1678 & 1667 \\
3 & 1648 & 1622 & 1612 \\
6 & 1597 & 1583 & 1584 \\
10 & 1545 & 1533 & 1524 \\
\hline
\end{tabular}

The rationale of the CAFT model can be understood through a recent analytical flame-ball analysis by Sanchez et al. [12]. For the stoichiometry of the global reaction $2 \mathrm{H}_{2}+\mathrm{O}_{2} \rightarrow 2 \mathrm{H}_{2} \mathrm{O}$, Equation (28) shows the energy conservation equation, where $r$ is the radius of the flame ball, $\widetilde{Y}_{\mathrm{H}_{2}}$ is the modified fuel mass fraction, $R$ is the volumetric radiation rate, and $D$ is the mass diffusivity. If the radiation heat loss is neglected, the temperature at the reaction layer can be estimated by integrating Equation (28) twice assuming constant $\rho \widetilde{D}_{\mathrm{H}_{2}} / k$ (Equation (29)). Incidentally, the effect of the neglected thermal radiation causes limitations of the CAFT model that follows later. Equation (30) provides the peak temperature $\left(\widetilde{Y}_{\mathrm{H}_{2}} \cong 0\right)$ at the reaction layer. For comparison with the adiabatic temperature in Equation (26), the mole is used as the unit. As a result, the proportional relation between peak temperature and CAFT can be confirmed using Equation (31). It means that the linear proportionality between two variables, which has been remarked by previous research, can also be asserted in the form of an equation. 
$\vec{c}_{p}^{*}$ is the average specific heat for all constituent mixtures, and $\widetilde{L}_{H_{2}}$ is the effective Lewis number which is an intrinsic mixture property [12,59]. For hydrogen-air premixed combustion, the effective Lewis number near the lean flammability limit is about 0.3 [12]. As discussed in Section 2.5, it was identified that the hydrogen gas flammability can roughly be evaluated by the flame ball experiments in non-gravity conditions.

$$
\begin{gathered}
\frac{1}{r^{2}} \frac{d}{d r}\left(k r^{2} \frac{d T}{d r}\right)=R+\frac{H_{f, H_{2} \mathrm{O}}^{0}}{r^{2}} \frac{d}{d r}\left(\frac{\rho \widetilde{D}_{H_{2}}}{M_{H_{2}}} r^{2} \frac{d \widetilde{Y}_{H_{2}}}{d r}\right) \\
T-T_{u}=\frac{\rho \widetilde{D}_{H_{2}}}{k} \frac{\left(-\Delta H_{f, H_{2} \mathrm{O}}^{0}\right)}{M_{\mathrm{H}_{2}}}\left(Y_{\mathrm{H}_{2} u}-\widetilde{Y}_{\mathrm{H}_{2}}\right) \\
T_{\text {peak }}=T_{u}+\frac{\rho \widetilde{D}_{H_{2}}}{k}\left(-H_{f, H_{2} \mathrm{O}}^{0}\right) X_{H_{2} u} \\
\frac{T_{\text {peak }}-T_{u}}{T_{\text {CAFT }}-T_{u}}=\frac{\rho \vec{c}_{p}^{*} \widetilde{D}_{H_{2}}}{k}=\frac{1}{\widetilde{L}_{H_{2}}}
\end{gathered}
$$

Recently, Jeon et al. substantially investigated the rationale of the CAFT approach to predict the LFL of hydrogen gases. Table 10 shows the measured LFL by previous experimental works and the corresponding CAFT values. Although the nearly constant temperature values at various initial conditions were identified $(\sim 600 \mathrm{~K})$, some mixtures show considerable differences. There are limited mixtures that even have a CAFT of $900 \mathrm{~K}$. It was noted that the discrepancies were noticeable for mixtures having a high initial temperature or the steam content. It means that the model accuracy can be greatly reduced depending on the mixture conditions. Jeon et al. highlighted that this limitation was caused by the adiabatic flame assumption [11]. A general flame cannot propagate under adiabatic conditions, and unavoidable heat loss affects the flame propagation. It means that the heat loss

\begin{tabular}{|c|c|c|c|c|c|c|}
\hline Researcher & Mixture & $T_{i}\left({ }^{\circ} \mathrm{C}\right)$ & Diluent (vol\%) & LFL (vol\%) & CAFT (K) & Ref. \\
\hline \multirow{10}{*}{ Terpstra } & $\mathrm{H}_{2}$-air & 20 & 0 & 3.9 & 610 & \multirow{10}{*}{ [15] } \\
\hline & $\mathrm{H}_{2}$-air & 50 & 0 & 3.8 & 633 & \\
\hline & $\mathrm{H}_{2}$-air & 100 & 0 & 3.6 & 667 & \\
\hline & $\mathrm{H}_{2}$-air & 150 & 0 & 3.3 & 692 & \\
\hline & $\mathrm{H}_{2}$-air & 200 & 0 & 2.8 & 701 & \\
\hline & $\mathrm{H}_{2}$-air & 300 & 0 & 2.4 & 769 & \\
\hline & $\mathrm{H}_{2}$-air-He & 20 & $0-50$ & $3.8-5.3$ & $600-800$ & \\
\hline & $\mathrm{H}_{2}$-air-Ar & 20 & $0-60$ & $3.0-3.8$ & $590-610$ & \\
\hline & $\mathrm{H}_{2}$-air- $\mathrm{N}_{2}$ & 20 & $0-20$ & $\sim 3.9$ & $\sim 610$ & \\
\hline & $\mathrm{H}_{2}$-air- $\mathrm{CO}_{2}$ & 20 & $0-40$ & $3.9-4.6$ & $602 \sim 620$ & \\
\hline \multirow{4}{*}{ Kumar } & $\mathrm{H}_{2}-\mathrm{O}_{2}-\mathrm{He}$ & 22 & $20-40$ & $5.1-5.8$ & $700-800$ & \multirow{4}{*}{ [34] } \\
\hline & $\mathrm{H}_{2}-\mathrm{O}_{2}-\mathrm{He}$ & 100 & $20-40$ & $3.9-4.3$ & $700-750$ & \\
\hline & $\mathrm{H}_{2}-\mathrm{O}_{2}-\mathrm{N}_{2}$ & 22 & $20-40$ & $\sim 4.0$ & $\sim 600$ & \\
\hline & $\mathrm{H}_{2}-\mathrm{O}_{2}-\mathrm{N}_{2}$ & 100 & $20-40$ & $\sim 3.5$ & $\sim 650$ & \\
\hline \multirow{2}{*}{ Hustad } & $\mathrm{H}_{2}$-air & 20 & 0 & 4.3 & 644 & \multirow{2}{*}{ [36] } \\
\hline & $\mathrm{H}_{2}$-air & 200 & 0 & 3.3 & 741 & \\
\hline \multirow{4}{*}{ Marshall } & $\mathrm{H}_{2}$-air-Steam & $100-120$ & 10 & 4.83 & 773 & \multirow{4}{*}{ [35] } \\
\hline & $\mathrm{H}_{2}$-air-Steam & $100-120$ & 20 & 5.31 & 804 & \\
\hline & $\mathrm{H}_{2}$-air-Steam & $100-120$ & 30 & 5.96 & 847 & \\
\hline & $\mathrm{H}_{2}$-air-Steam & $100-120$ & 40 & 6.93 & 913 & \\
\hline
\end{tabular}
mechanism in propagating flames should be considered for predicting the LFL.

Table 10. The CAFT for various limiting mixtures, Reproduced from Ref. [11], Korean Nuclear Socity: 2019. 
In addition to the studies based on the adiabatic flame temperature concept as discussed, other systematic studies for predicting flammability limit have been conducted. Burgess et al. suggested that the flammability limits of most gaseous fuels can be predicted as shown in Equation (32). Where $L(25)$ are the flammability limits at $25^{\circ} \mathrm{C}$ and $T$ is the temperature, $C$ is the specific heat of the mixture, $\Delta H_{C}$ is the heat of combustion per mole of fuel [114]. Kumar et al. simplified this equation to Equation (33) for hydrogen-air mixtures ignited at the top (downward propagation) [44]. These linear approximation methods can be useful, but the accuracy dramatically decreased in the presence of a diluent.

$$
\begin{gathered}
L(T) / L(25)=1-C /\left[L(25) \Delta H_{C}\right](T-25) \\
L(T) / L(25)=1-0.0013(T-25)
\end{gathered}
$$

Britton developed a method to predict the LFL in the air under normal conditions by using the parameter of combustion heat as shown in Equation (34) [115]. The combustion heat can be used for breaking each molecular oxygen bond demanded to start chain reactions with oxygen. Where $c_{0}$ is a constant based on the methane type, $S$ is the ratio of oxygen to fuel. This estimation calculated the LFL of fuel in proportion to its heat of combustion relative to that of methane [116]. Ma provided a method to estimate the flammability limits based on the thermal balance which quantified the heating potentials $H_{F}$ and quenching potentials $Q_{F}$ of each element of a mixture. The quenching potential of a diluent is the enthalpy change at the referred CAFT with respect to that of air. The LFL is the point where the heat released is barely enough to raise the system temperature to the CAFT as shown in Equation (35) [117]. Since these methods employed the assumption that the adiabatic flame temperature is identical, it can be considered as a modified adiabatic temperature approaches [116]. The heat transfer characteristics in flame propagation dependent on diluent type are also neglected in these methods.

$$
\begin{gathered}
L F L=c_{0} * S / \Delta H_{C}^{2} \\
X_{L}=1 /\left(1+H_{F}-Q_{F}\right)
\end{gathered}
$$

\subsection{Analytical Analyses of Propagating Flame}

The systematic combustion analysis allows effective LFL prediction as discussed in Section 4.1, but it is difficult to consider the nature of propagating flames. In upward propagating flames, the combustion proceeds in a stretched thin reaction zone not an ideal homogeneous space. The heat transfer to the burned gas greatly affects the peak flame temperature in the reaction zone and hence the flammability limit. In addition, it was deduced that the elevated stretch rate in flame tip leads to the flame extinction in methane flames [76]. For this reason, analytical studies considering the nature of the propagating flame including heat transfer and flame stretch have been conducted to predict the flammability limit more precisely.

Many studies have been analyzed the propagating flames for predicting the flammability limit in a different manner with adiabatic flame temperature theory. Spalding solved energy and diffusion equations based on one-dimensional, laminar premixed combustion to calculate the flame speed at the flammability limit with special attention to experimental evidence for the existence of two flame speed. The analytical solution is based on a single-step chemical reaction to give greater clarity and save computational cost while still representing real flames in important respects. The basic conservation equations of energy, fuel A, and oxidant B are shown in Equations (36)-(38) [97].

$$
\begin{gathered}
\frac{d}{d x}\left(k \frac{d T}{d x}\right)+H \frac{d}{d x}\left(D_{A} \rho \frac{d m_{A}}{d x}\right)-G \frac{d}{d x}\left(\sum_{j} c_{j} m_{j} T+m_{A} H\right)=L \\
\frac{d}{d x}\left(D_{A} \rho \frac{d m_{A}}{d x}\right)-G \frac{d m_{A}}{d x}=R_{A}
\end{gathered}
$$




$$
\frac{d}{d x}\left(D_{B} \rho \frac{d m_{B}}{d x}\right)-G \frac{d m_{B}}{d x}=R_{B}
$$

The equations can be converted to dimensionless form as shown in Equations (39) and (40). The flame speed at the flammability limit can be obtained in Equation (41) by finding the eigenvalue $\lambda$ with an approximate analytical solution. $K$ is the dimensionless heat loss parameter considering radiation and convection heat loss. The three types of heat loss mechanisms in flame propagation were discussed in Section 1. If the reaction rate constants are known, the flammability limit can be calculated based on the general method for flame speed as described in Ref. [97]. He concluded that the heat loss mechanism from the burned gas can explain the possible two flame speed and ultimately affect the flammability limit. It was predicted that the gas radiation effect was dominant if the bounding walls of the gas are too far away for convection heat loss to be effective. This theoretical prediction was further confirmed by numerical studies for one-dimensional, planar, premixed, and methane flame by Lakshmisha. He identified quantitatively that the convection relative to radiation gradually decreased with the tube diameter [81]. Figure 17 shows the burning velocity against the mixture ratio. Spalding suggested that the analytical calculation can predict the fact that flame will not be propagated below certain concentrations of fuel and oxygen (Figure 17c) as different to previous studies (Figure 17b) [97].

$$
\begin{gathered}
\frac{d^{2} \tau}{d \xi^{2}}=-\frac{\lambda}{\xi^{2}}\{\phi(\alpha, \tau)-K \psi(\tau)\} \\
\frac{d^{2} \alpha}{d \xi^{2}}=\frac{\lambda}{\xi^{2}} \phi(\alpha, \tau) \\
S_{u, c}=\frac{1}{c \rho_{u}} \sqrt{\frac{k_{b} L^{*}}{\left(T_{b}-T_{u}\right) K_{c} \lambda_{c}}}
\end{gathered}
$$

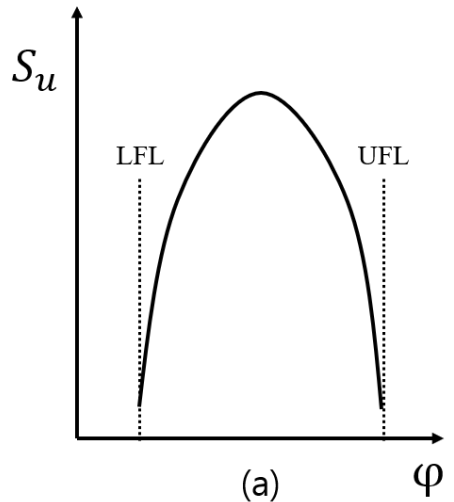

(a)

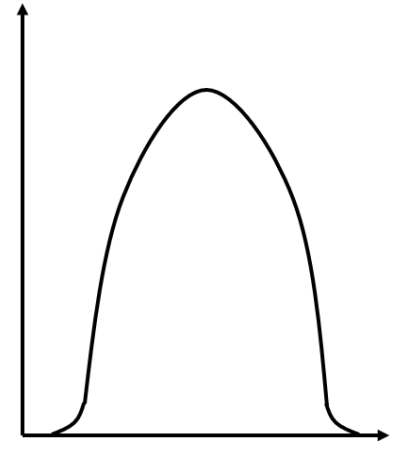

(b)

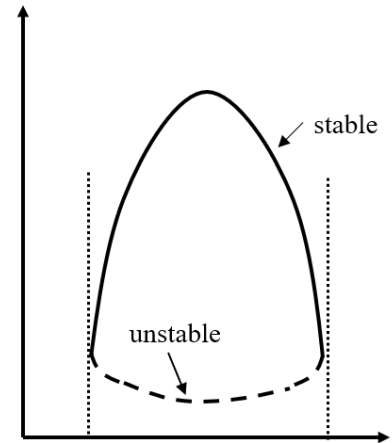

(c)

Figure 17. Burning velocity against equivalence ratio. (a) experimental findings, (b) prediction of previous studies neglecting heat loss, (c) prediction of Spalding's study. Reproduced from Ref. [97], The Royal Society: 1957.

Around the same time, Mayer proposed a flammability limit theory by analytical calculating the heat loss amount with the energy balance equation. Similar to the study of Spalding, he insisted that the flammability limit for propagating flame was determined by radiative heat loss unless the flame was propagated in a small diameter of the tube. In steady-state one-dimensional flame propagation, the temperature profile in the post-reaction zone can be calculated by solving Equation (42). Where $R$ is the volumetric heat loss rate determined by the effective thermal emissivity and temperature as shown in Equation (43). Mayer described that, on the left of Equation (42), the transport term is much greater than the conduction (diffusion) term for typical mass flow rates. The temperature gradient near the end of the reaction zone can be calculated by Equation (44). By multiplying the thermal conductivity, the conduction heat loss amount can be calculated as shown in Equation (45). The conduction 
mechanism is frequently called indirect radiation mechanism since it is ultimately caused by the radiation mechanism generating a negative temperature gradient. On the other hand, the amount of direct radiation can be calculated by Equation (46). $\delta$ is the flame thickness. He suggested that the direct radiation can be neglected as compared to the indirect radiation by the scaling analysis [10]. It is noted that the recent flame analyses including flame ball analysis also made the same conclusion [23].

$$
\begin{gathered}
\rho_{u} c_{p} S_{u} \frac{d T}{d x}-\frac{d}{d x} k \frac{d T}{d x}=-R \\
R=C^{a} T^{2}=4.1 \times 10^{-7} \cdot\left(p_{\mathrm{CO}_{2}}+0.18 p_{\mathrm{H}_{2} \mathrm{O}}\right) T^{2} \\
\left(\frac{d T}{d x}\right)_{x=x_{f}}=-\frac{R}{\rho_{u} c_{p} S_{u}} \\
q_{r a d, i}=k_{f} \frac{R}{\rho_{u} c_{p} S_{u}} \\
q_{r a d, d}=\int_{0}^{\delta} R_{r} d x
\end{gathered}
$$

The analytical procedure for predicting the flammability limit consists of solving the energy balance equation in Equation (47) with the tangency condition in Equation (48). Mayer expresses the energy balance equation with the dimensionless parameter as shown in Equation (49). $A$ is the radiation heat loss parameter and $\psi$ is the temperature defect $\left(T_{f}^{a}-T_{f}\right) / T_{f}^{a}$. The tangency condition obtained by differentiation of both sides of the energy balance equation with respect to $\psi$ can be combined with Equation (49) to arrive at an equation for the value of $\psi$ at the flammability limit as shown in Equation (50). The limiting radiation heat loss parameter $A$ can be determined with $\psi / G$. As a result, the diluent concentration limit as well as the limit of the effective thermal diffusivity can be obtained depends on the mixture conditions. Although these two 1950s studies cannot reflect the characteristics of propagating upward flame, it paves the path for a flammability limit theory based on thermal analysis [10].

$$
\begin{gathered}
q_{\text {loss }}\left(T_{f}^{a}, T_{f}\right)=q_{\text {rad }, i}\left(C^{a}, T_{f}\right) \\
\frac{d q_{\text {loss }}\left(T_{f}^{a}, T_{f}\right)}{d T_{f}}=\frac{d q_{r a d, i}\left(C^{a}, T_{f}\right)}{d T_{f}} \\
\psi \exp \left(-\frac{G}{1-\psi}\right)=A \frac{(1-\psi)^{2.75} \exp [G /(1-\psi)]}{(2 G)^{1.75}} \\
\frac{1}{\psi}+\frac{2.75}{1-\psi}-\frac{2 G}{(1-\psi)^{2}}=0
\end{gathered}
$$

Although almost thermal theory focused on the flammability limit due to heat loss, Lovachev dealt with the flame extinction mechanism by convection. The theoretical prediction of the flammability limit came through the calculation of the nonstationary energy balance equation. The basic energy balance equation was almost the same as the previous studies but does not include the heat loss amount. Since it is difficult to neglect the heat loss effects on flammability limit in general flame conditions, this theory was established for special flame conditions. He suggested that, at low pressures and greatly diluted mixtures, the flame can propagate at extremely lean fuel conditions in the absence of heat losses to the wall. It was theoretically observed that bromine-hydrogen flames will propagate at pressures down to $0.001 \mathrm{~atm}$ and to dilutions at which the flame velocity is less than $0.1 \mathrm{~cm} / \mathrm{s}$ [118]. By the approximate estimation of the mean temperature gradient with the energy balance equation, the flame thickness can be calculated by Equation (51). The rising velocity of a heated flame $\omega_{\infty}$ was calculated under the 
buoyancy force and the resistance force, assuming the sphere flame shape as shown in Equation (52). He assumed that the extension velocity of the heated sphere was equal to the rising velocity on the flame extinction condition. Then no change in the sphere radius $R$ will be observed in the system of coordinates. Finally, the fundamental flame velocity at the flammability limit can be derived by Equation (53) and hence the limiting composition and pressure for flame propagation in the given mixture can be estimated [119].

$$
\begin{gathered}
\delta=2 \lambda_{m} /\left(u_{0} \rho_{0} c p_{m}\right) \\
\omega_{\infty}^{2}=\frac{8}{3} R\left(1-\frac{\rho_{b}}{\rho_{0}}\right) \frac{g}{c_{w}} \\
\left(u_{0}\right)_{l i m}=2\left[\frac{2}{3} \frac{\lambda_{m}}{c \rho_{0} p_{m}}\left(1-\frac{\rho_{b}}{\rho_{0}}\right)\left(\frac{\rho_{b}}{\rho_{0}}\right)^{2} \frac{g}{c_{w}}\right]^{1 / 3}
\end{gathered}
$$

As flammability limits are wider than other orientation, practical considerations of fire safety focused on the upward propagation. Bregeon et al. noticed that the upward-moving flames were highly non-planar since the buoyance force rose the heated flame and consequently strongly subjected to flame stretch. However, the downward propagating flame can be very nearly planar and the number of perturbing physical influence thereby is reduced. It means that the fundamental flame analyses based on the planar flame can be further clarified with the downward propagating flames. For this reason, they measured the limiting nitrogen concentration of downward propagation in $\mathrm{H}_{2}-\mathrm{O}_{2}-\mathrm{N}_{2}$ mixtures by investigating the effects of conduction (indirect conduction) heat loss. They focused on the development of cellular flames during downward propagation and its impact on flame speeds and conductive loss [63]. They observed the cellular flames in lean hydrogen conditions and identified that the cellular pattern was more pronounced by reducing the molar ratio of hydrogen to oxygen. It was interesting that even a small difference in flammability limit by tube diameter was not confirmed under lean hydrogen condition as shown in Figure 18. They suggested that the downward propagation limit can be independent of tube diameter because conduction occurs from cells to their boundary gases, not a wall, through a mechanism whereby many cells are formed [64].

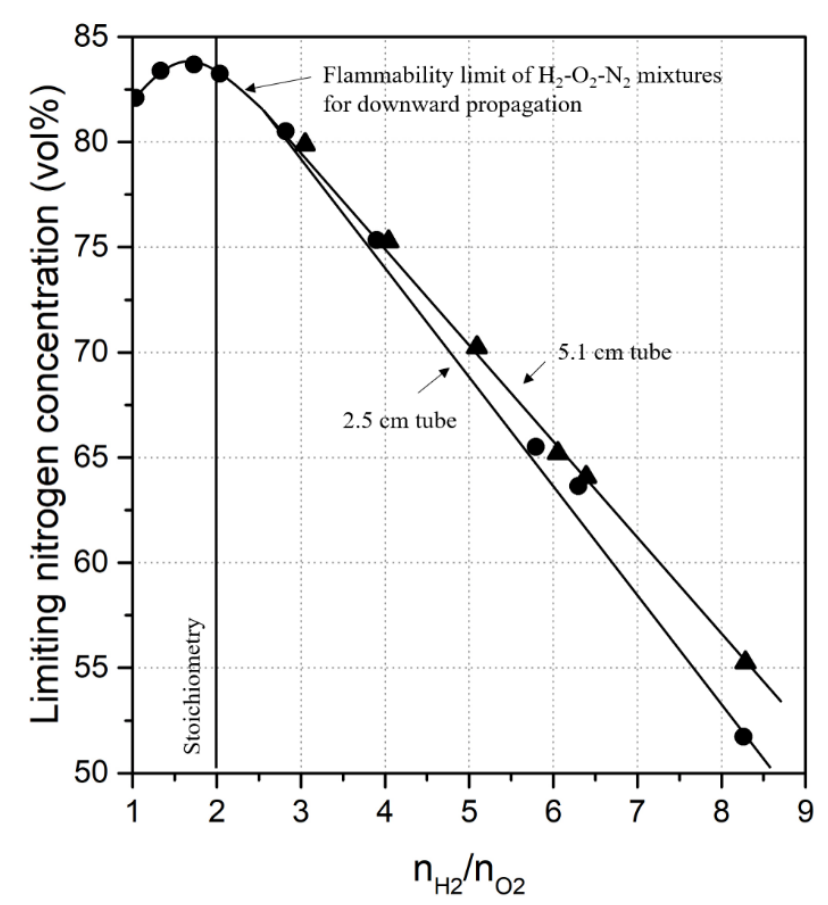

Figure 18. Limiting mole percent of nitrogen as a function of the hydrogen-oxygen ratio for downward propagation. Reproduced from Ref. [64], The Combustion Institute: 1978. 
To formulate a model for flammability limits based on the preceding mechanism, begin with the approximate formulas for flame thickness $\delta$ and flame speed $v$ as shown in Equations (54) and (55). It was known that the quenching distance of cellular flames for conductive heat loss is not dependent on the tube diameter but rather the cell size. Therefore, the flammability limit of the downward flame is corresponding with a cell size $d$ which is proportional to $\delta$. Finally, the flammability limit condition was derived by Equation (56). Within the accuracy of the experimental data, the limit condition of $v d / \alpha$ was estimated at 5.7 [64]. However, it is difficult to measure the cell size for each mixture condition. This study emphasized that understanding the nature of propagating flames is important for predicting the flammability limit regardless of propagating orientations.

$$
\begin{gathered}
\delta=\sqrt{\lambda /\left(c_{p} w\right)} \\
v=\sqrt{\left(\lambda / c_{p}\right) w / \rho} \\
v d>k \alpha
\end{gathered}
$$

In the 1980s, the stretch theory began to explain the mechanism of flammability limit in place of thermal theory. Lewis and von Elbe suggested that the non-planar flame is the key to understanding flammability limits. Buckmaster et al. developed a flammability limit model based on this idea [19]. Lewis and von Elbe noted that the rising buoyant volume of burned gas behind the flame will tend to displace the cold mixture ahead and generate a straining flow for upward propagating flames as shown in Figure 19 [110]. This flow divergence causes a continuous Lagrangian area increase of the flame hence Karlovitz proposed that the flame will be quenched if this stretch rate is large enough [71].

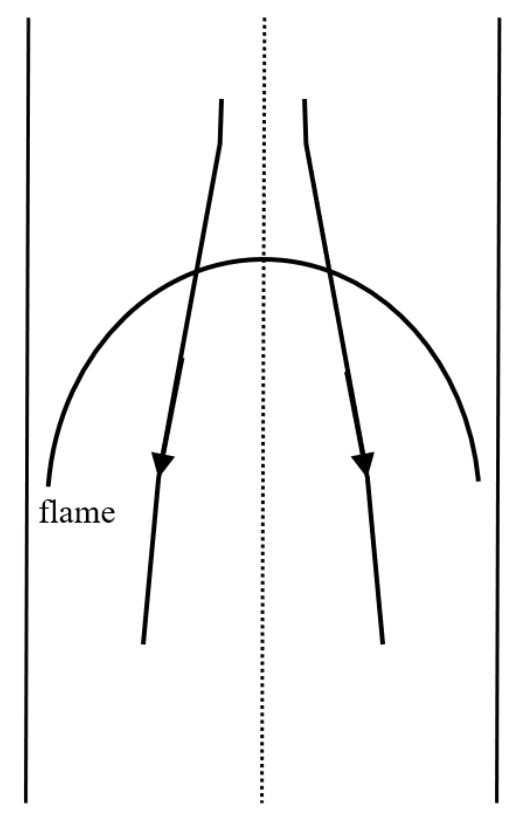

Figure 19. Straining flow is generated by rising hot gases. Reproduced from Ref. [19], The Combustion Institute: 1982.

In a mixture slightly below the flammability limit, a flame that is initiated with ignition propagates some distance up the tube but promptly disappears. After the flame extinction occurs, the tube contains two bodies of gas, cold unburned gas and hot burned gas. Subsequently, the burned gas will rise in the tube extruding the fresh mixture, as an air bubble rising in a tube of water. On the other hand, the flame can propagate far from the ignition source in a mixture slightly exceeding the limit. Buckmaster et al. remarked that the rise speeds are similar before and after extinction by experimental observations. Based on these observations, they predicted the flammability limit by comparing the 
local straining rate of quenched flame in Equation (57) and the rate $\beta_{c}$ which reduces the flame speed to zero in a simple straining flow in Equation (58). is the mass fraction of fresh unburned gas, $T$ is the temperature of fresh unburned gas. By equating the two straining rates, a simple criterion for flame propagation was derived in Equation (59). $Q_{t}$ is the adiabatic flame speed and $\delta$ is the flame thickness [19]. As mentioned, it is difficult to predict the LFL of hydrogen mixture by models that consider only the stretch effect, excluding the heat loss effect.

$$
\begin{gathered}
\frac{q_{s}}{s}=\sqrt{\frac{2 g}{(0.7) D}} \\
\beta_{c}=\frac{\pi}{4} \exp \left(\frac{-Y_{-\infty} \lambda_{1}}{2\left(Y_{-\infty}+T_{-\infty}\right)^{2}}\right) \\
\sqrt{\frac{2 g}{(0.7) D}} \leq \frac{Q_{t}}{\delta} \frac{\pi}{4} \exp \left(\frac{-Y_{-\infty} \lambda_{1}}{2\left(Y_{-\infty}+T_{-\infty}\right)^{2}}\right)
\end{gathered}
$$

After the Three Mile Island (TMI) Unit 2 accident, considerable interest was drawn to computational analyses for the threat of hydrogen combustion. Ural et al. calculated containment pressure during the postulated TMI Unit 2 accident using a simple flammability limit model based on burning velocity criterion [120]. He noticed that the burning velocity has a critical value since the energy generation rate by combustion is proportional to the burning velocity. Based on the Frank-Kamenetskii formulation, the critical burning velocity for flame quenching is predicted by Equation (60) [121]. $S_{T_{A D}}$ is the adiabatic total burning velocity. The adiabatic burning velocity equation can be calculated as shown in Equation (61). $S_{L_{A D}}$ is the adiabatic laminar burning velocity determined by hydrogen concentration, steam concentration, and unburned gas temperature (Liu and MacFarlane correlations [122]). Each burning velocity term was calculated by a separate correlation as described in Ref. [120]. As suggested by Crescitelli et al. and others [121,123,124], the decrease of burning velocity can be calculated by the one-step Arrhenius reaction rate relationship as shown in Equation (62). They assumed that the burned gas and unburned gas are mixed instantly when queening occurs at criterion in Equation (60).

$$
\begin{gathered}
\frac{S_{T}^{*}}{S_{T_{A D}}}=e^{-1 / 2} \\
S_{T_{A D}}=S_{L_{A D}}+u_{F A N}^{\prime}+u_{S p r a y s}^{\prime}+u_{F I T}^{\prime} \\
S_{T}(T)=S_{T_{A D}} \exp \left[\frac{E}{2 R} \frac{T_{A D}-T}{T_{A D} T}\right]
\end{gathered}
$$

Ural et al. compared the calculated overpressures with various combustion tests as well as TMI Unit 2 accident data. Although the calculated results agreed quite well with the measured values, this agreement required specific values of the empirical correction factor in certain cases. He noted that this limitation was particularly caused by the simplifying assumptions in the flame quenching/flammability [120]. As discussed in Section 2.1, most nuclear reactor accident analysis code of system-level such as MAAP developed by Fauske and Associates Inc. and MELCOR by Sandia National Laboratories still rely on these experimental results. The HyRAM 2.0 developed by Sandia National Laboratories for investigating hydrogen hazards' impact in various hydrogen-related facilities like hydrogen refueling stations also predicts the hydrogen gas flammability by the experimental results [125].

However, the catastrophic experience of the Fukushima accident in 2011 underlined the limitation of the current prediction method of hydrogen flammability which significantly relied on experimental results [126]. Especially, the molten corium-concrete interaction (MCCI) in a nuclear reactor can generate non-condensable gases [52]. It means that the types of hydrogen mixture which need to 
be analyzed in accident analysis is significantly increased. Hydrogen is a promising energy source for transportation and the research related to the hydrogen-fuel infrastructure is being vigorously explored in many countries including South Korea [2]. As the industry of hydrogen energy expands, risk analysis in various hydrogen gas type will be further required. In conclusion, a widely reliable model for predicting hydrogen flammability is still demanding.

For this reason, there were several attempts to improve the CAFT method by considering the heat loss mechanism of actual flame propagation. There are three types of heat loss mechanism in flame propagation as discussed in Section 1, convection, conduction (indirect radiation), and radiation. Liaw et al. proposed a model for predicting the variation of flammability limit derived from the energy balance equation including direct radiation heat loss. The radiation heat loss per mole of the combustible mixture was calculated by Equation (63). Where $\alpha$ is the radiation heat transfer surface area efficiency factor, $e$ is the emissivity, $\sigma$ is the Stephan-Boltzmann constant. They carried out the scaling analysis and determined the maximum value of $\alpha e A \sigma \Delta t$ to approximately $10^{-8} \mathrm{~J} / \mathrm{K}^{4} \cdot \mathrm{mol}$. The heat loss effect on the estimated flammability limits was analyzed for various fuels including hydrogen. They concluded that the prediction differences of LFLs by heat loss effect are negligible for the 11 fuel types [127]. This small difference is acceptable since the heat loss amount by direct radiation can be ignored compared to indirect radiation [10]. Zhao et al. proposed a calculated flame temperature (CFT) model where the basic principle was nearly identical to Liaw's model. They calculated the flame temperature considering not only direct radiation heat loss but convective heat loss. The convection heat loss can be calculated using Equation (64). Where $\alpha$ is heat loss effectiveness factor, $h_{\text {in }}$ is convective heat transfer coefficient, $L$ is flame propagation distance from ignition source to the thermistor. However, it is known that heat losses to the wall are negligible for axisymmetric flames propagating in tubes over $2 \mathrm{~cm}$ in diameter [24]. Turns noted that the indirect radiation (conduction) heat loss can account for the LFL of gas mixtures [17].

$$
\begin{gathered}
Q_{r}=\alpha e A \sigma\left(T_{L}^{4}-T_{i}^{4}\right) \Delta t \\
Q_{c}=\alpha h_{i n} 2 \pi R_{i} L\left(T_{f}-T_{i n}\right) \Delta t
\end{gathered}
$$

Recently, a calculated non-adiabatic flame temperature (CNAFT) model was developed to advance the existing CAFT approach, especially for hydrogen mixtures. This model includes a one-dimensional analysis of propagating flame to consider the heat loss mechanisms for predicting LFL. The flame analysis was focused on the thermal behavior of the reaction zone to estimate the heat loss amount during upward propagation. They suggested that the indirect radiation was dominant for determining the LFL of hydrogen mixtures. The amounts of indirect radiation heat loss depended on the heat transfer characteristics of each mixture condition and the amount can be estimated by the CNAFT coefficient $\pi$. The coefficient is calculated by dividing thermal diffusivity by molar concentration [11,41]. To confirm whether the coefficient can represent the amount of heat loss during flame propagation, the hydrogen mixtures were divided into two groups by magnitude of the CNAFT coefficient. Figure 20 shows the average relative error for the LFL prediction by the CAFT model. It should be noted that the tendency in CAFT model accuracy was significantly different depending on the CNAFT coefficient group. While all of the mixtures in the first group having a lower coefficient has a less than $6 \%$ relative error, the second group has a maximum relative error close to $40 \%$ [11]. These discrepancies further increase for the H2-air-steam mixtures [41].

By obtaining the coefficient of a mixture for which the LFL is not known experimentally, the CNAFT value can be calculated using Equation (65) [11,41]. The initial hydrogen and steam concentration were multiplied for reflection of increasing of thermal radiation rate based on optically thin approximation [43]. The threshold peak temperature during flame propagation is proportional to the CNAFT. Finally, the hydrogen concentration corresponding to the CNAFT value of $610 \mathrm{~K}$ is determined as the predicted limit concentration by the CNAFT model with optical thin approximation. Figure 21 shows the improved accuracy of the CNAFT model by comparing with the various experimental 
results. More detailed description of the model can be found in Ref. [11,41]. The fundamental reason for the reasonable accuracy of the CNAFT model seems to be that hydrogen flame has a much lower Lewis number than hydrocarbon fuel including methane. As discussed in Section 3.1, the extinction of hydrogen flame $(L e<1)$ proceeds as the trailing edges on both sides become shorter since the local burning intensity is focused at the flame tip due to strong preferential mass diffusion. This process is totally different from the extinction of methane flame at flame tip understood by the stretch extinction limit. It means that the balance of generated combustion heat and heat loss on the trailing edge can determine whether a flame continuously propagates for hydrogen flames [41].

$$
\begin{aligned}
& \sum_{\text {reactants }} n_{i}\left[\Delta H_{f, i}^{0}+\bar{c}_{p, i}\left(T_{i}-T_{\text {ref }}\right)\right]-\sum_{\text {products }} n_{i}\left[\Delta H_{f, i}^{0}+\bar{c}_{p, i}\left(T_{C N A F T}-T_{\text {ref } f}\right)\right] \\
& =\left\{\begin{array}{cc}
C_{1}\left(\pi-\pi_{r e f}\right) & \text { for }\left[X_{H_{2} O}\right]_{\text {reactants }}=0 \\
C_{1}\left(\pi-\pi_{r e f}\right) \cdot\left(\frac{X_{H_{2}, \text { in }}+X_{\text {steam, in }}}{X_{\text {steam,ref }}}\right) & \text { for }\left[X_{H_{2} O}\right]_{\text {reactants }}>0
\end{array}\right.
\end{aligned}
$$

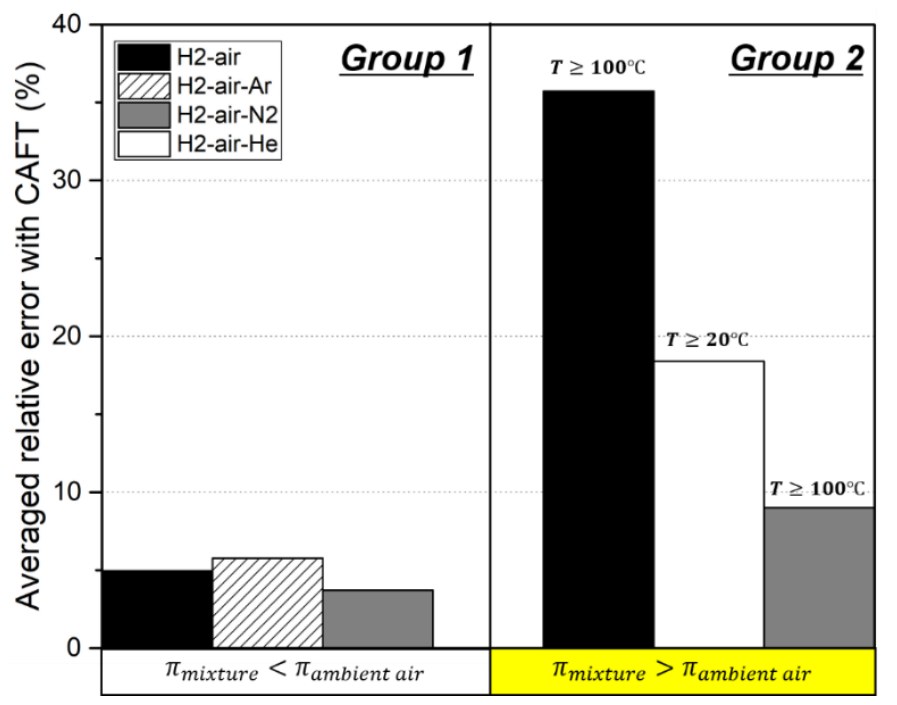

Figure 20. Classification of mixtures according to CNAFT coefficient to confirm the deterministic effects on heat loss mechanism, Reproduced from Ref. [11], Korean Nuclear Society: 2019.

As discussed in Section 2.4, Wierzba et al. identified that the CAFT model has less accuracy for the LFL prediction of $\mathrm{H}_{2} / \mathrm{CO}$ binary fuel, unlike UFL [7]. Recently, Kim et al. suggested that the combination of the CAFT model and the CNAFT model based on Le Chatelier's law can improve the LFL prediction accuracy [54]. As shown in Equation (66), a flammability limit of a binary mixture can be predicted by Le Chatelier's law if each fuel limit was predicted considering the mixture condition. Although there are many historical attempts to predict the flammability limit of the binary fuel based on Le Chatelier's law, the narrow applicable mixture range was the limitation due to dependence on the experimental results. The detailed review of the previous studies was well described in Ref. [54]. Therefore, Kim et al. predicted $L F L_{H_{2}}$ by CNAFT model, while the $L F L_{\mathrm{CO}}$ was predicted using the CAFT model. The accuracy of the methodology was verified using various experimental data relevant to nuclear reactor accident conditions. For example, the methodology shows good agreement with the measured LFL by Kilchyk as shown in Figure 22 [54].

$$
\frac{1}{L F L_{\text {mix }}}=\frac{1}{L F L_{\mathrm{CO}}}+\frac{1}{L F L_{\mathrm{H}_{2}}}
$$




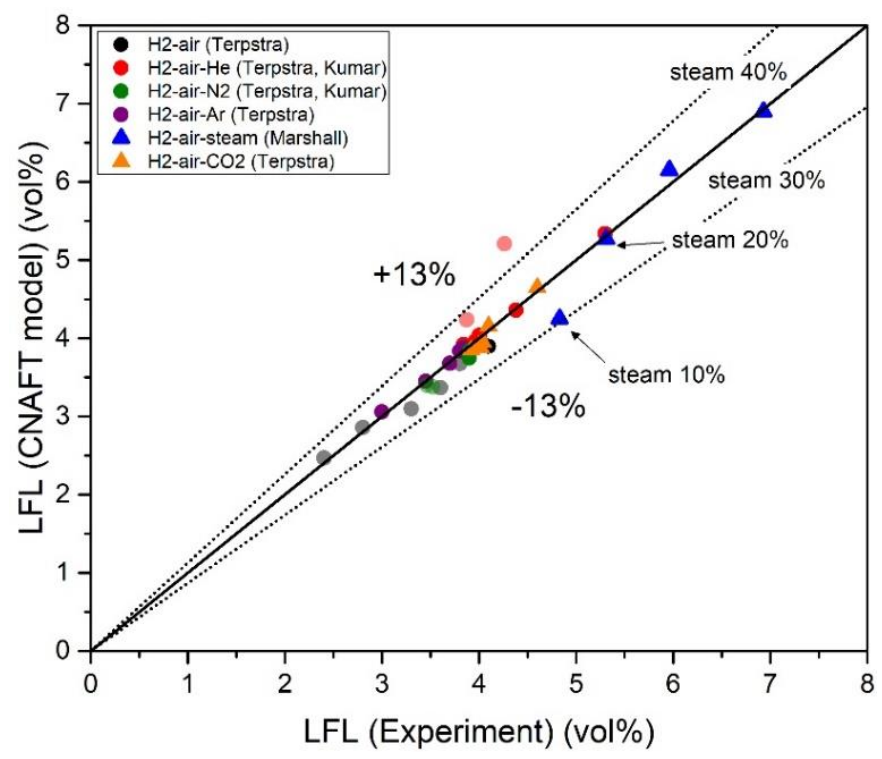

Figure 21. Validation of CNAFT model for various mixtures. The maximum relative error was analyzed as 13\%. Reproduced from Ref. [11], Korean Nuclear Society: 2019.

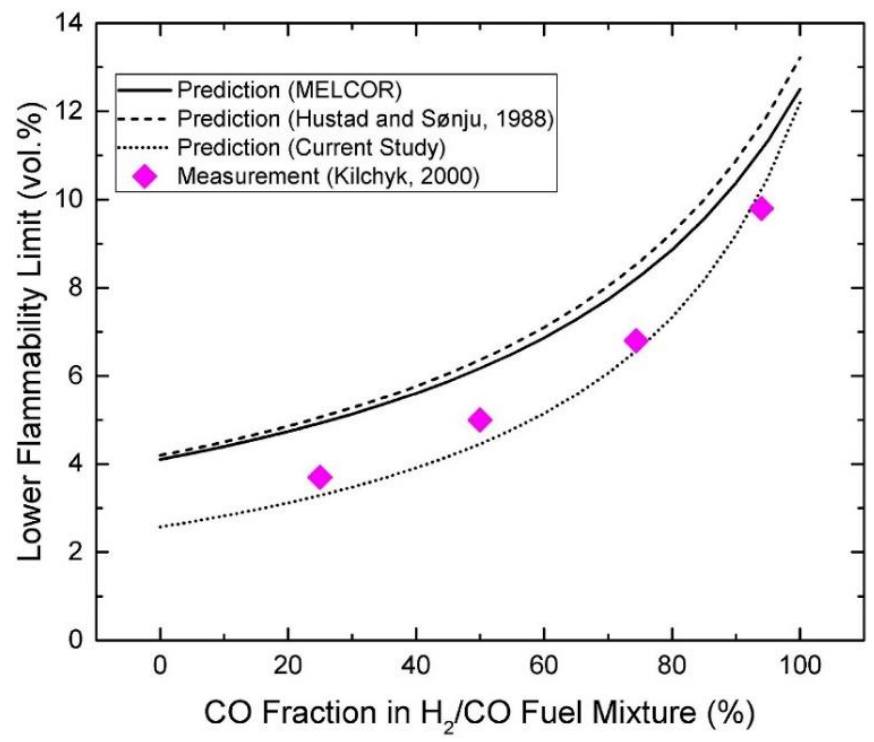

Figure 22. LFL as a function of $\mathrm{CO}$ fraction in the $\mathrm{H}_{2} / \mathrm{CO}$ mixtures in the air at 1 bar and $150{ }^{\circ} \mathrm{C}$ [54].

\subsection{Flame Ball Analyses}

Matsukov et al. observed that an unstable cellular flame is developed for mixtures with $\mathrm{Le}<1$ while a stable smooth flame is generated for $L e>1$ mixture by Schlieren photos [128]. The cellular flame propagation had been theoretically discussed by numerous authors including Markstein [63,129,130]. Especially for very lean hydrogen mixtures, the generated strongly cellular flames seem an array of flame balls which burns as if each one is isolated [23]. For this reason, previous studies deduced that the flame ball analysis can lead to an improved understating of hydrogen flammability limit [20]. As discussed in Section 2.5, the existence of non-propagating steady spherical flame balls was first predicted theoretically by Zeldovich [59]. Ronney et al. experimentally identified that flame ball can be generated at low gravity when buoyancy effects are small [61]. Buckmaster et al. described that generating the stationary flame-balls was possible with a near-limit mixture, small Lewis number, and heat loss mechanisms [20]. 
The existence of stabilized flame-ball is important because previous analytical studies for flammability were mainly conducted through steady planar flame as discussed in Section 4.2. The main reason for assuming the steady planar flame is that there are too many physical phenomena in freely propagating flame. The analysis in upward flame due to the buoyance force should include the flow characteristics near the flame which ultimately affects the heat loss mechanisms as well as the stretch effect and the Lewis number effect. Therefore, many studies have focused on a dominant mechanism in freely propagating flame or considered flame physics based on a steady planar flame, for effectively predicting flammability limit. The stabilized flame ball made it possible to improve understanding of flammability limit while time-independent properties enable analytical modeling. The progress in flame ball analysis to investigate the flammability limit and near-limit phenomena was detailed in Ref. [12]. In this paper, a recent analytical model of flammability limit using the stabilized flame ball concept was briefly introduced.

As discussed in Section 4.1, the temperature at the reaction layer of radiation neglected flame ball can be estimated by Equation (28). In the one-step approximation of chemical kinetics, the peak temperature lower than the crossover temperature $T_{c}$ causes the disappearance of the radicals, leading to $\omega=0$ [23]. Since the peak temperature occurs at the reaction layer where $\widetilde{Y}_{H_{2}}=0$, the kinetically controlled LFL concentration where the peak temperature reaches the $T_{c}$ can be estimated in Equation (67). The $T_{\mathcal{c}}$ can be computed from Equation (68) with the one-step reduced mechanism. $k_{i}$ is the rate constant of reaction $i$. The effective third-body efficiency $C_{M}$ depends on the steam mass fraction at the reaction zone as shown in Equation (69) [80].

$$
\begin{gathered}
Y_{\mathrm{H}_{2} u, \text { limit }}=-\frac{k}{\rho \widetilde{D}_{\mathrm{H}_{2}}} \frac{M_{\mathrm{H}_{2}}}{\Delta H_{f, \mathrm{H}_{2} \mathrm{O}}^{0}}\left(T_{c}-T_{u}\right) \\
k_{1 f}=k_{4 f} C_{M} \\
C_{M}=\frac{p}{R T}\left(1+15 Y_{\mathrm{H}_{2} \mathrm{O}_{r}} \frac{w}{w_{\mathrm{H}_{2} \mathrm{O}}}\right)
\end{gathered}
$$

The steam mass fraction at the reaction zone can be calculated based on the species conservation equation in Equation (70). If we can assume the constant value of mass diffusivity for each gas, Equation (70) can be integrated as shown in Equation (71). It means that the steam mass fraction can be calculated by mass fractions of the unburned fresh mixture in Equation (72).

$$
\begin{gathered}
\frac{1}{r^{2}} \frac{d}{d r}\left(\frac{\rho D_{\mathrm{O}_{2}}}{M_{\mathrm{O}_{2}}} r^{2} \frac{d Y_{\mathrm{O}_{2}}}{d r}\right)=-\frac{1}{r^{2}} \frac{d}{d r}\left(\frac{\rho D_{\mathrm{H}_{2} \mathrm{O}}}{2 M_{\mathrm{H}_{2} \mathrm{O}}} r^{2} \frac{d Y_{\mathrm{H}_{2} \mathrm{O}}}{d r}\right)=\frac{1}{r^{2}} \frac{d}{d r}\left(\frac{\rho \widetilde{D}_{\mathrm{H}_{2}}}{2 M_{\mathrm{H}_{2}}} r^{2} \frac{d \widetilde{Y}_{\mathrm{H}_{2}}}{d r}\right)=\omega \\
Y_{\mathrm{H}_{2} \mathrm{O}}-Y_{\mathrm{H}_{2} \mathrm{O}_{u}}=2 \frac{M_{\mathrm{H}_{2} \mathrm{O}}}{M_{\mathrm{O}_{2}}} \frac{D_{\mathrm{O}_{2}}}{D_{\mathrm{H}_{2} \mathrm{O}}}\left(Y_{\mathrm{O}_{2 u}}-Y_{\mathrm{O}_{2}}\right)=\frac{M_{\mathrm{H}_{2} \mathrm{O}}}{M_{\mathrm{H}_{2}}} \frac{\widetilde{D}_{\mathrm{H}_{2}}}{D_{\mathrm{H}_{2} \mathrm{O}}}\left(Y_{\mathrm{H}_{2 u}}-\widetilde{Y}_{\mathrm{H}_{2}}\right) \\
\frac{Y_{\mathrm{H}_{2} \mathrm{O} \mathrm{r}}-Y_{\mathrm{H}_{2} \mathrm{O}_{u}}}{Y_{\mathrm{H}_{2 u}}}=\frac{M_{\mathrm{H}_{2} \mathrm{O}}}{M_{\mathrm{H}_{2}}} \frac{\widetilde{D}_{\mathrm{H}_{2}}}{D_{\mathrm{H}_{2} \mathrm{O}}}
\end{gathered}
$$

As a result, the LFL can be evaluated through the sequential calculation of Equations (67)-(69) and Equation (72). For a hydrogen-air mixture at normal temperature and pressure, the LFL was evaluated to be about $2.4 \mathrm{vol} \%(\varphi=0.06)$ [23]. Compared with their predicted value of $9.5 \mathrm{vol} \%$ ( $\varphi=0.251)$ by planar flame analysis with the one-step reduced mechanism, the analytical model shows improved accuracy for the experimental results (4.1 vol\%). Fernandez-Tarrazo described that the model can be improved by using the turning point analysis as discussed in Section 3.2. This further study included radiation heat loss in the far-field. They suggested that radiation could be negligible in the near-field where the volumetric heat losses due to conduction are about twenty times greater than those associated with radiation. The importance of radiation emerges in the far-field, affecting the temperature profile towards the ambient temperature. The turning point analysis predicted the 
LFL about $3.0 \mathrm{vol} \%$ [23]. Figure 23 shows the predicted LFL by these two analytical models with FITS experiments. The presence of steam in the atmosphere increases the LFL by increasing influences of radiation heat loss as similar to experimental results. Strehlow et al. observed the near limit flame propagation of methane and propane at gravity levels that ranged from $0.01 \mathrm{~g}$ to $0.17 \mathrm{~g}$. Although the fuel type is different from hydrogen, they noticed that the extinguishment process is significantly different between zero $g$ and one $g$ [131]. As the analysis of the stabilized flame ball corresponds to a zero-gravity environment, it is difficult to predict the exact LFL in general except possibly in a spacecraft environment.

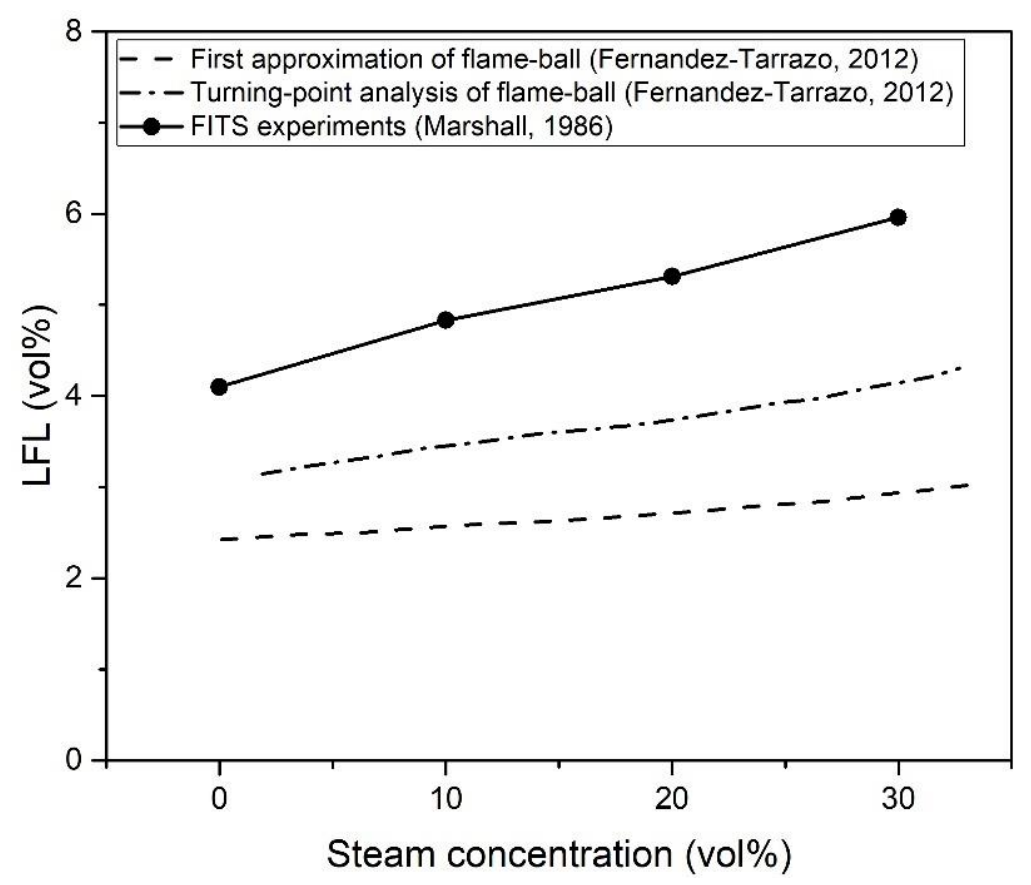

Figure 23. Predicted LFL by two analytical models based on flame ball analysis. The increase of LFL can be explained by the increasing influences of radiation. Reproduced from Ref. [23], Hydrogen Energy Publications, LLC: 2011.

\section{Concluding Remarks}

Many countries including South Korea being considered hydrogen as a promising energy source to contribute to addressing the energy challenges facing the Earth. The knowledge concerning hydrogen flammability is essential to ascertain the safe use of hydrogen energy including production, storage, and transportation. In this paper, we have provided a comprehensive review of the studies for predicting hydrogen flammability by dividing it into three types: experimental, numerical, and analytical. While the earlier experimental studies had focused only on measuring limit concentration, recent studies have been conducted to thoroughly clarify the extinction mechanism of a hydrogen flame. In numerical studies, the continued advances in computer performance enabled even multi-dimensional stretched flame analysis following one-dimensional planar flame analysis. Finally, historical attempts to predict the limit concentration by analytical modeling of flammability characteristics were discussed. As shown in Figure 24, to analyze the upward propagating flames, more physical phenomena should be considered than the theoretical stationary planar flame. For example, the Lewis number effect (preferential diffusion) has a great influence on the local burning intensity along the flame front. Furthermore, each phenomenon is interrelated to another phenomenon. The stretch extinction at the flame tip has been understood with the flow characteristics and the heat loss mechanisms (convection, conduction, radiation) near the flame. Recent studies tried to propose dominant physical phenomena in LFL prediction and develop practical analytical models. Although developed models 
have been successfully predicted LFL at NTP, vigorous studies are still needed especially for multiple diluent conditions.

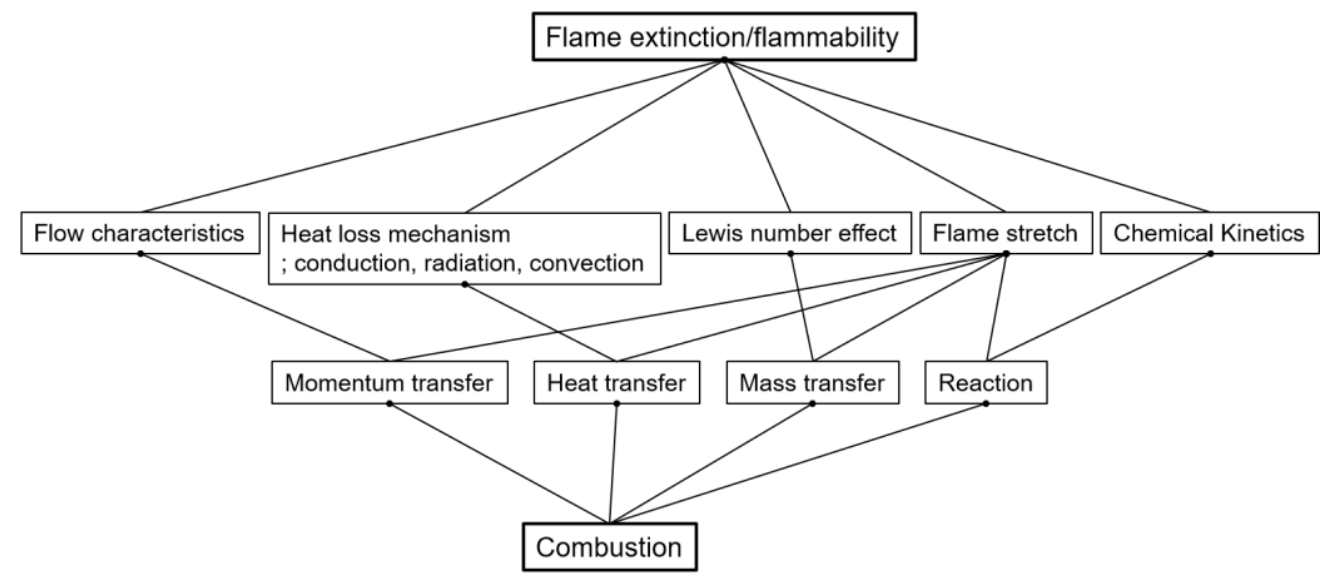

Figure 24. Synopsis of relations between the combustion phenomena and flammability limit. The lean limit flame characteristics according to fuel type should be thoroughly investigated to identify the dominant phenomena and develop a useful analytical model.

Author Contributions: Conceptualization, J.J. and S.J.K.; methodology, J.J. and S.J.K.; software, J.J.; validation, J.J. and S.J.K.; formal analysis, J.J. and S.J.K.; investigation, J.J. and S.J.K.; resources, J.J. and S.J.K.; data curation, J.J. and S.J.K.; writing—original draft preparation J.J.; writing—review and editing, S.J.K.; supervision, S.J.K.; project administration, S.J.K.; funding acquisition, S.J.K. All authors have read and agreed to the published version of the manuscript.

Funding: This work was supported by the National Research Foundation of Korea (NRF) funded by the Ministry of Science, ICT \& Future Planning (MISP) [grant number NRF-2017M2A8A4018213] and by the Nuclear Safety Research Program through the Korea Foundation of Nuclear Safety (KOFONS) using the financial resource granted by the Nuclear Safety and Security Commission (NSSC) of the Republic of Korea (grant number 2003006-0120-CG100).

Conflicts of Interest: The authors declare no conflict of interest.

\section{References}

1. Fuel Cells and Hydrogen Joint Undertaking (FCHJU). Hydrogen Roadmap Europe; Fuel Cells and Hydrogen Joint Undertaking: Bietlot, Belgium, 2019.

2. Kim, J.H.; Kim, H.J.; Yoo, S.H. Willingness to pay for fuel-cell electric vehicles in South Korea. Energy 2019, 174, 497-502. [CrossRef]

3. Molnarne, M.; Schroeder, V. Hazardous properties of hydrogen and hydrogen containing fuel gases. Process Saf. Environ. 2019, 130,1-5. [CrossRef]

4. Kim, N.K.; Jeon, J.; Choi, W.; Kim, S.J. Systematic hydrogen risk analysis of OPR1000 containment before RPV failure under station blackout scenario. Ann. Nucl. Energy 2018, 116, 429-438. [CrossRef]

5. Sarikurt, F.S.; Hassan, Y.A. Large eddy simulations of erosion of a stratified layer by a buoyant jet. Int. J. Heat Mass Trans. 2017, 112, 354-365. [CrossRef]

6. Bauer, C.; Forest, T. Effect of hydrogen addition on the performance of methane-fueled vehicles. Part I: Effect on SI engine performance. Int. J. Hydrogen Energy 2001, 26, 55-70. [CrossRef]

7. Wierzba, I.; Kilchyk, V. Flammability limits of hydrogen-carbon monoxide mixtures at moderately elevated temperatures. Int. J. Hydrogen Energy 2001, 26, 639-643. [CrossRef]

8. Nikolaidis, P.; Poullikkas, A. A comparative overview of hydrogen production processes. Renew. Sustain. Energy Rev. 2017, 67, 597-611. [CrossRef]

9. Ciccarelli, G.; Dorofeev, S. Flame acceleration and transition to detonation in ducts. Prog. Energy Combust. 2008, 34, 499-550. [CrossRef]

10. Mayer, E. A theory of flame propagation limits due to heat loss. Combust. Flame 1957, 1, 438-452. [CrossRef] 
11. Jeon, J.; Choi, W.; Kim, S.J. A flammability limit model for hydrogen-air-diluent mixtures based on heat transfer characteristics in flame propagation. Nucl. Eng. Technol. 2019, 51, 1749-1757. [CrossRef]

12. Sánchez, A.L.; Williams, F.A. Recent advances in understanding of flammability characteristics of hydrogen. Prog. Energy Combust. 2014, 41, 1-55. [CrossRef]

13. Von Lavante, E.; Strehlow, R.A. The mechanism of lean limit flame extinction. Combust. Flame 1983, 49, 123-140. [CrossRef]

14. Coward, H.F.; Jones, G.W. Limits of Flammability of Gases and Vapors; Bureau of Mines: Washington, DC, USA, 1952.

15. Terpstra, M. Flammability Limits of Hydrogen-Diluent Mixtures in Air. Master's Thesis, University of Calgary, Calgary, AB, Canada, 2012.

16. Zhou, Z.; Shoshin, Y.; Hernández-Pérez, F.E.; Van Oijen, J.A.; De Goey, L.P. Experimental and numerical study of cap-like lean limit flames in $\mathrm{H}_{2}-\mathrm{CH}_{4}$-air mixtures. Combust. Flame 2018, 189, 212-224. [CrossRef]

17. Bentaib, A.; Meynet, N.; Bleyer, A. Overview on hydrogen risk research and development activities: Methodology and open issues. Nucl. Eng. Technol. 2015, 47, 26-32. [CrossRef]

18. Hernández-Pérez, F.E.; Oostenrijk, B.; Shoshin, Y.; Van Oijen, J.A.; De Goey, L.P. Formation, prediction and analysis of stationary and stable ball-like flames at ultra-lean and normal-gravity conditions. Combust. Flame 2015, 162, 932-943. [CrossRef]

19. Buckmaster, J.; Mikolaitis, D. A flammability-limit model for upward propagation through lean methane/air mixtures in a standard flammability tube. Combust. Flame 1982, 45, 109-119. [CrossRef]

20. Buckmaster, J.; Smooke, M.; Giovangigli, V. Analytical and numerical modeling of flame-balls in hydrogen-air mixtures. Combust. Flame 1993, 94, 113-124. [CrossRef]

21. Fernández-Galisteo, D.; Sánchez, A.L.; Liñán, A.; Williams, F.A. The hydrogen-air burning rate near the lean flammability limit. Combust. Theory Model 2009, 13, 741-761. [CrossRef]

22. Zhou, Z.; Shoshin, Y.; Hernandez-Perez, F.E.; Van Oijen, J.A.; De Goey, L.P. Effect of Lewis number on ball-like lean limit flames. Combust. Flame 2018, 188, 77-89. [CrossRef]

23. Fernández-Tarrazo, E.; Sánchez, A.L.; Liñán, A.; Williams, F.A. Flammability conditions for ultra-lean hydrogen premixed combustion based on flame-ball analyses. Int. J. Hydrogen Energy 2012, 37, 1813-1825. [CrossRef]

24. Kazakov, K.A. Premixed flame propagation in vertical tubes. Phys. Fluids 2016, 28, 042103. [CrossRef]

25. White, A.G. Limits for the propagation of flame in inflammable gas-air mixtures. Part I. Mixtures of air and one gas at the ordinary temperature and pressure. J. Chem. Soc. 1924, 125, 2387-2396. [CrossRef]

26. Egerton, A.C.; Powling, J. The limits of flame propagation at atmospheric pressure II. The influence of changes in the physical properties. Proc. R. Soc. Lond. A 1948, 193, 190-209.

27. Jones, G.W. Inflammability of Mixed Gases; US Government Printing Office: Washington, DC, USA, 1929.

28. Burgoyne, J.; Williams-Leir, G. The influence of incombustible vapours on the limits of inflammability of gases and vapours in air. Proc. R. Soc. Lond. A 1948, 193, 525-539.

29. Clusius, K.; Gutschmidt, H. Die untere Explosionsgrenze der Gemische von schwerem Wasserstoff mit Luft. Naturwissenschaften 1934, 22, 693. [CrossRef]

30. Payman, W. The propagation of flame in complex gaseous mixtures. Part I. Limit mixtures and the uniform movement of flame in such mixtures. J. Chem. Soc. 1919, 115, 1436-1445. [CrossRef]

31. Van Den Schoor, F. Influence of Pressure and Temperature on Flammability Limits of Combustible Gases in Air. Ph.D. Thesis, Katholieke Universiteit Leuven, Flanders, Belgium, 2007.

32. Scott, F.; Van Dolah, R.; Zabetakis, M. The flammability characteristics of the system $\mathrm{H}_{2}-\mathrm{NO}-\mathrm{N}_{2} \mathrm{O}-\mathrm{Air}$. Proc. Combust. Inst. 1957, 6, 540-545. [CrossRef]

33. Shebeko, Y.N.; Iliin, A.; Ivanov, A. An experimental investigation of flammability limits in mixtures of hydrogen-oxygen-diluent. J. Chem. Soc. 1984, 58, 862-865.

34. Kumar, R. Flammability limits of hydrogen-oxygen-diluent mixtures. J. Fire Sci. 1985, 3, 245-262. [CrossRef]

35. Marshall, B.W. Hydrogen: Air: Steam Flammability Limits and Combustion Characteristics in the FITS Vessel; Sandia National Laboratories: Albuquerque, NM, USA, 1986.

36. Hustad, J.E.; Sønju, O.K. Experimental studies of lower flammability limits of gases and mixtures of gases at elevated temperatures. Combust. Flame 1988, 71, 283-294. [CrossRef] 
37. Shebeko, Y.N.; Tsarichenko, S.G.; Korolchenko, A.Y.; Trunev, A.V.; Navzenya, V.Y.; Papkov, S.N.; Zaitzev, A.A. Burning velocities and flammability limits of gaseous mixtures at elevated temperatures and pressures. Combust. Flame 1995, 102, 427-437. [CrossRef]

38. Ale, B.B. Flammability Limits of Gaseous Fuels and Their Mixtures in Air at Elevated Temperatures. Ph.D. Thesis, University of Calgary, Calgary, AB, Canada, 1998.

39. Liu, X.; Zhang, Q. Influence of initial pressure and temperature on flammability limits of hydrogen-air. Int. J. Hydrogen Energy 2014, 39, 6774-6782. [CrossRef]

40. Hu, X.; Xie, Q.; Zhang, J.; Yu, Q.; Liu, H.; Sun, Y. Experimental study of the lower flammability limits of $\mathrm{H}_{2} / \mathrm{O}_{2} / \mathrm{CO}_{2}$ mixture. Int. J. Hydrogen Energy 2020, 45, 27837-27845. [CrossRef]

41. Jeon, J.; Kim, Y.S.; Jung, H.; Kim, S.J. A mechanistic analysis of $\mathrm{H}_{2} \mathrm{O}$ and $\mathrm{CO}_{2}$ diluent effect on hydrogen flammability considering flame extinction mechanism. Nucl. Eng. Technol. Under Review.

42. Satterly, J.; Burton, E. Combustibility of Mixtures of Hydrogen and Helium. Trans. R. Soc. Can. 1919, 13, 211-215.

43. Law, C.; Egolfopoulos, F. A unified chain-thermal theory of fundamental flammability limits. Proc. Combust. Inst. 1992, 24, 137-144. [CrossRef]

44. Kumar, R.; Tamm, H.; Harrison, W.C. Combustion of hydrogen-steam-air mixtures near lower flammability limits. Combust. Sci. Technol. 1983, 33, 167-178. [CrossRef]

45. Plys, M.G. Hydrogen production and combustion in severe reactor accidents: An integral assessment perspective. Nucl. Technol. 1993, 101, 400-410. [CrossRef]

46. Jeon, J.; Choi, W.; Kim, N.K.; Kim, S.J. Numerical investigation of in-vessel core coolability of PWR through an effective safety injection flow model using MELCOR simulation. Ann. Nucl. Energy 2018, 121, 350-360. [CrossRef]

47. Choi, W.; Yu, S.O.; Kim, S.J. Efficacy analysis of hydrogen mitigation measures of CANDU containment under LOCA scenario. Ann. Nucl. Energy 2018, 118, 122-130. [CrossRef]

48. Byun, C.; Jerng, D.; Todreas, N.; Driscoll, M. Conceptual design and analysis of a semi-passive containment cooling system for a large concrete containment. Nucl. Eng. Des. 2000, 199, 227-242. [CrossRef]

49. Martín-Valdepeñas, J.; Jiménez, M.; Martín-Fuertes, F.; Fernández, J. Improvements in a CFD code for analysis of hydrogen behaviour within containments. Nucl. Eng. Des. 2007, 237, 627-647. [CrossRef]

50. Jeon, J.; Kim, Y.S.; Choi, W.; Kim, S.J. Identification of Hydrogen Flammability in steam generator compartment of OPR1000 using MELCOR and CFX codes. Nucl. Eng. Technol. 2019, 51, 1939-1950. [CrossRef]

51. Law, C. Propagation, structure, and limit phenomena of laminar flames at elevated pressures. Combust. Sci. Technol. 2006, 178, 335-360. [CrossRef]

52. Choi, W.; Kim, T.; Jeon, J.; Kim, N.K.; Kim, S.J. Effect of Molten Corium Behavior Uncertainty on the Severe Accident Progress. Sci. Technol. Nucl. Ins. 2018, 2018, 5706409. [CrossRef]

53. Baird, A.R.; Archibald, E.J.; Marr, K.C.; Ezekoye, O.A. Explosion hazards from lithium-ion battery vent gas. J. Power Sources 2020, 446, 227257. [CrossRef]

54. Kim, Y.S.; Jeon, J.; Song, C.; Kim, S.J. Improved prediction model for $\mathrm{H}_{2} / \mathrm{CO}$ combustion risk using a calculated non-adiabatic flame temperature model. Nucl. Eng. Technol. 2020, 52, 2836-2846. [CrossRef]

55. Wang, P.; Zhao, Y.; Chen, Y.; Bao, L.; Meng, S.; Sun, S. Study on the lower flammability limit of $\mathrm{H}_{2} / \mathrm{CO}$ in $\mathrm{O}_{2} / \mathrm{H}_{2} \mathrm{O}$ environment. Int. J. Hydrogen Energy 2017, 42, 11926-11936. [CrossRef]

56. Grune, J.; Breitung, W.; Kuznetsov, M.; Yanez, J.; Jang, W.; Shim, W. Flammability limits and burning characteristics of $\mathrm{CO}-\mathrm{H}_{2}-\mathrm{H}_{2} \mathrm{O}-\mathrm{CO}_{2}-\mathrm{N}_{2}$ mixtures at elevated temperatures. Int. J. Hydrogen Energy 2015, 40, 9838-9846. [CrossRef]

57. Kilchyk, V. Flammability Limits of Carbon Monoxide and Carbon Monoxide-Hydrogen Mixtures in Air at Elevated Temperatures. Ph.D. Thesis, University of Calgary, Calgary, AB, Canada, 2000.

58. Oostenrijk, B. Earth Gravity Flame Balls, or Are They? Master's Thesis, Eindhoven University of Technology, Eindhoven, The Netherlands, 2012.

59. Zel'dovich, Y.B. Teoriya Goreniya $i$ Detonatsii Gazov (Theory of Combustion and Detonation of Gases); Akad, Nauk SSSR: Moscow, Russia, 1944.

60. Ronney, P.D. Understanding combustion processes through microgravity research. Proc. Combust. Inst. 1998, 27, 2485-2506. [CrossRef]

61. Ronney, P.D. Near-limit flame structures at low Lewis number. Combust. Flame 1990, 82, 1-14. [CrossRef] 
62. Ronney, P.D. Effect of gravity on laminar premixed gas combustion II: Ignition and extinction phenomena. Combust. Flame 1985, 62, 121-133. [CrossRef]

63. Markstein, G.H. Nonsteady Flame Propagation; Pergamon Press: Oxford, UK, 1964.

64. Bregeon, B.; Gordon, A.S.; Williams, F.A. Near-limit downward propagation of hydrogen and methane flames in oxygen-nitrogen mixtures. Combust. Flame 1978, 33, 33-45. [CrossRef]

65. Liu, G.; Ye, Z.; Sohrab, S.H. On radiative cooling and temperature profiles of counterflow premixed flames. Combust. Flame 1986, 64, 193-201. [CrossRef]

66. Ishizuka, S.; Law, C.K. An experimental study on extinction and stability of stretched premixed flames. Proc. Combust. Inst. 1982, 19, 327-335. [CrossRef]

67. Sato, J. Effects of Lewis number on extinction behavior of premixed flames in a stagnation flow. Proc. Combust. Inst. 1982, 19, 1541-1548. [CrossRef]

68. Tsuji, H.; Yamaoka, I. Structure and extinction of near-limit flames in a stagnation flow. Proc. Combust. Inst. 1982, 19, 1533-1540. [CrossRef]

69. Sohrab, S.; Ye, Z.; Law, C.K. An experimental investigation on flame interaction and the existence of negative flame speeds. Proc. Combust. Inst. 1985, 20, 1957-1965. [CrossRef]

70. Ju, Y.; Guo, H.; Maruta, K.; Liu, F. On the extinction limit and flammability limit of non-adiabatic stretched methane-air premixed flames. J. Fluid Mech. 1997, 342, 315-334. [CrossRef]

71. Karlovitz, B.; Denniston, D.W., Jr.; Knapschaefer, D.H.; Wells, F. Studies on Turbulent flames: A. Flame Propagation Across velocity gradients B. turbulence Measurement in flames. Proc. Combust. Inst. 1953, 4, 613-620. [CrossRef]

72. Matalon, M.; Cui, C.; Bechtold, J. Hydrodynamic theory of premixed flames: Effects of stoichiometry, variable transport coefficients and arbitrary reaction orders. J. Fluid Mech. 2003, 487, 179-210. [CrossRef]

73. Platt, J.; Tien, J. Flammability of a Weakly Stretched Premixed Flame: The Effect of Radiation Loss; Fall Technical Meeting of the Eastern States Section of the Combustion Institute: Orlando, FL, USA, 1990.

74. Tsuji, H. Thermal Engineering Joint Conference Proceedings. In Proceedings of the JSME-ASME Thermal Engineering Joint Conference, Honolulu, HI, USA, 20-24 March 1983.

75. Guo, H.; Ju, Y.; Maruta, K.; Niioka, T.; Liu, F. Radiation extinction limit of counterflow premixed lean methane-air flames. Combust. Flame 1997, 109, 639-646. [CrossRef]

76. Jarosinski, J.; Strehlow, R.; Azarbarzin, A. The mechanisms of lean limit extinguishment of an upward and downward propagating flame in a standard flammability tube. Proc. Combust. Inst. 1982, 19, 1549-1557. [CrossRef]

77. Shoshin, Y.; Jarosinski, J. On extinction mechanism of lean limit methane-air flame in a standard flammability tube. Proc. Combust. Inst. 2009, 32, 1043-1050. [CrossRef]

78. Fernández-Galisteo, D.; Sánchez, A.L.; Liñán, A.; Williams, F.A. One-step reduced kinetics for lean hydrogen-air deflagration. Combust. Flame 2009, 156, 985-996. [CrossRef]

79. Bertolino, A.; Stagni, A.; Cuoci, A.; Faravelli, T.; Parente, A.; Frassoldati, A. Prediction of flammable range for pure fuels and mixtures using detailed kinetics. Combust. Flame 2019, 207, 120-133. [CrossRef]

80. Saxena, P.; Williams, F.A. Testing a small detailed chemical-kinetic mechanism for the combustion of hydrogen and carbon monoxide. Combust. Flame 2006, 145, 316-323. [CrossRef]

81. Lakshmisha, K.; Paul, P.; Mukunda, H. On the flammability limit and heat loss in flames with detailed chemistry. Proc. Combust. Inst. 1991, 23, 433-440. [CrossRef]

82. Giovangigli, V.; Smooke, M. Application of continuation methods to plane premixed laminar flames. Combust. Sci. Technol. 1993, 87, 1993. [CrossRef]

83. Ju, Y.; Masuya, G.; Ronney, P.D. Effects of radiative emission and absorption on the propagation and extinction of premixed gas flames. Proc. Combust. Inst. 1998, 27, 2619-2626. [CrossRef]

84. Van den Schoor, F.; Verplaetsen, F.; Berghmans, J. Calculation of the upper flammability limit of methane/air mixtures at elevated pressures and temperatures. J. Hazard. Mater. 2008, 153, 1301-1307. [CrossRef] [PubMed]

85. Shoshin, Y.; Tecce, L.; Jarosinski, J. Experimental and computational study of lean limit methane-air flame propagating upward in a $24 \mathrm{~mm}$ diameter tube. Combust. Sci. Technol. 2008, 180, 1812-1828. [CrossRef]

86. Yakovenko, I.; Ivanov, M.; Kiverin, A.; Melnikova, K. Large-scale flame structures in ultra-lean hydrogen-air mixtures. Int. J. Hydrogen Energy 2018, 43, 1894-1901. [CrossRef] 
87. Jeon, J.; Jung, H.; Kim, Y.S.; Kim, S.J. Numerical study of lean limit hydrogen flames propagating upward to validate a flammability limit model. In Proceedings of the NURETH-18, Portland, OR, USA, 18-22 August 2019.

88. Gerstein, M.; Stine, W.B. Analytical criteria for flammability limits. Proc. Combust. Inst. 1973, 14, 1109-1118. [CrossRef]

89. Tsatsaronis, G. Prediction of propagating laminar flames in methane, oxygen, nitrogen mixtures. Combust. Flame 1978, 33, 217-239. [CrossRef]

90. Warnatz, J. Rate Coefficients in the C/H/O System; Springer: New York, NY, USA, 1984.

91. Giovangigli, V.; Smooke, M. Adaptive continuation algorithms with application to combustion problems. Appl. Numer. Math. 1989, 5, 305-331. [CrossRef]

92. Lee, S.; Chung, D.; Chung, S. Local equilibrium temperature as a measure of stretch and preferential diffusion effects in counterflow $\mathrm{H}_{2}$ /air premixed flames. Proc. Combust. Inst. 1998, 27, 579-585. [CrossRef]

93. Dong, Y.; Holley, A.T.; Andac, M.G.; Egolfopoulos, F.N.; Davis, S.G.; Middha, P.; Wang, H. Extinction of premixed $\mathrm{H}_{2}$ /air flames: Chemical kinetics and molecular diffusion effects. Combust. Flame 2005, 142, 374-387. [CrossRef]

94. Wu, M.S.; Liu, J.B.; Ronney, P.D. Numerical simulation of diluent effects on flame balls. Proc. Combust. Inst. 1998, 27, 2543-2550. [CrossRef]

95. Wu, M.S.; Ronney, P.D.; Colantonio, R.O.; VanZandt, D.M. Detailed numerical simulation of flame ball structure and dynamics. Combust. Flame 1999, 116, 387-397. [CrossRef]

96. Seigel, R.; Howell, J.R. Thermal Radiation Heat Transfer; CRC Press: New York, NY, USA, 1981.

97. Spalding, D. A theory of inflammability limits and flame-quenching. Proc. R. Soc. Lond. A 1957, 240, 83-100.

98. Kee, R.J.; Miller, J.A.; Evans, G.H.; Dixon-Lewis, G. A computational model of the structure and extinction of strained, opposed flow, premixed methane-air flames. Proc. Combust. Inst. 1989, 22, 1479-1494. [CrossRef]

99. Giovangigli, V.; Smooke, M. Extinction of strained premixed laminar flames with complex chemistry. Combust. Sci. Technol. 1987, 53, 23-49. [CrossRef]

100. Egerton, A.C. Limits of inflammability. Proc. Combust. Inst. 1953, 4, 4-13. [CrossRef]

101. Zabetakis, M.G. Flammability Characteristics of Combustible Gases and Vapors; Bureau of Mines: Washington, DC, USA, 1965.

102. MAČEK, A. Flammability limits: A re-examination. Combust. Sci. Technol. 1979, 21, 43-52. [CrossRef]

103. Cheng, T.K.H. An Experimental Study of the Rich Flammability Limits of Some Gaseous Fuels and Their Mixtures in Air. Master's Thesis, University of Calgary, Calgary, AB, Canada, 1985.

104. Hansen, T.J.; Crowl, D.A. Estimation of the flammability zone boundaries for flammable gases. Process Saf. Prog. 2010, 29, 209-215. [CrossRef]

105. Bade Shrestha, S.O. Systematic Approach to Calculations of Flammability Limits of Fuel-Diluent Mixtures in Air. Master's Thesis, University of Calgary, Calgary, AB, Canada, 1993.

106. Mashuga, C.V.; Crowl, D.A. Flammability zone prediction using calculated adiabatic flame temperatures. Process Saf. Prog. 1999, 18, 127-134. [CrossRef]

107. Razus, D.; Molnarne, M.; Fuß, O. Limiting oxygen concentration evaluation in flammable gaseous mixtures by means of calculated adiabatic flame temperatures. Chem. Eng. Process. 2004, 43, 775-784. [CrossRef]

108. Wan, X.; Zhang, Q.; Shen, S.L. Theoretical estimation of the lower flammability limit of fuel-air mixtures at elevated temperatures and pressures. J. Loss Prevent. Process Ind. 2015, 36, 13-19. [CrossRef]

109. White, A.G. Limits for the propagation of flame in inflammable gas-air mixtures. Part III. The effects of temperature on the limits. J. Chem. Soc. 1925, 127, 672-684. [CrossRef]

110. Lewis, B.; Von Elbe, G. Combustion, Flames and Explosions of Gases; Combustion and Explosives Researches, Inc.: Pittsburg, PA, USA, 2012.

111. Bartok, W.; Sarofim, A.F. Fossil Fuel Combustion: A Source Book; Wiley: New York, NY, USA, 1991.

112. Vidal, M.; Wong, W.; Rogers, W.; Mannan, M.S. Evaluation of lower flammability limits of fuel-air-diluent mixtures using calculated adiabatic flame temperatures. J. Hazard. Mater. 2006, 130, 21-27. [CrossRef] [PubMed]

113. Melhem, G. A detailed method for estimating mixture flammability limits using chemical equilibrium. Process Saf. Prog. 1997, 16, 203-218. [CrossRef]

114. Burgess, D.; Hertzberg, M. The flammability limits of lean fuel-air mixtures: Thermochemical and kinetic criteria for explosion hazards. ISA Trans. 1975, 14, 129-136. [PubMed] 
115. Britton, L.G. Using heats of oxidation to evaluate flammability hazards. Process Saf. Prog. 2002, 21, 31-54. [CrossRef]

116. Vidal, M.; Rogers, W.; Holste, J.; Mannan, M.S. A review of estimation methods for flash points and flammability limits. Process Saf. Prog. 2004, 23, 47-55. [CrossRef]

117. Ma, T. A thermal theory for estimating the flammability limits of a mixture. Fire Saf. J. 2011, 46, 558-567. [CrossRef]

118. Lovachev, L.; Kaganova, Z. Calculation of hydrogen bromide flame characteristics. Dokl. Akad. Nauk SSSR $1969,188,1087$.

119. Lovachev, L. The theory of limits on flame propagation in gases. Combust. Flame 1971, 17, 275-278. [CrossRef]

120. Ural, E.A.; Zalosh, R.G. A mathematical model for lean hydrogen-air-steam mixture combustion in closed vessels. Proc. Combust. Inst. 1985, 20, 1727-1734. [CrossRef]

121. Frank-Kamenetskii, D.A. Diffusion and Heat Transfer in Chemical Kinetics; Princeton University Press: Princeton, NJ, USA, 1969.

122. Liu, D.; MacFarlane, R. Laminar burning velocities of hydrogen-air and hydrogen-air steam flames. Combust. Flame 1983, 49, 59-71. [CrossRef]

123. Crescitelli, S.; Russo, G.; Tufano, V. Flame propagation in closed vessels and flammability limits. Combust. Sci. Technol. 1977, 15, 201-212. [CrossRef]

124. Fenn, J.B.; Calcote, H.F. Activation energies in high temperature combustion. Proc. Combust. Inst. 1953, 4, 231-239. [CrossRef]

125. Morales, G.F.; Ehrhart, B.D.; Muna, A.B. HyRAM (Hydrogen Risk Assessment Models), Version 2.0 User Guide; Sandia National Laboratories: Albuquerque, NM, USA, 2019.

126. Nishimura, T.; Hoshi, H.; Hotta, A. Current research and development activities on fission products and hydrogen risk after the accident at Fukushima Daiichi nuclear power station. Nucl. Eng. Technol. 2015, 47, 1-10. [CrossRef]

127. Liaw, H.J.; Chen, K.Y. A model for predicting temperature effect on flammability limits. Fuel 2016, 178, 179-187. [CrossRef]

128. Matsukov, I.; Kunetzov, M.; Alekseev, V.; Dorofeev, S. Photographic Study of the Characteristic Regimes of Turbulent Flame Propagation, Local and Global Quenching in Obstructed Areas; FZK-INR: Moscow, Russia, 1998.

129. Joulin, G.; Clavin, P. Linear stability analysis of nonadiabatic flames: Diffusional-thermal model. Combust. Flame 1979, 35, 139-153. [CrossRef]

130. Clavin, P.; Williams, F.A. Effects of molecular diffusion and of thermal expansion on the structure and dynamics of premixed flames in turbulent flows of large scale and low intensity. J. Fluid Mech. 1982, 116, 251-282. [CrossRef]

131. Strehlow, R.A.; Noe, K.A.; Wherley, B.L. The effect of gravity on premixed flame propagation and extinction in a vertical standard flammability tube. Proc. Combust. Inst. 1988, 21, 1899-1908. [CrossRef]

Publisher's Note: MDPI stays neutral with regard to jurisdictional claims in published maps and institutional affiliations.

(C) 2020 by the authors. Licensee MDPI, Basel, Switzerland. This article is an open access article distributed under the terms and conditions of the Creative Commons Attribution (CC BY) license (http://creativecommons.org/licenses/by/4.0/). 